\title{
Electric Industry Restructuring and Environmental Issues: A Comparative Analysis of the Experience in California, New York, and Wisconsin
}

Jeffrey M. Fang

Paul S. Galen

National Renewable Energy Laboratory 1617 Cole Boulevard Golden, Colorado 80401-3393

A national laboratory of the U.S. Department of Energy Managed by Midwest Research Institute for the U.S. Department of Energy under Contract No. DE-AC36-83CH10093

Prepared under Task No. AS115502

August 1996 


\section{NOTICE}

This report was prepared as an account of work sponsored by an agency of the United States government. Neither the United States government nor any agency thereof, nor any of their employees, makes any warranty, express or implied, or assumes any legal liability or responsibility for the accuracy, completeness, or usefulness of any information, apparatus, product, or process disclosed, or represents that its use would not infringe privately owned rights. Reference herein to any specific commercial product, process, or service by trade name, trademark, manufacturer, or otherwise does not necessarily constitute or imply its endorsement, recommendation, or favoring by the United States government or any agency thereof. The views and opinions of authors expressed herein do not necessarily state or reflect those of the United States government or any agency thereof.

Available to DOE and DOE contractors from:

Office of Scientific and Technical Information (OSTI)

P.O. Box 62

Oak Ridge, TN 37831

Prices available by calling (615) 576-8401

Available to the public from:

National Technical Information Service (NTIS)

U.S. Department of Commerce

5285 Port Royal Road

Springfield, VA 22161

(703) $487-4650$ 


\section{Preface}

This report was prepared by the Center of Energy Analysis and Applications, National Renewable Energy Laboratory (NREL) for the Competitive Resource Strategies (CRS) Program of the Office of Utility Technologies, Office of Energy Efficiency and Renewable Energy, U.S. Department of Energy (DOE). It is intended to provide stakeholders in other states with impartial information concerning the experience in addressing environmental and related issues in the electric industry restructuring process in three "early adopter" states - Califormia, New York, and Wisconsin. The study was performed as a task under NREL's project to assist the Office of Utility Technologies in the area of CRS.

The electric utility industry in the United States is undergoing fundamental changes in its structure and regulation. Since the Califomia Public Utilities Commission (CPUC) issued its April 20, 1994, Blue Book proposal to restructure the regulation of electric utilities in California to allow more competition, over 40 states have initiated similar activities. In this process, the question of how major public policy objectives such as environmental protection, energy efficiency, renewable energy, and assistance to low-income customers can be sustained under the new competitive environment is an important element being considered. Because many other states will undergo restructuring in the future, the experience of these three states in addressing public policy objectives in the electric restructuring process can be useful to them. This report focuses on environmental issues. Energy efficiency and renewable energy issues are included only to the extent that they have pertinence to environmental protection.

We hereby acknowledge the support and guidance of Val Jensen and Diane Pirkey of the CRS Program, Office of Utility Technologies, DOE. We also wish to thank the members of the Informal Advisory Panel for their review and comments on initial outlines, draft letter reports, and earlier versions of this report. Their suggestions and assistance have contributed greatly to the final report. Panel members are: Ralgh C. Cavanagh and Kari Smith of Natural Resource Defense Council, Jim Gallagher of New York Public Service Commission, John Hughes of ELCON, Kenneth P. Linder of Edison Electric Institute, David Morse and Stuart Chaitlin of CPUC's Division of Ratepayer Advocate, and Paul Newman of Public Service Commission of Wisconsin. Further, we would thank the following individuals who reviewed and commented on earlier drafts: Jan Eckert, Kevin Porter and Karin Sinclair of NREL; Dave Dworzak of Edison Electric Institute; David Meyer and David Boomsma of Office of Electric Policy, DOE; Rick Weston of the Vermont Public Service Board; and Ryan Wiser of Lawrence Berkeley National Laboratory. Their comments and suggestions helped to improve this report. However, we take sole responsibility for the report's content.

Jeffrey M. Fang

Paul S. Galen 


\section{Contents}

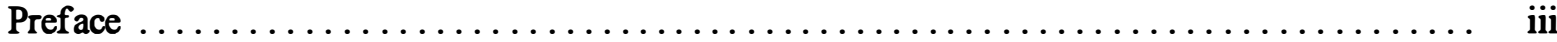

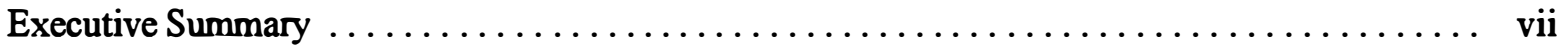

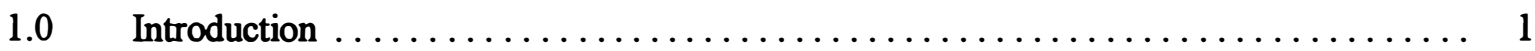

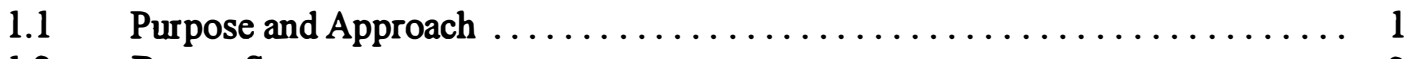

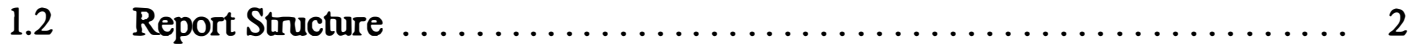

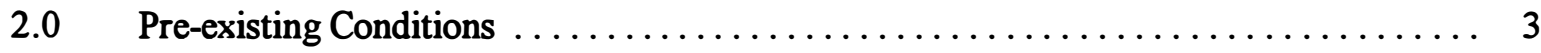

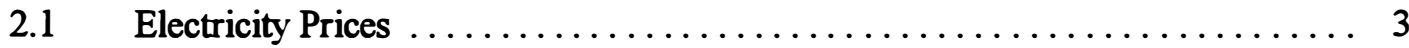

2.2 Regulatory Practices with Environmental Implications $\ldots \ldots \ldots \ldots \ldots \ldots$

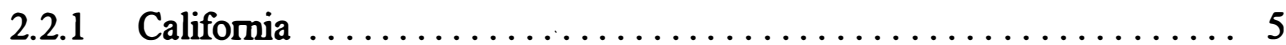

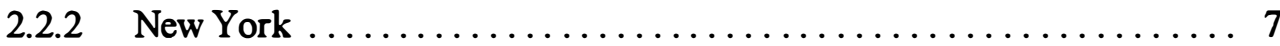

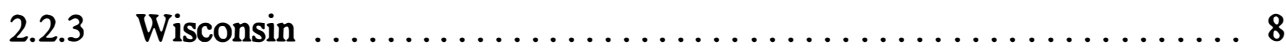

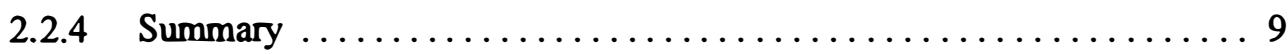

3.0 The Process of Environmental Considerations During Industry Restructuring $\ldots \ldots \ldots \ldots 10$

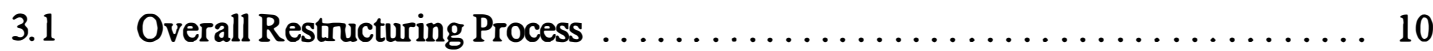

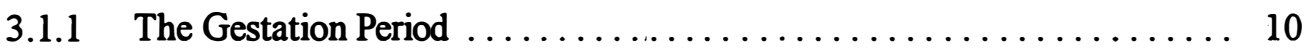

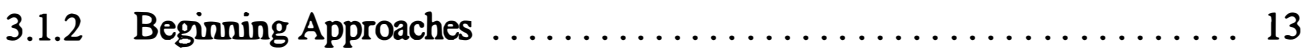

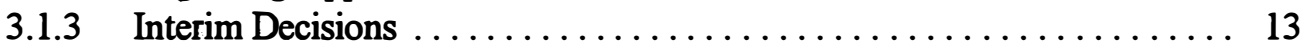

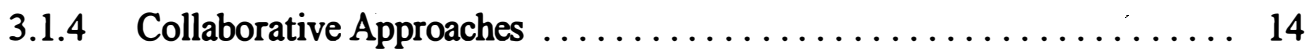

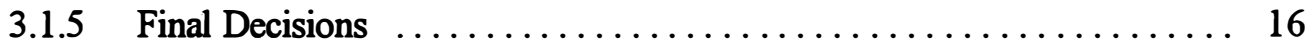

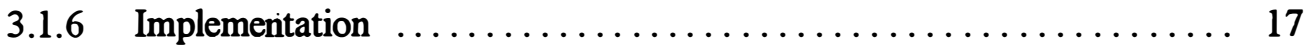

3.2 Consideration of Environmental Issues $\ldots \ldots \ldots \ldots \ldots \ldots \ldots \ldots \ldots \ldots \ldots$

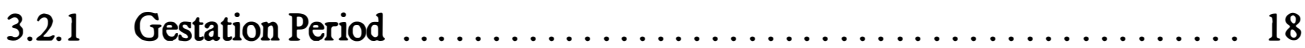

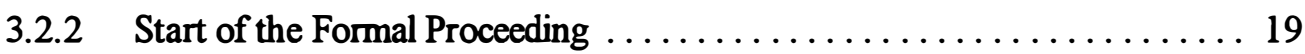

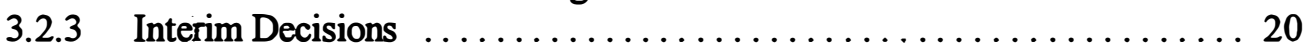

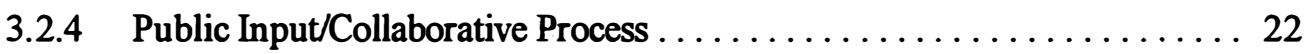

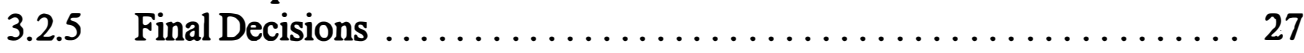

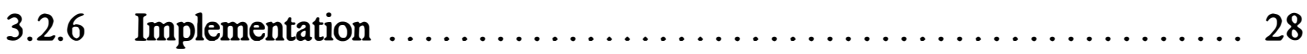




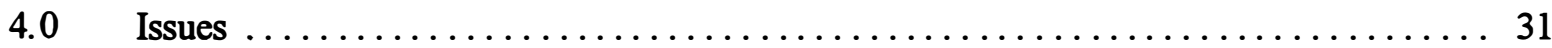

4.1 The Role of State Agencies $\ldots \ldots \ldots \ldots \ldots \ldots \ldots \ldots \ldots \ldots \ldots \ldots \ldots \ldots \ldots \ldots \ldots \ldots \ldots$

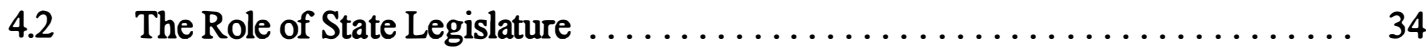

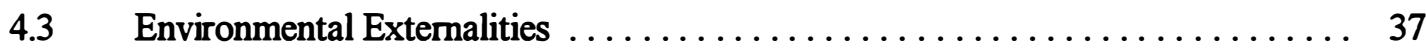

$4.4 \quad$ Funding and Implementation Mechanisms $\ldots \ldots \ldots \ldots \ldots \ldots \ldots$

4.4.1 Non-bypassable System Benefits Charge . . . . . . . . . . . . . 39

4.4 .2 Utility Funds . . . . . . . . . . . . . . . . . . 42

4.4.3 State General Funds . . . . . . . . . . . . . . . . . . . . . 42

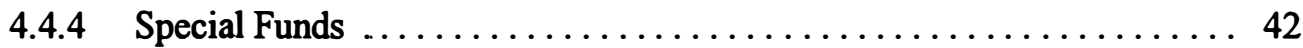

4.4.5 Pollution Tax .............................. 43

4.4.6 Renewables Portfolio Standard ....................... 43

4.4.7 Green Pricing/Green Aggregation . . . . . . . . . . . . . . . . 45

4.4.8 Emission Caps with Tradeable Credits . . . . . . . . . . . . . 47

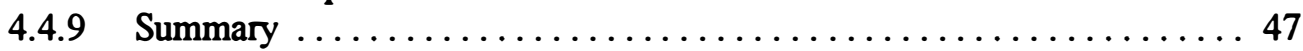

4.5 Environmental Impact Statement/Report $\ldots \ldots \ldots \ldots \ldots \ldots \ldots \ldots \ldots \ldots$

4.6 The Role of Environmental and Other Interest Groups . . . . . . . . . . . . 52

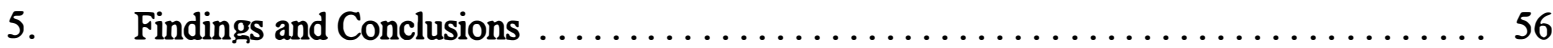




\section{List of Tables}

Page

1. Average State Electricity Prices as Percentage

of U. S. Average, by Sector, 1993 and $1994 \ldots \ldots \ldots \ldots \ldots \ldots \ldots \ldots \ldots \ldots$

2. The CPUC Externality Values for Five Major Air Emissions $\ldots \ldots \ldots \ldots \ldots \ldots \ldots \ldots$

3. Stages and Elements of the Overall Restructuring

Process in Three States . . . . . . . . . . . . . . . . . . . . . . . . . . . 11

\section{List of Figures}

Page

ES.1. Average Electricity Prices in Three States and the U.S. by Sector, 1993 and 1994

ix

1. Average Electricity Prices in Three States and the U.S. by Sector, 1993 and 1994 


\section{Executive Summary}

This report describes and compares the experience of three states - California, New York, and Wisconsin - in addressing environmental and related issues in their electric industry restructuring processes. Its purpose is to provide stakeholders in other states with impartial information from these early adopter states. It was prepared for the Competitive Resource Strategies Program in the U. S. Department of Energy, Office of Utility Technologies.

The electric utility industry in the United States is undergoing fundamental changes in its structure and regulation. Since the California Public Utilities Commission (CPUC) issued its April 20, 1994 Blue Book proposal to restructure the regulation of electric utilities in Califomia to allow more competition, over 40 states have initiated similar activities. In this process, the question of how major public policy objectives such as environmental protection, energy efficiency, renewable energy, and assistance to low-income customers can be sustained in the new competitive environment is an important element being considered. Because many other states will undergo restructuring in the future, the experience of these three states in addressing public policy objectives in the electric restructuring process can be useful to them.

This report addresses the following issues:

- What were the electricity prices and regulatory practices in the three states prior to restructuring?

- What are the differences and similarities of the overall restructuring processes?

- How were environmental issues considered in various stages of the restructuring?

- What should the environmental protection role of different state agencies be in a restructured electric industry?

- What is the role of state legislatures in the electric industry restructuring process?

- How might environmental externalities be treated?

- How should environmental protection and other public policy objectives be funded or implemented in a competitive electric industry?

- How did state public utility commissions treat the preparation of environmental impact statements (EIS) in the restructuring process?

- What was the role of environmental and other interest groups?

This report starts with a comparison of the electricity prices and regulatory practices with environmental implications prevailing in the three states before restructuring began. This is followed by descriptions of the overall restructuring process and the treatment of environmental issues. It then goes on to discuss some of the above issues in more detail. The following sections present the fimdings and conclusions concerning these issues derived from the experience of the three states. 


\section{Price Differences}

Prior to restructuring their respective electric industries, Califomia and New York had relatively high electricity prices, while Wisconsin was a relatively low-cost state. In 1993 and 1994, the average price per $\mathrm{kWh}$ for end-use sectors in Califormia and New York ranged from $17 \%$ to $61 \%$ above the national average. In contrast, the average price in Wisconsin was about $15 \%$ to $24 \%$ below the national average. Figure ES. 1 depicts such price disparities.

The differences in existing electricity prices have affected the initial attitudes of stakeholders and their support for retail competition in the electric industry. Where electric prices were relatively high, as in California and New York, support for retail competition was initially more pervasive. Where electric prices were relatively low, as in Wisconsin, support for retail competition was limited to large investor-owned utilities, some independent power producers, and some large industrial customers. One reason for this difference is fairly obvious: In California and New York, competition from out-of-state suppliers holds the promise for lowering electric prices for all customer classes. In Wisconsin, competition from out-of-state buyers of electricity could lead to higher electricity prices for those who currently enjoy low rates. This is reflected in Commissioner Scott Neitzel's view that the prices associated with Wisconsin's current low-cost generating facilities be tied to Wisconsin consumers. An interesting comparison is that while large industrial users in New York and California supported retail competition, some of their counterparts in Wisconsin initially expressed doubts that the process being pursued by the Public Service Commission of Wisconsin (PSCW) would lead to true retail competition.

\section{Differences in Environmental Practices}

Prior to restructuring, responsibility for environmental quality and stewardship in California, New York, and Wisconsin was shared by the environmental and utility/energy regulatory agencies. monetization of environmental externalities in the resource planning and acquisition process. In fact, they were among the only seven states in the United States that had adopted monetized values for specific emissions. The other four states were Massachusetts, ${ }^{*}$ Minnesota, Nevada, and Oregon. In developing externality values, the CPUC followed the explicit direction of a state law. The New York and Wisconsin commissions based their authority to require monetization of environmental externalities on their interpretation of the agency's responsibilities under state laws. It should be noted, however, that in New York the administrative law judge (ALJ) in Case 92-E-1187 has recommended eliminating the requirement to include environmental externalities in the evaluation of competitive bidding and demand-side management (DSM) programs. As of the publication date of this report, the New York Public Service Commission (NYPSC) had yet to decide on the recommendation.

Among the three states, Wisconsin has explicitly considered and outlined the environmental responsibilities of the Public Service Commission in a restructured electric industry. In generation, the PSCW will reform its procedures to streamline the siting review to facilitate competition, maintain environmental protection, and to check for conformance with the transmission system and for the existence of "environmental fatal flaws." In

* In December 1994, the Massachusetts Judicial Supreme Court ruled that the Massachuttes Department of Public Utilities (MDPU) exceeded its authority in specifying such monetary values that raise the electricity costs. As a result, utilites are no longer required to use those values adopted by the MDPU. Subsequently, in a case invloving pre-approval of demand-side management programs, the MDPU directed Boston Edison Company to include the cost impacts of potential future environmental regulations in weighing resource procurement alternatives. 

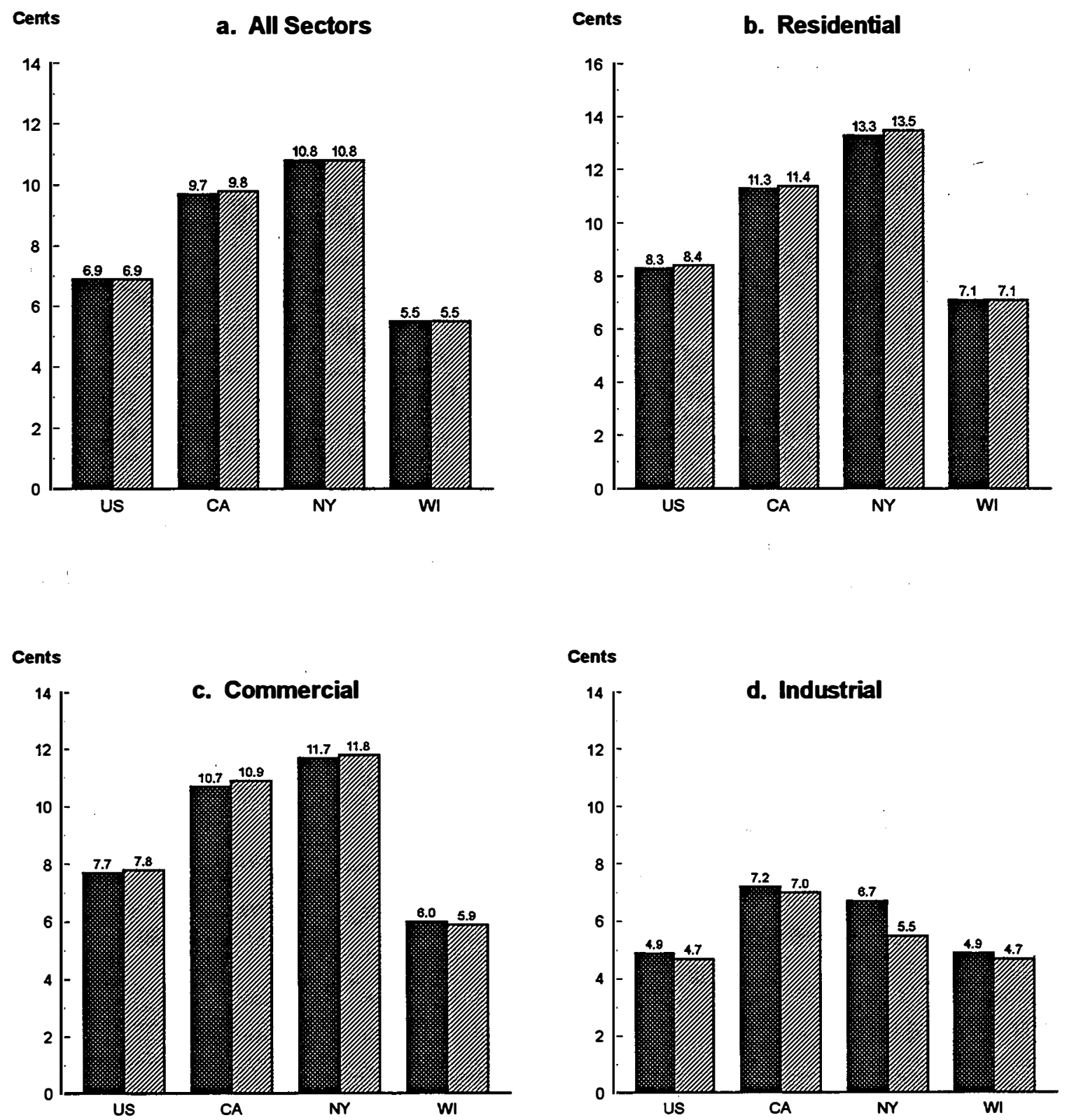

Key: 1993

Fig. ES.1. Average electricity prices in three states and the U.S. by sector, 1993 and 1994 
transmission, the PSCW retains its planning and siting authority and reforms its proceedings to conform to regional transmission group or regional market with environmental protection. It will retain its environmental protection and mitigation authority with respect to transmission systems throughout. In Califormia, although the final CPUC decision did not explicitly consider state agency responsibility and authority with respect to environmental protection in a restructured market structure, it did indicate the need and desirability of legislative actions on many of the public purpose programs. In addition, the roles of the Public Utility Comission and environmental regulatory agencies could be further developed in the on-going environmental impact report (EIR) process. In New York, it appears that the roles of the economic and environmental regulatory agencies would reamin relatively the same. The NYPSC would work with the DEC to monitor potentially adverse environmental impacts of wholesale and retail competition and to develop mitigation strategies which are competitively neutral. It is also envisioned that the DEC would play a central role in managing the special auction of emission credits for emissions that would adversely impact environmentally sensitive regions like the Adivrondacks and the Catskills.

With respect to monetization of environmental externalities, because the CPUC will no longer apply the Biennial Resource Plan Update (BRPU) process, there will be no explicit consideration of environmental externalities. ${ }^{*}$ In New York, the ALJ in the electric industry restructuring case did not address the issue. In Wisconsin, the PSCW would reform the generation Stage I competitive bidding process, which requires scoring the bids according to environmental compliance. In addition, utilities are directed to develop and implement green pricing, and the green aggregation concept will also be developed further.

\section{The Collaborative Approach}

All three states utilized collaborative working groups in the electric restructuring process. There are some differences, however, in the timing, the duration of, and the participation in the collaborative processes. In timing, the collaborative process began at the outset of the investigation in New York but sometime later in California and Wisconsin. The duration of the collaborative process was shorter in Califormia where the working group was initially directed to address issues pertaining only to public policy programs.

Alternatively, the collaborative approach can be used continually during the restructuring process, as in New York and Wisconsin, where the group was directed to address all applicable issues. As to participation, the commission staff can be either included or excluded in the collaborative working group. In addition, the working group could be formally appointed by the commission, as in Wisconsin, or participation can be voluntary, except for the investor-owned utilities, as in California and New York. Another aspect is that a coalition building approach seemed to play a more prominent role in California. The collaborative approach also figures prominently in the implementation stage in all three states.

\section{Role of State Legislatures}

The legislatures in the three states acted differently in the process. The California General Assembly was the most active among the three states. It got involved early, requiring the CPUC to report on progress, to look into public policy matters intensively. The legislature also conducted hearings to consider various restructuring related bills. In contrast, the Wisconsin legislature stayed away from the electric restructuring

\footnotetext{
* Note that other mechanisms such as renewables portfolio standard, emission credit trading, and relevant environment regulations may be used to address the environmental externalties issue.
} 
arena during the consideration of the issues by the PSCW. In New York, the state legislature was somewhat active in considering proposed legislation that might have an impact on the restructuring process being conducted by the NYPSC.

The difference in the role played by state legislatures in the restructuring process in the three states may be due to, in large measure, the differences in electricity prices among them and in the initial phases of the restructuring processes. As explained in Section 2.1, Wisconsin enjoyed relatively low electricity prices, while California and New York were among the high-cost states. High electricity prices were more likely to lead to high level of consumer dissatisfaction and agitation for change through various mechanisms, including the legislative process. Organized stakeholder groups would lobby their lawmakers to propose legislation and other measures that could result in changes favoring their respective positions. In contrast, there was less consumer dissatisfaction in low-cost states such as Wisconsin and, hence, less agitation for legislative action. In addition, the PSCW took a proactive role in addressing the restructuring issues. Thus, the legislature could afford to take a more leisurely approach. In response to the initial proposal, the CPUC presented a formal proposal stating that many stakeholders immediately perceived themselves to be potential winners or losers. Such sentiments were soon adopted by state legislators. As a result, the California legislature took an early and substantial interest in restructuring issues. In contrast, Wisconsin started with the more limited objective of adopting a set of principles for restructuring. This proved to be much less controversial than the California approach.

\section{Funding and Implementation Mechanisms}

Different mechanisms for funding or implementing programs for ensuring environmental protection and achieving other public policy objectives have been proposed, considered, or adopted. These mechanisms are: non-bypassable system benefits charge, utility funds, state general fund special funds, pollution taxes, renewables portfolio standards, green pricing/green aggregation, and pollution caps with tradeable credits. Among them, the non-bypassable system benefits charge appears to enjoy rather wide support. The CPUC has adopted it and called it the "Public Goods Charge." It will be effective on January 1, 1997. Initially, it would be a line item on utility bills. When the state legislature enacts a law, it could become a surcharge. Levels of funding would initially be set to correspond to authorized DSM funding and would be reevaluated after implementation workshops are conducted. There would be no percentage cap initially.

In New York, the commission adopted the non-bypassable system benefits charge to fund the transition and the longer-term public policy initiatives that are not adequately addressed by competitive markets. Initially, the charge will be set at the level of current utility expenditures and will be closely reviewed for its impacts on rates. After retail competition begins, the use of the system benefits charge will be assessed to determine if its use should be continued.

The renewables portfolio standard is a potentially useful approach for promoting development of renewable generation. It has strong support from renewable, environmental, and energy efficiency interests. California will impose a minimum renewables purchase requirement on either retail providers or on generators from 1998 through 2000. A review of the requirement will then be conducted. The CPUC would prefer the minimum level be set at the same level for all electric utilities on a statewide basis but would allow a transitional strategy to account for the differences in the current resource portfolios of utilities. Credits for meeting the minimum purchase requirement would be tradeable. Meaningful penalties would be imposed for noncompliance. 
In California, the CPUC's initial Blue Book proposal relied on existing environmental regulation and an enhanced green pricing approach for improving the state's environmental quality and resource diversity under a competitive industry structure. Following critical comments from many parties, the CPUC no longer relies on green pricing. Instead, it adopted both the Public Goods Charge and the renewables portfolio standard. In Wisconsin, the PSCW will require investor-owned and municipal utilities to investigate and propose green-pricing programs. In addition, the commission will establish a Public Benefits Policy Advisory Board to address low-income issues and services, conservation and DSM, customer-installed renewables, research and development issues, and market reforms to encourage renewable resource development. It will further develop the concept of green aggregation. Subsequently, the commission will act on the recommendations of the Board regarding funding levels and appropriate funding mechanisms. Every three years, the commission will conduct a review to determine the need for the programs of the board.

The utility fund approach uses the traditional utility ratemaking process by including the costs of environmental and other public policy objectives in the cost of utility service. This option could be useful during the transition to a competitive electric market. Beyond the transition, it would be necessary to allocate the costs of public policy objectives among the retail and direct access customers. The state general fund approach would include the total costs of environmental protection and other public policy programs in the state's spending plan and would be finance through general tax revenues. A Special Fund can be established as an independent, nonprofit organization or statutory entity within an existing state agency to administer funds for DSM, renewables, research and development, and public advocacy for environmental concerns, and small business and residential matters. Such a fund may be financed through a line charge, a usage fee, a pollution tax, or a bond authority. Pollution tax and emission caps with tradeable credits are marketbased mechanisms that may play an increasing role in the future as the electric industry becomes more competitive.

\section{Preparation of Environmental Impact Statement}

The elapsed time from the start of formal procoeding to the issuance of a final Environmental Impact Statement (EIS) varies greatly among the three states. The PSWC took only 5 months to order the review of potential environmental impacts and 13 months to have a final EIS for use in its deliberations. In contrast, it took New York 18 months and Califomia 20 months, to direct that an EIS or EIR be prepared. The NYPSC adopted a final EIS in May, 1996, about 21 months from the beginning of the formal proceeding. In Califomia, the EIR is expected to be completed in the spring of 1997, about three years after the initiation of the formal proceeding. It follows that, if the electric industry restructuring process requires preparation of an EIS, it is possible to reduce the time lines significantly if care is taken to consider the issue early and make an early decision to undertake the EIS process. In addition, where state laws do not specify otherwise, early preparation of the EIS affords the commission the added opportunity to consider, prior to making a final choice, the potential adverse impacts of alternative market structures and useful public inputs and involvement.

\section{Role of Environmental and Other Interest Groups}

Environmental and other interest groups have successfully impacted the electric industry restructuring process, arguing that environmental and other public policy issues need to be fully considered. In California, such interest groups have effected a change in the proposed mechanisms: The CPUC shifted from its initial proposal of relying on existing environmental regulations and enhanced green pricing to adopting both the "Public Goods Charge" (PGC) and the renewables portfolio standard. The PGC would collect funds for 
energy efficiency programs related to market transformation and funding for research and development related to the broader public good. The renewables portfolio standard will promote the use of renewable energy, support the objective of resource diversity, and improve environmental quality. In addition, in both California and New York, the environmental groups were first to raise the issue of evaluating the environmental impacts of the commission's restructuring policies. In New York, these groups also succeeded in promoting the system benefits charge to the $\mathrm{ALJ}$ and the commission for funding environmental, energy efficiency, and other public policy programs. They convinced the ALJ and the commission that an EIS needs to be prepared prior to the commission's final decision concerning the restructuring models to be adopted. Finally, in Wisconsin, they contributed to the PSCW's decision to seek increases in the statutory funding for intervenors' organizations and to establish a Public Benefits Policy Advisory Board to oversee the tasks of allocating the available funds for renewables, energy efficiency, low income, and other public policy programs. 


\section{Introduction}

Since the Califomia Public Utilities Commission (CPUC) issued its April 20, 1994, Blue Book proposal to restructure the regulation of electric utilities in Califomia to allow more competition, over 40 states have initiated similar activities. The question of how major public policy objectives such as environmental protection, energy efficiency, renewable energy, and assistance to low-income customers can be sustained in the new competitive environment is also an important element being considered. Because many other states will undergo restructuring in the future, the experience of the "early adopter" states in addressing public policy objectives in their electric service industry restructuring processes can provide useful information to other states. The Competitive Resource Strategies Program of the U. S.Department of Energy's (DOE's) Office of Utility Technologies, is interested in documenting and disseminating the experience of the pioneering states. The Center for Energy Analysis and Applications of the National Renewable Energy Laboratory assisted the Office of Utility Technologies in this effort with a project on the treatment of environmental issues in electric industry restructuring.

\subsection{Purpose and Approach}

The purpose of the project is to provide stakeholders with impartial information on the treatment of environmental issues during their respective states' electric restructuring process. This report describes and compares the experience of three states - California, New York, and Wisconsin. It addresses the following issues:

- What were the electricity prices and regulatory practices in the three states prior to restructuring?

- What are the differences and similarities of the overall restructuring processes?

- How were environmental issues considered in various stages of restructuring?

- What should the environmental protection role of different state agencies be in a restructured electric industry?

- What is the role of state legislatures in the restructuring processes?

- How might environmental externalities be treated?

- How should environmental protection and other public policy objectives be funded or implemented in the transition to a competitive electric industry?

- How did state public utility commissions treat the preparation of environmental impact statements (EIS) in the restructuring process?

- What was the role of environmental and other interest groups?

In addressing these issues, relevant reports and documents in the three proceedings, including commission orders, draft recommendations, and written comments and filings were reviewed. Initial descriptions and drafts were prepared for review by an informal advisory panel, consisting of contact persons with the three states and representatives from Edison Electric Institute, Electricity Consumers Resource Council (ELCON), and Natural Resource Defense Council. ${ }^{3}$ In the process, progress reports were prepared in October and December, 1995 (Fang \& Galen 1995a \& 1995b). A draft final report was then prepared and distributed for peer review. It included appropriate parts of the previous reports and new developments. Comments and suggestions from members of the informal advisory panel and other peer reviewers have been considered and incorporated as appropriate in this report.

\footnotetext{
${ }^{3}$ See Appendix A for the listing of the informal advisory panel.
} 
The focus of this report is on the treatment of environmental issues. However, investments in energy efficiency, demand-side management (DSM), and renewable energy can contribute to the reduction of air emissions and other pollutants because they reduce the need for additional generation of electricity from fossil fuels. In other words, they are environmentally benign. Hence, they are often mentioned in the discussion on environmental protection and quality in the restructuring debate. For this reason, this report will touch on these topics as appropriate.

\subsection{Report Structure}

In order to consider the changes occurring in electric industry restructuring, it is useful to have an understanding of what the pre-existing conditions were in the three states. The next section of the report compares electricity prices and regulatory practices with environmental implications prevailing in the three states before electric industry restructuring considerations began. Regulatory practices covered include the role of state agencies in environmental protection, and the treatment of environmental externalities in resource planning and demand-side management.

To discuss specific electric restructuring issues in detail, the restructuring process itself must be described first. The next part of the report compares the overall restructuring process in the three states, dividing it into the following stages: gestation period, initiation of formal proceedings, interim decisions, public inputs/collaboration, final decision, and implementation. Significant milestones and major components of the new industry structure within each stage are noted. Then, the specific actions in each stage with environmental implications are described in detail.

The report also discusses the role of state agencies, the role of state legislature, treatment of environmental externalities, funding and implementation mechanisms, preparation of environmental impact statements or reports, and the role of environmental and other interest groups. Finally, this report summarizes the findings of this study and offers some conclusions. 


\section{Pre-Existing Conditions}

The conditions facing the stakeholders in each of the three states prior to the start of their effort to restructure the electric industry vary. The differences may affect the outcomes of their restructuring process. This section presents data on electric prices in 1993 and 1994. It also provides a brief description of regulatory practices that have environmental implications, focusing on the role of environmental and utility regulatory agencies and the treatment of environmental externalities.

\subsection{Electricity Prices}

Prior to the start of electric industry restructuring, Califomia and New York had relatively high electricity prices, while Wisconsin electricity prices were relatively low (Figure 1). In 1993 and 1994, the average price per $\mathrm{kWh}$ for end use sector in California and New York ranged from $17 \%$ to $61 \%$ above the national average. In contrast, average electricity prices in Wisconsin were about $15 \%$ to $24 \%$ below the national average (Table 1). In 1994, New York was the second highest-cost state in terms of overall average price for all sectors combined and the highest-cost state for the residential and commercial sectors. Califormia ranked ninth highest in terms of overall average price in 1994 (Energy Information Administration 1995, p.46).

The high electricity prices in Califormia and New York were a major driver behind the effort to reform the electric industry structure and its regulation. The CPUC stated in its order initiating the formal proceeding: "... we are single-minded in its objective - to lower the cost of electric service to Califormia's residential and business consumers without sacrificing the utility's financial integrity" (CPUC 1994a, p. 1). In New York, the New York Public Service Commission (NYPSC), though not as direct as the CPUC, stated that the objective of its investigation was "to identify regulatory and ratemaking practices that will assist in the transition to a more competitive electric industry designed to increase efficiency in the provision of electricity while maintaining safety, environmental, affordability, and service quality goals" (NYPSC 1994a, pp. 1-2). In Wisconsin, the Public Service Commission of Wisconsin (PSCW) noted that the state had relatively low electric rates and the third lowest electric bills in the country. Nevertheless, the PSCW stated that "it is possible that costs could be reduced further and customer choices enhanced by additional competition at both the wholesale and retail level." Thus, the purpose of the PSCW's investigation was to devise a prudent, rational, and sustainable policy that would allow Wisconsin to continue to prosper in an ever-changing, market-driven environment (PSCW 1994, pp. 1-2). In other words, the PSCW proactively took advantage of the opportunities afforded by the low electricity prices in the state to consider restructuring of the electric industry. In this way, the process could be more deliberate, less controversial, and the collaborative process could work better than in states with high electricity prices.

One particularly illuminating aspect of the differences in electric prices among the three states is the difference in support for retail wheeling among some customer groups in the three states. In New York and California, large industrials, independent power producers, power marketers, and regulators supported retail wheeling because of its potential for lowering electric rates, while smaller customers of utilities, renewable and energy efficiency groups, and environmental organizations initially opposed it. In Wisconsin there was substantial opposition to retail wheeling initially because of the fear that electric prices to most customers would rise as a result of exporting electricity to other states and regions. In response to the PSCW's initial order to comment on the objectives of electric regulation, utility institutional structures, and regulatory regimes, a coalition of consumer, labor, environmental, business, publicly-owned utilities and other organizations indicated that it opposed the retail wheeling proposal because it would likely lead to higher 

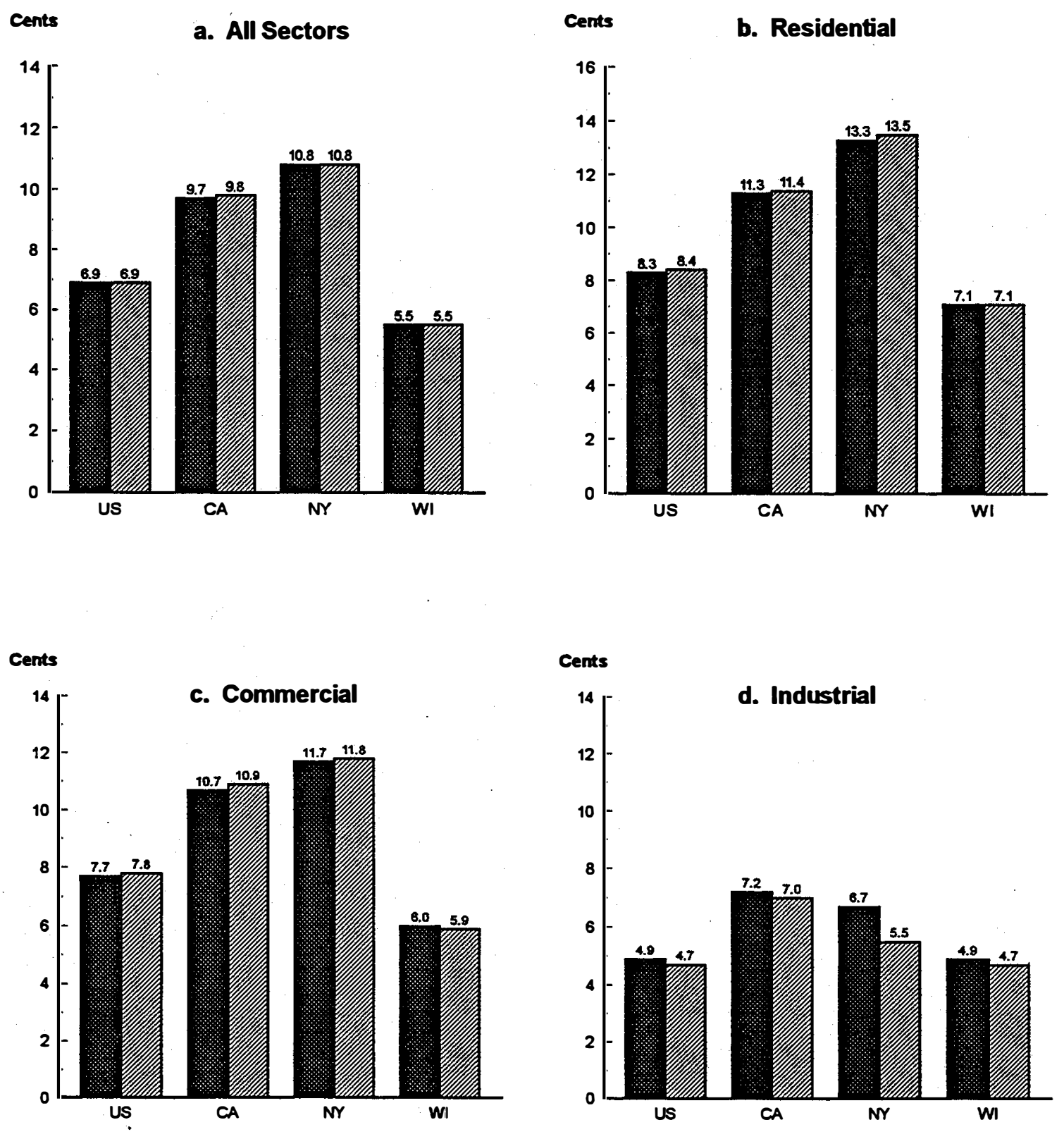

Key: 1993

Fig. 1. Average electricity prices in three states and the U.S. by sector, 1993 and 1994 
Table 1: Average State Electricity Prices as Percentage of U.S. Average by Sector, 1993 and $1994(\%)$

\begin{tabular}{lcccc}
\hline State & All Sectors & Residential & Commercial & Industrial \\
\hline & & $\underline{\mathbf{1 9 9 3}}$ & & \\
California & 140.2 & 135.5 & 138.6 & 148.1 \\
New York & 156.1 & 159.5 & 151.6 & 137.9 \\
Wisconsin & 79.5 & 85.1 & 77.7 & 82.3 \\
& & $\underline{\mathbf{1 9 9 4}}$ & & \\
California & 141.6 & 135.6 & 140.6 & 148.3 \\
New York & 156.1 & $\mathbf{8 4 . 4}$ & 152.3 & 116.5 \\
Wisconsin & 79.5 & & $\mathbf{7 6 . 1}$ & 82.6 \\
\hline
\end{tabular}

Source: Computed from Energy Information Administration (1995), Table 30, p. 46.

electric rates (Electric Utility Week, 1994). ${ }^{4}$ The Wisconsin Industrial Energy Group, representing 26 large industrial companies, while supporting the concept of retail competition, expressed doubts that the process initiated by the PSCW would lead to true retail competition. The Wisconsin Paper Council favored a cautious go-slow approach to retail competition (The Energy Report, 1995).

\subsection{Regulatory Practices with Environmental Implications}

In this section, some of the existing regulatory practices in California, New York, and Wisconsin that have environmental implications are discussed. The practices considered are the role of environmental and utility regulatory agencies, the treatment of environmental externalities, and the role of energy efficiency, demandside management, and renewable energy.

\subsubsection{California}

In California, the responsibility for environmental quality and protection is shared by environmental and utility or energy regulatory agencies. Environmental agencies include the California Environmental Protection Agency, California Air Resources Board, and the local air quality management districts (AQMD). The local AQMDs set air quality standards in coordination with the California Air Resources Board. For example, all AQMDs with major utility boilers located within their areas have adopted the Best Available Retrofit Control Technology (BARCT) rules for nitrogen oxides and are planning to adopt nitrogen oxides BARCT rules for non-utility boilers and gas turbines. In operating their generation plants, utilities have to comply with the air emission rules of the local AQMD. Sulfur dioxide emission credit trading is permitted

\footnotetext{
${ }^{2}$ Members of the Coalition are Wisconsin Electric Cooperative Association, Wisconsin Federation of Cooperatives, Municipal Electric Utilities of Wisconsin, Citizens' Utility Board, American Association of Retired People, International Brotherhood of Electric Workers, Renew Wisconsin, Sierra Club-John Muir Chapter, Wisconsin's Environmental Decade, and Wisconsin Farmer's Union.
} 
for all districts under the Federal Acid Rain Program of the Clean Air Act Amendments (CAAA) of 1990. ${ }^{5}$ Similarly, emission credit trading of nitrogen oxides is allowed in the South Coast Air Quality Management District under the Regional Clean Air Incentives Market (RECLAIM) Program. The Califomia Environmental Protection Agency has jurisdiction over pollutants other than air emissions.

The utility and energy regulatory agencies in Califormia are the Califomia Energy Commission (CEC) and the CPUC. The CEC is the one-stop construction permitting agency for all thermal powerplants greater than 50 MW. The CEC prepares the biennial Electricity Report, forecasting the demand for electricity for 5-, 12and 20-year periods and modeling air quality. Califomia Public Resource Code requires the CEC to incorporate monetized values of environmental externalities in computing the cost-effectiveness of energy resources, including energy efficiency and demand-side management. ${ }^{6,7}$ The costs associated with meeting existing environmental regulations are already factored into the electricity costs and are not part of environmental externalities. In other words, environmental externalities are residual environmental impacts. The CEC has developed estimates of environmental externalities and used them in its Electricity Report modeling efforts. ${ }^{8}$ However, the externality values developed by the CEC are not binding on the CPUC.

The CPUC reviews electric utilities' applications for a certificate of public convenience and necessity for generation and transmission facilities. Assembly Bill 3995 amended Public Utilities Code section 701.1 to require the CPUC to include monetized values of environmental externalities in cost-effectiveness computations for energy resources. The CPUC has adopted externality values for five major air emissions for use by the investor-owned electric utilities as shown in Table 2.

Two other state laws influence the application of the externality values by the CPUC. In 1993, a law limiting the applicability of the externality values in certain circumstances became effective. Specifically, the inclusion of externality values can advance the need for new generation plants by no more than 15 months. Moreover, externality values should not be used as a justification to force a utility to retire or to decommission a power plant. The externality values are not applicable when a carbon tax is adopted or when a market-based emission trading system or offset requirement is adopted for any pollutant. Another law, effective in 1992, requires that the value of resource diversity provided by renewable energy be recognized. It provides that, until the CPUC adopts a methodology for valuing diversity, a specific portion of resource additions be set aside for renewable generation resources. ${ }^{9}$

5 All California utilities are covered under Phase II of the Program. In other words, they are not directly affected until the year 2000. However, they are eligible to apply for the bonus credits for energy efficiency and renewables.

6 California Public Resource Code, Section 25000.1, as modified by Assembly Bill 3995 of 1990.

7 In the case of electricity, environmental externalities are the costs or benefits, not reflected in its prices, that are associated with effects on the physical-biological environment resulting from the gneration and use of electricity.

\footnotetext{
${ }^{8}$ For the externality values developed by CEC, see CEC (1995a), Appendix A, Part II, pp. A-II-D-4 through A-II-D-14, and A-II-E-1 through A-II-E-3.

9 Public Utilities Code section 701.3.
} 
Table 2: The CPUC Externality Values for Five Major Air Emission

\begin{tabular}{lrrr}
\hline Emission & SCE/ & PG\&E & $\begin{array}{c}\text { Out-of-State/ } \\
\text { Attainment Area }\end{array}$ \\
\hline & SDG\&E & $(1992 \$ /$ Ton $)$ & \\
\cline { 2 - 4 } Nitrogen oxide & 31,568 & 9,155 & 7,526 \\
Sulfur dioxide & 23,579 & 4,493 & 1,726 \\
Particulate matter & 6,829 & 2,634 & 4,626 \\
Reactive organic matter & 22,548 & 4,252 & 1,306 \\
Carbon & 34 & 34 & 34 \\
& & & \\
\hline
\end{tabular}

Sources: Fang, J.M. \& P.S. Galen (1994), p. 41.

Notes: SCE: Southern California Edison Company

SDG\&E: San Diego Gas and Electric Company

PG\&E: Pacific Gas and Electric Company

The above externality values and the renewable set-aside requirement were applied to the Biennial Resource Plan Update (BRPU) process, which proved to be quite controversial. Challenges and protests by participating utilities and independent power producers caused delays in the selection of the projects. In February 1995, the Federal Energy Regulatory Commission (FERC) found that the California bidding process violated the Public Utility Regulatory Policy Act (PURPA) and FERC regulations, casting in doubt the viability of the BRPU process. Following FERC's rejection of the CPUC petition, the CPUC directed the utilities to try negotiating settlements with the winning bidders.

The CPUC has also adopted policies that encourage utilities to invest in energy efficiency and demand-side management. For example, the commission adopted the Energy Rate Adjustment Mechanism (ERAM) in 1982. ERAM decouples utility revenues from electricity sales. It makes the amount of money that a utility is allowed to recover independent of the amount of electricity the utility sells. Thus, ERAM eliminates a disincentive for a utility to promote conservation and demand-side management. As investment in energy efficiency grows, the need for additional new power supplies is correspondingly reduced, leading to reduced emissions.

\subsubsection{New York}

In New York, two principal agencies are responsible for the environmental aspects of the electric generation: the New York Department of Environmental Conservation (DEC) and the NYPSC. The DEC has broad responsibility for environmental protection including implementation of the Clean Air and Water Acts, the environmental review of smaller electric generation and transmission facilities. The NYPSC has responsibility for regulation of the state's electric utilities as well as the certification of major transmission facilities. Both DEC and NYPSC, along with other agencies, ${ }^{10}$ have responsibility for the certification of new

10 The state board on electric generation siting and the environment consists of seven persons, including the chairman of the NYPSC, the commissioner of environmental conservation, the commissioner of health, the commissioner of the state energy office, the commissioner of economic development, and two citizens residing, respectively, in the judicial district or county of the proposed facility, and appointed by the Governor. However, the 
generation facilities 80 megawatts or larger under Article X of the Public Service Law. Both agencies have collaborated in the development of New York State Energy Master Plans.

Environmental externality values in New York were developed to equalize the differences in environmental impacts of various resource-supply projects in the competitive bidding process. In a 1989 case involving Orange and Rockland Utilities, the NYPSC stated that just because different projects would have complied with various existing environmental regulations, they are not necessarily environmentally equal. The commission relied on judgmental estimates of control costs developed by the State Energy Office for the State Energy Plan. Total control cost was estimated to be 1.405 cents/kWh. ${ }^{11}$ In subsequent cases, the 1.405 cents $/ \mathrm{kWh}$ was applied to increase the cost of supply side resources when comparing them with demand-side resources (Rose, K., et.al. 1994, pp. 87-89). During 1993-94, a computerized New York Environmental Externalities Model (EXMOD) for deriving damage-function based, ${ }^{12}$ site-specific estimates of externalities for certain emissions was developed. As a result, New York utilities now have the option of using the 1.405 cents/kWh value (appropriately adjusted for inflation) or those derived from the EXMOD runs (United States General Accounting Office (USGAO) 1995, pp. 22-26). However, in April 1995, in a case ${ }^{13}$ considering the use of environmental externality adders in different utility decisions such as evaluation of demand-side management programs, an administrative law judge (ALJ) recommended that "the current policy of mandating the use of monetized externalities in supply-side bidding and in DSM programs be discontinued and that the proposals to expand the current policy be rejected" (NYPSC 1995a, p.32). The NYPSC has not yet acted upon the recommendation.

\subsubsection{Wisconsin}

In Wisconsin, the 1972 Wisconsin Environmental Policy Act required the PSCW to consider environmental factors in all its major decisions. For each project, an EIS should be prepared. It must address unavoidable adverse environmental effects, alternatives to the proposed action, the relationship between short-term uses of the environment and the maintenance and enhancement of long-term productivity, and any irreversible or irretrievable commitments of resources. The 1975 Power Plant Siting Act defined the responsibilities of the Department of Natural Resources (DNR) and the PSCW in power plant and transmission line siting. In general, existing environmental regulatory authority for electricity generation and transmission is shared by the DNR and the PSCW. The DNR exercises its authority by approving or disapproving specific permit applications. To construct and operate generation plants, a utility or an independent power producer needs

State Energy Office was abolished in April 1995. Some of its responsibilities were transferred to the NYPSC and the Energy Research and Development Authority.

1 This total cost includes 0.25 cents/kWh for sulfur oxides, 0.55 cents/kWh for nitrogen oxides, 0.10 cents/kWh for carbon dioxides, 0.005 cents/kWh for particulates, 0.10 cents/kWh for impacts on water, and 0.40 cents/kWh for land use impacts.

12 The damage function approach to estimate environmental externalities would identify the specific beneficial and harmful impacts of emissions or pollutants for each resource option, measure the damages and benefits in physical terms, assign economic values to each impact, and sum the values of all impacts to derive the total impact value of a resource option. The assigned economic values may be based on market prices, published values, damage awards in court cases, approximations based on some observed behaviors or other market prices, and estimates derived for willingness to pay to avoid the damages or willingness to accept compensation for the damanges sustained. For additional discussion of this approach, see Fang \& Galen (1994), pp. $27-29$.

${ }^{13}$ Case 92-E-1187. 
permits for the construction of the powerplant, for plant operations, for nonattainment-area major source emissions, for prevention of significant deterioration, for control of particulate and sulfur emissions, and for a Title IV - Federal Acid Rain permit. However, the DNR regulates permit by permit, pollutant by pollutant; it does not have a comprehensive authority conceming environmental regulation (PSCW Staff 1995, pp.37 40). In contrast, the PSCW has a more comprehensive authority over power plant siting and resource selection. It can look at a project as a whole. The PSCW can also assess alternatives to the construction of a major power plant, such as demand-side management programs and renewable resources. The DNR and the PSCW cooperate on environmental issues through a Memorandum of Understanding (MOU) or through interagency work teams on a project-by-project basis (PSCW Staff 1995, pp. 40-45).

The Advance Plan process affords the PSCW the public review and involvement in developing the electric utilities' resource plan for the future. Through the process, the PSCW has required utilities to monetize environmental externalities. In 1989, Advance Plan 5 adopted a 15\% "noncombustion" credit for resources such as demand-side management and renewables to meet customers' demand for electricity without the burning of fuels. This requirement was successfully challenged in court by Wisconsin utilities. In 1992, the PSCW considered various ways of including environmental externalities in the resource planning process in Advance Plan 6. Because of the increasing concern about global warming, the commission concluded that there was a high likelihood that a carbon tax or new regulations on greenhouse gases would be imposed in the near future. Under such circumstances, decisions made about new power plants without considering the costs associated with greenhouse gases could force utilities to pay substantial additional costs for retrofitting plants to meet the new requirements. Therefore, the PSCW found it prudent to consider monetization associated with greenhouse gases as a hedge against the risk of possibility of future federal greenhouse gas regulations. As a result, the PSCW adopted externality values for three greenhouse gases: \$15 (in 1992 dollars) per ton for carbon dioxide, $\$ 150 /$ ton for methane, and $\$ 2,700 /$ ton for nitrous oxide. For other emissions, the PSCW requires the utilities to use the most appropriate methods for estimating the externality values.

\subsubsection{Summary}

Prior to the electric industry restructuring, the responsibility of environmental quality and stewardship in California, New York, and Wisconsin was shared by the environmental and utility/energy regulatory agencies. All three states required monetization of environmental externalities in the resource planning and acquisition process. In fact, they were among only seven states in the United States that have adopted monetized values for specific emissions. The other four states are Massachusetts, Minnesota, Nevada, and Oregon. ${ }^{14}$ In acting to develop externality values, Califomia followed the explicit direction of a state law. The New York and Wisconsin commissions appeared to have based their authority to require monetization of environmental externalities on their interpretation of the agency's responsibility and authority under state laws.

\footnotetext{
${ }^{14}$ In December, 1994, the Massachusetts Judicial Supreme Court ruled that the Massachusetts Department of Public Utilities (MDPU) exceeded its authority in specifying such monetary values that raise the electricity costs. As a result, utilities are no longer required to use those values adopted by the MDPU. Subsequently, in a case involving pre-approval of demand-side management programs, the MDPU directed Boston Edison Company to include the cost impacts of potential future environmental regulations in weighing resource procurement alternatives.
} 


\section{The Process of Environmental Considerations During Industry Restructuring}

In order to discuss the treatment of environmental issues in the electric industry restructuring process in the three states, it is necessary to describe the restructuring process itself. This chapter starts with an overview of the restructuring process in the three states. It breaks the process into six stages or elements, noting the major milestones within each. This discussion is followed by more detailed descriptions of specific environmental considerations.

\subsection{The Overall Process}

The process in electric industry restructuring initiated by a regulatory commission generally has the following stages or elements:

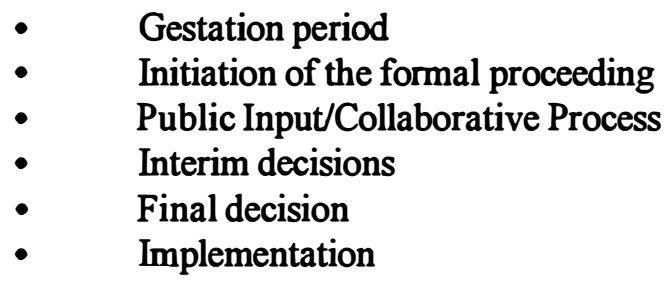

These stages and elements are generally sequential as listed above. However, public involvement and interim decisions can involve several internal loops; i.e., there may be several interim decisions, interspersed with public inputs. Table 3 compares the processes in California, New York, and Wisconsin. Some of the salient points are highlighted below. ${ }^{15}$

\subsubsection{The Gestation Period}

The gestation period refers to the period before a commission opens a formal proceeding to consider restructuring and after some consideration of industry restructuring has started. During this time, issues and concems regarding all aspects of regulation and competition in the industry are studied, discussed, and debated without commission action in initiating a formal process. Because California was the first state to formally initiate a restructuring proceeding, it had a relatively long gestation period, about 2 years. From April 1992 through February 1993, the CPUC staff conducted an internal study of the electric utility industry and its regulation in California. The result was released as a staff report, the Yellow Book (CPUC Staff 1993) for public comments and hearings, which lasted until the initiation of formal proceeding in April, 1994.

The gestation period in Wisconsin was considerably shorter, lasting from March to September, 1994. The Wisconsin Public Utility Institute (WPUI) Roundtable on Electric Power Industry Trends and Regulatory Policy Directions was convened by PSCW Commissioner John Coughlin. The PSCW chairman and the third commissioner addressed separate sessions of the Roundtable. Various groups were represented in the

15 Note, how ver, that this section covers only the principal ideas or events in each stage. Specific consideration of environmental and related public policy issues are covered in section 3.2. 
Table 3: Stages and Elements of the Overall Restructuring Process in Three States

\begin{tabular}{|c|c|c|c|}
\hline Stage/Element & Califormia & New York & Wisconsin \\
\hline Gestation & $\begin{array}{l}\text { 4/92-2/93: internal study } \\
\text { by commission staff } \\
\text { 2/93: study report, the } \\
\text { Yellow Book, published } \\
\text { 2/93-4/94: comments and } \\
\text { hearings on the Yellow } \\
\text { Book }\end{array}$ & $\begin{array}{l}7 / 11 / 94: \text { order on flexible } \\
\text { rates }\end{array}$ & $\begin{array}{l}\text { 1994: roundtable } \\
\text { discussion } \\
\text { 9/94: Wisconsin Public } \\
\text { Utility Institute report on } \\
\text { policy options published }\end{array}$ \\
\hline $\begin{array}{l}\text { Start of the Formal } \\
\text { Proceeding }\end{array}$ & $\begin{array}{l}4 / 20 / 94: \text { CPUC released } \\
\text { the Blue Book proposal }\end{array}$ & $\begin{array}{l}\text { 8/09/94: NYPSC order: } \\
\text { the goal is to develop } \\
\text { guiding principles for the } \\
\text { transition to competitive } \\
\text { electric market }\end{array}$ & $\begin{array}{l}\text { 9/08/94: the PSCW } \\
\text { directed parties to comment } \\
\text { on three specific issues }\end{array}$ \\
\hline Interim Decisions & $\begin{array}{l}\text { 12/7/94: set new schedule, } \\
\text { formed a working group on } \\
\text { public policy programs, } \\
\text { responded to Califomia } \\
\text { Environmental Quality Act } \\
\text { issues } \\
\text { 5/24/95: proposed policy } \\
\text { decision - the Majority and } \\
\text { Minority proposals }\end{array}$ & $\begin{array}{l}\text { 12/22/94: proposed } \\
\text { principles issued for } \\
\text { comments } \\
\text { 6/07/95: Final guiding } \\
\text { principles issued } \\
\text { 12/21/95: ALJs } \\
\text { recommended decision } \\
\text { 2/13/96: Memorandum \& } \\
\text { resolution }\end{array}$ & $\begin{array}{l}\text { 2/02/95: supplemental } \\
\text { notice set objectives of } \\
\text { investigation and principles } \\
\text { for the transition to electric } \\
\text { competition and established } \\
\text { 22-member advisory } \\
\text { committee }\end{array}$ \\
\hline $\begin{array}{l}\text { Public Input/ Collaborative } \\
\text { Process }\end{array}$ & $\begin{array}{l}\text { 4/20/94-11/95: written } \\
\text { comments and public } \\
\text { hearings } \\
\text { 12/94-2/95: working group } \\
\text { process } \\
\text { 2/22/95: working group } \\
\text { report issued }\end{array}$ & $\begin{array}{l}\text { 8/94-9/95: written } \\
\text { comments, workshops, and } \\
\text { participation in working } \\
\text { group } \\
\text { 9/95: Staffs draft } \\
\text { Environmental Assessment } \\
\text { Form } \\
\text { 9/95: Final working group } \\
\text { report issued }\end{array}$ & $\begin{array}{l}\text { 9/94-11/95: written } \\
\text { comments, participation in } \\
\text { the Advisory Committee } \\
\text { process } \\
\text { 7/95 Draft EIS published } \\
\text { 10/95: Final EIS published }\end{array}$ \\
\hline
\end{tabular}


Table 3: Stages and Elements of the Overall Restructuring Process in Three States (cont.)

\begin{tabular}{|c|c|c|c|}
\hline Stage/Element & California & New York & Wisconsin \\
\hline $\begin{array}{l}\text { Public Input/ Collaborative } \\
\text { Process (continued) }\end{array}$ & $\begin{array}{l}\text { 9/1 1/95: SCE, et al., MOU } \\
\text { 10/2/95: Customer } \\
\text { Statement of Principles } \\
\text { 10/2/95: Framework for } \\
\text { Restructuring by } \\
\text { environmental and other } \\
\text { public interest groups }\end{array}$ & $\begin{array}{l}\text { 11/95: Full EAF \& Staffs } \\
\text { motion on State } \\
\text { Environmental Quality } \\
\text { Review Act applicability } \\
\text { 3/06/96: Draft generic EIS } \\
\text { issued } \\
\text { 5/03/96: Final generic EIS } \\
\text { issued }\end{array}$ & $\begin{array}{l}\text { 10/95: Energy Center of } \\
\text { Wisconsin Report on public } \\
\text { opinion released } \\
\text { 11/95: Advisory } \\
\text { Committee report issued; } \\
\text { statewide hearing held } \\
\text { 12/6/95: Commission } \\
\text { Q\&A session with } \\
\text { Advisory Committee }\end{array}$ \\
\hline Final Decision & $\begin{array}{l}\text { 12/20/95 Decision 95-12- } \\
063 \\
\text { 1/10/96 Decision 96-01- } \\
009, \text { minor corrections }\end{array}$ & 5/16/96 Decision 96-12 & $\begin{array}{l}\text { 12/19/95: "A Reasonable } \\
\text { Strategy" adopted } \\
\text { 2/22/96 Report to the } \\
\text { Wisconsin Legislature }\end{array}$ \\
\hline Implementation & $\begin{array}{l}\text { 3/13/96 Road Map } \\
\text { Decision } \\
\text { 3/29/96 Notice of } \\
\text { Preparation of EIR. }\end{array}$ & $\begin{array}{l}\text { 10/1/96 Various utility } \\
\text { filings expected }\end{array}$ & $\begin{array}{l}\text { 32-Step work plan to } \\
\text { implement retail competiton } \\
\text { by } 2000 \\
12 \text { Steps being Started in } \\
1996\end{array}$ \\
\hline
\end{tabular}

Roundtable, including the PSCW, DNR, investor-owned utilities, municipal utilities, rural electric cooperatives, independent power producers, residential, commercial and industrial customers, citizens and environmental organizations, and the University of Wisconsin-Madison. The results of the Roundtable discussions are documented in a report entitled Policy Options for Competition in Wisconsin's Electric Power Industry (Cullen, et al. 1994). It identified a plausible set of policy options to serve as a starting point for the restructuring debate.

There was no similar gestation period in New York. In a case addressing selected issues of competition in the overall energy market, the NYPSC adopted, in July, 1994, an order setting forth general guidelines for the sale of electricity at flexible rates to customers with competitive opportunities. The Commission decided that it was appropriate to investigate issues related to the future regulatory regime in light of the competitive opportunities for electric services (NYPSC 1995a, p. 2). ${ }^{16}$

${ }^{16}$ Note, however, that the NY Department of Public Service collaborated with the New York State Department of Environmental Conservation on the development of the 1994 New York State Energy Plan. The Plan did address the role of state energy plans in a competitive market environment (New York State Energy Office, New York State Department of Environmental Conservation, and NYPSC, 1994). In a sense, this might be regarded as a precursor 
Thus, the initial preparation of the parties involved in the electric industry restructuring process was quite different in the three states. Califomia had a long gestation period, and the Commission staff was the principal generator of the initial ideas which became inputs to the CPUC's vision and initial proposals. Wisconsin had a public gestation period with open public discussion of the ideas, and the resulting report served as a starting point for further debate. New York's process was started within a formal proceeding addressing a number of competitive issues in the overall energy market.

\subsubsection{Beginning Approaches}

Califormia started a formal restructuring proceeding, four and five months before New York and Wisconsin. Califormia began with a formal proposal for phased-in direct customer access and performance-based ratemaking (CPUC 1994a). New York started with the initial goal of developing a set of guiding principles for the restructuring of the electric industry. The NYPSC directed the parties to work collaboratively (NYPSC 1994a, p.3). Wisconsin started in September 1994 with the PSCW requesting interested parties to comment on an initial set of three questions concerning regulatory objectives, institutional structures, and the appropriate regulatory regime to achieve the objectives (PSCW 1994).

The CPUC proposals were controversial. They immediately thrust the stakeholders into confrontation because of the perceived winners and losers inherent in the proposals. New York and Wisconsin, benefitting from a later start than the California case, were able to begin with initial tasks that were more manageable and easier to agree on before going into the more complex ones such as developing and assessing alternative market structures. Specifically, both New York and Wisconsin began by developing principles that outlined the desirable attributes and necessary conditions of the new market structure.

\subsubsection{Interim Decisions}

All three states arrived at some interim decisions and activities. In Califormia, the first interim decision was issued on December 7, 1994, setting a new and expanded schedule, directing that a working group be formed to address the public policy issues, and responding to a motion conceming the preparation of an EIS (CPUC 1994b). A second interim decision, on May 24, 1995, designated the CPUC's preferred policy (the Majority proposal) and an alternative policy (the Minority proposal). The Majority proposal would create a central pool, or "poolco;" set electricity prices to reflect the true cost of service in real time, or "real-time pricing." It would allow all customers to enter into contractual transactions with generators to hedge against the fluctuations in the pool price of electricity. The Minority proposal would institute retail wheeling, or "direct access," and require utilities to sell off their generation plants (CPUC 1995b).

New York issued five interim decisions or resolutions. The first, issued on December 27, 1994, presented the NYPSC's proposed principles for comment (NYPSC 1994b). The second interim decision was issued on June 7, 1995. It adopted the final guiding principles for restructuring the electric industry (NYPSC 1995b). On December 21, 1995, an ALJ's Recommended Decision was issued (NYPSC 1995c). It recommended that the commission adopt a transition leading to a flexible retail poolco model for the electric industry in New York. In the transition, there would be a wholesale poolco with an independent system operator (ISO) and implementation of various market mechanisms to facilitate an orderly movement to full retail access. In the process, generation would be separated from transmission and distribution functions. An ISO would be established and an energy service market developed (NYPSC 1995c, Vol. I pp. $111-112$ and Appendix F in Vol II). On February 13, 1996, the NYPSC (1996a) issued a memorandum and resolution, concurring with

to the restructuring efforts. 
the ALJ's findings on the preparation of an EIS and directing that an EIS be prepared. On May 3, 1996, the Commission issued its final generic EIS (NYDPS, 1996b).

In Wisconsin, the PSCW adopted an interim decision on February 2, 1995, setting the objectives of the investigation, stating the principles for restructuring, and appointing an advisory committee to develop and assess alternative market structures, and transmission and distribution systems (PSCW 1995a).

\subsubsection{Collaborative Approaches}

All three states used a collaborative approach to some extent. There are, however, some differences in the timing, duration of, and participation in the collaborative processes in the three states. In timing, the collaborative process can begin at the outset of the investigation, as in New York, or later, as in California and Wisconsin. The duration of the collaborative process may be shorter with a more focused assignment, as in Califomia, where the working group was asked to address issues pertaining only to public policy programs. Alternatively, the collaborative approach can be used continually during the restructuring process, as in New York and Wisconsin, where the group was directed to address all applicable issues. As to participation, the commission staff can be either included or excluded in the working group. In addition, the working group can be formally appointed by the commission, as in Wisconsin, or participation can be voluntary, except for the investor-owned utilities, as in California and New York.

California did not designate a collaborative approach until about 7 months after the start of the formal restructuring process, following substantial public comments on the need to guard against losing the gains in achieving various public policy objectives made over the past two decades. At the direction of the CPUC, the working group was formed to explore the sustainability of public policy objectives, including environmental issues, and to provide options for implementing public policy programs. The three investor-owned electric utilities were required to join the working group. At the direction of the commission, the CPUC staff, with the exception of the Division of Ratepayer Advocates, did not participate in the working group sessions. All other interested parties could join in the working group voluntarily (CPUC 1994b, p. 8 and p. 12). Since the CPUC.did not try to limit the number of parties in the working group, there were more than 100 . The working group submitted its report, entitled Options for Commission Consideration (Working Group 1995), to the CPUC on February 22, 1995, about 3 months after it was formed. At that time, the working group was disbanded. In its final decision, the CPUC indicated that it may reconvene the working group to work on implementation issues.

The CPUC also allowed another form of collaboration: a coalition of groups of stakeholders. Following the Majority and Minority proposals contained in the second interim order, there was an informal coalition building and collaboration process. On September 11, 1995, a coalition of SCE, California Manufacturers Association, Califomia Large Energy Consumers Association, and Independent Energy Producers filed a memorandum of understanding (MOU) (SCE, et al. 1995). The MOU combined major elements of both the Majority and the Minority CPUC proposals with significant modifications and refmements. It provided for the simultaneous development of a power pool or exchange and direct access by January, 1998. According to the MOU, there would be a voluntary statewide pool or power exchange that would perform the functions of a short-term spot market. In addition, an ISO would manage and provide access to the transmission system on a nondiscriminatory basis and would perform settlement functions. Direct access for retail customers and a nonbypassable competitive transition charge (CTC) would be established simultaneously. 
On October 2, 1995, a coalition of customer groups ${ }^{17}$ and the Division of Ratepayer Advocates of the CPUC filed a response to the MOU: the "Customer Statement of Principles on Electric Restructuring in Response to Commission's Order for Comments" (Customer Statement Parties, 1995). The Statement suggested that the MOU contained "market structure elements that could serve as a far more appropriate starting point for restructuring the electricity industry than the Commission's Majority proposal." The Statement set forth principles on rate reduction, market structure, stranded costs, market power, public policy programs, and the process of further proceedings.

Also on October 2, 1995, another coalition of environmental, energy efficiency, renewable energy, and other public interest groups filed a framework for restructuring in the electric industry. ${ }^{18}$ The framework provided general guidelines on rates and bills and other benefits from restructuring; performance-based ratemaking; stranded costs; market power; generation resources and wholesale power market; equitable direct access for small customers; and for low-income and public interest programs. It also specified principles for environmental, renewable resources, and public policy programs such as research, demonstration, and development; energy efficiency; and renewable resources (Framework Parties, 1995).

In New York, the collaborative process was started right at the beginning. The NYPSC urged the parties to work collaboratively to identify comprehensive principles (NYPSC 1994a). The New York Department of Public Service (NYDPS) staff participated actively in the process. The assigned ALJ prepared regular reports on the progress and discussions of the parties. Various working groups were formed: coordination, institutional issues, financial issues, customer service, planning Issues, operation and pricing issues, stranded costs, and public policy issues. Environmental issues were covered by the working group on public policy issues. In September, 1995, the NYDPS issued the Final Phase II Report, entitled Restructuring New York's Electric Industry: Alternative Models and Approaches (NYDPS 1995a). It documented the results of the working groups collaborative process on three basic alternative competitive models (the evolving regulatory, wholesale, and retail models). It covered various issues considered by the working groups.

In Wisconsin, the collaborative process was started when the PSCW issued its supplemental notice of generic investigation on February 2, 1995, five months after the initial notice (PSCW 1995a). This was a formal process in the sense that the participants in the Advisory Committee were formally designated by the PSCW. Excluding the chair, who was a member of the PSCW, the committee had 21 members representing different interests groups. The commission staff was also represented on the Committee. The Advisory Committee often divided itself into subcommittees for more in-depth work on particular set of issues. These subcommittees frequently included parties other than those represented on the Advisory Committee.

17 The groups are: Association of California Water Agencies, Agricultural Energy Consumers Association, California City-County Street Light Association, California Department of General Services, California Farm Bureau Federation, California Hotel and Motel Association, California Industrial Users, California League of Food Processors, California Restaurant Association, California Retailers Association, Division of Ratepayer Advocates, and School Project for Utility Rate Reduction. Collectively, they are referred to as the "Customer Statement Parties."

${ }^{18}$ Parties to this group include Utility Consumer Action Network, Union of Concerned Scientists, Toward Utility Rate Normalization (TURN), Sierra Club California, Public Citizen, Natural Resource Defense Council (NRDC), Environmental Defense Fund, Center for Energy Efficiency and Renewable Technologies (CEERT), California Public Interest Research Group, California Nevada Community Action Association, and American Wind Energy Association (AWEA). Collectively, they are referred to as the "Framework Parties." 
The Advisory Committee was directed to examine every aspect of electric service to determine which functions could best be performed by a competitive market. In February, 1995, the Advisory Committee developed $A$ Framework for Identifying and Evaluating Alternatives for the Future Structure of the Electric Industry in Wisconsin (Public Service Commission Advisory Committee, 1995a). The document outlined steps to follow in identifying and evaluating functions and procedures in electric industry restructuring. The Advisory Committee worked continuously until the completion of the Report of the Advisory Committee to the Commission on Electric Utility Restructuring in October, 1995 (PSCW 1995d). The report examined options for transmission, generation, distribution, and public policies, and then formulated five consolidated market structures.

In addition to the Advisory Committee process, the PSCW prominently utilized the EIS process for public participation and input. The PSCW decided early on that an EIS should be prepared. A draft EIS and the final EIS were issued in July and October, 1995, respectively (PSCW Staff 1995; PSCW 1995c). ${ }^{19}$

\subsubsection{Final Decisions}

In December, 1995, the Commissions in California and Wisconsin adopted final decisions. The New York Commission issued a final order in May 1996. The principal characteristics of the envisioned market structures or systems are briefly described in this section. The details conceming environmental issues and related considerations are described in Section 3.2.5.

In California, the CPUC issued a "final" policy decision on electric industry restructuring on December 20, 1995 (Decision 95-12-063). On January 10, 1996, the CPUC made minor corrections and changes to the decision (Decision 96-01-009). The CPUC's final decision created two new institutions to handle the wholesale power market and transmission; the Power Exchange and the Independent System Operator (ISO). The Power Exchange would foster the development of a transparent spot market for the generation of electricity. The ISO would coordinate the daily scheduling and dispatch of generation to provide open and nondiscriminatory access to the transmission system. The order anticipates that, shortly after January 1 , 1998, electric consumers would choose among three options: (a) retain the traditional relationship as a full service customer of the local electric utility; (b) conduct financial hedges to maintain price stability and predictability; and (c) attain direct access through physical, bilateral contracts. Performance-based ratemaking would be applied to distribution utilities regulated by the Commission (CPUC 1995c).

In Wisconsin, the PSCW adopted "A Reasonable Strategy for Restructuring Wisconsin's Electric Utility Industry" on December 19, 1995 (PSCW 1995e). The commission's preference is to use competition to attain an efficient and customer-driven electricity marketplace for Wisconsin. All customers should have access to competitive energy supplies. The target date for implementing retail competition is the year 2000. However, retail competition will be implemented only if the PSCW is satisfied that necessary conditions are in place to sustain a competitive market that is in the public interest.

In New York, the NYPSC issued its final decision on May 16, 1996. It decided to implement wholesale competition by early 1997 and retail competition by early 1998. It directed utilities to file proposals and plans by October 1,1996 . To prevent the onset of market power, it encouraged utilities to divest generation from transmission and distribution systems. Divestiture of energy services is also encouraged if it will provide consumer benefits (NYPSC, 1996b, pp. 89-91).

19 See Section 4.5 below for discussion on the DEIS and the EIS. 


\subsubsection{Implementation}

As of May, 1996, implementation of the adopted restructuring decisions in California and Wisconsin were ongoing. In New York, it was just getting started. This section provides information available only through May 1996, to provide an implementation outline; a detailed description of the implementation processes is beyond the scope of this study.

In Califormia, the CPUC issued a restructuring roadmap decision on March 13, 1996. It grouped implementation issues into four subject areas: (1) management and coordination, including compliance with the California Environmental Quality Act; (2) market structure issues such as the ISO, power exchange, and market power; (3) consumer choice issues such as direct access, consumer protection, public purpose programs including renewables, energy efficiency, research, development and demonstration, low-incoine programs; and (4) ratesetting issues such as unbundling, pricing, rate design, performance based ratemaking, and transition costs. The decision also established different working groups to address and work toward consensus on implementation issues. It encouraged any interested party to join a working group and laid out a procedure for a working group to obtain commission recognition of its status to ensure completeness in issue coverage and to avoid duplication. The decision also set milestones for various implementation filings:

- $\quad$ Proposal for establishing the independent system operator - April 29, 1996, to be filed simultaneously with the CPUC and FERC

- $\quad$ Proposal for establishing the Power Exchange - April 29, 1996, to be filed simultaneously with the CPUC and FERC

- Divestiture plans and comments on corporate restructuring (functional unbundling) - March 19, 1996

- Utility proposals on direct access, including eligibility criteria - August 30, 1996; initial phase of direct access to begin no later than January 1, 1998

- Working group report on consumer protection - October 30, 1996

- Working group reports on: renewable issues - July 1, 1996; public goods charge issues on competitive and public interest DSM, competitive and public interest research,development and demonstration (RD\&D), and definition of market transformation, July 1, 1996; public goods charge issues on proposed public funding level for $1 / 1 / 98$, independent administrator, proposed implementation legislation, and analysis of impact of treatment of electric energy efficiency and RD\&D on gas programs - October 1, 1996; low-income issues - September 6, 1996

- Utility filings on separate proposals for distribution and generation of performance based regulation (PBR) - July 15, 1996; application to identify and value the sunk costs of non-nuclear generation assets - July 15, 1996; applications to estimate transition costs as of January 1, 1998 - August 30, 1996; proposals to provide information on separating rates into identifiable components - July 15 , 1996. 
With respect to environmental issues, the CPUC issued a notice of preparation of the environmental impact report (EIR) on March 29, 1996. It included a calendar for scoping meetings and requests for comments. It also initiated the public involvement process by announcing informational meetings (CPUC, 1996b).

In Wisconsin, the commission adopted a two-phase 32-step process to implement retail competition by 2000 (PSCW 1995e). However, implementation of retail competition will be contingent upon fulfilling conditions the commission deems necessary for sustaining a competitive market and are in the public interest. Phase I is generally devoted to conducting studies, developing plans, and initiating reforms to help generate the necessary conditions. Phase II generally involves implementation of plans and programs developed in Phase I. At the end of each phase, there will be a "check phase" at which four steps will be taken: (1) evaluate progress; (2) examine the state of the industry; (3) determine the need for any legislation; and (4) make any mid-course corrections and adjustments. Among the 32-steps outlined, 12 will be started in 1996 . Six of the 12 are expected to be completed during 1996 and the other six during the first half of 1997.

In New York, the commission would implement its adopted policy decision in two ways. First, it directed that a collaborative effort among staff, the utilities, and other interested parties be pursued to conduct technical studies on market power concerns, the role of energy service companies and reporting requirements, to make necessary FERC filings, and to engage in public educational forums by October 1, 1996. Second, it directed that five utilities make their filings by October 1,1996 to address issues such as the corporate structure of the utilities, retail access proposals, long-term rate plans, public programs, market power, and energy services (NYPSC, 1996b, p. 91).

\subsection{Consideration of Environmental Issues by Process Element}

In the context of the process described above, this section compares the specific considerations of environmental issues associated with each process element. General descriptions of the issues are provided in this section. In some cases, however, references are made to the specific sections which will treat those issues in more detail.

\subsubsection{Gestation Period}

During the gestation period, both Califomia and Wisconsin addressed the environmental issues. In Califomia, the Yellow Book traced the developments of environmental regulations from an historical perspective. It discussed the "greening" of electric utilities in the 1970s, owing to the enactment of the National Environmental Policy Act (NEPA), the Califomia Environmental Quality Act (CEQA) of 1970, the Clean Air Act of 1971, and the Endangered Species Act. The Yellow Book noted that compliance with the regulations derived from these statutes added to the cost of electricity (CPUC Staff 1993, pp. 32-33). It mentioned the creation of the CEC in 1975 as the one-stop powerplant licensing agency, and the partnership between utilities, CPUC, and environmental regulatory agencies to form the South Coast "emission trading market" in the late 1980's, and the 1990 legislation to assign monetary values to environmental externalities. The Yellow Book also noted that green pricing was consistent with the concept of customer choice and the general perception that a balance between economic growth and environmental quality could be achieved (CPUC Staff 1993, pp. 130-131). Finally, the CPUC staff identified environmental quality and resource diversity as two criteria for developing strategies to reform the regulation of the electric utility industry and applied them to assess the alternative strategies developed in the Yellow Book (CPUC Staff 1993, pp. 157$159,170,178,187$, and 193). 
In Wisconsin, the report to the Roundtable listed five criteria for assessing the proposed change to electric industry structure: fair prices, economic efficiency, safety and reliability, environmental protection, and customer choice. Four of these criteria are derived from the traditional regulatory scheme. The last criterion customer choice - is from the new emphasis on competition. With respect to environmental protection, the report states (Cullen, et. al. 1994, p.16):

The public has a right to know the environmental impacts of generation and transmission projects. The environmental costs and benefits of all such projects are taken into account in deciding which projects should be built. Negative impacts are minimized whenever feasible. Alternative resources (such as energy efficiency or renewables) are considered.

The report also developed three options for treating environmental protection in a restructured electric industry (Cullen, et. al. 1994, pp. 78-81):

1. Adding to existing procedures: new legislation authorizing PSCW to explicitly include estimates of environmental effects (either monetized or prioritized) or to require set asides of renewables

2. Revamp current review procedures: Simplify the current review procedures embodied in Wisconsin Environmental Protection Act (WEPA), the Advanced Plan and the certificate of public convenience and necessity (CPCN) statutes to cover only the opportunity for public input, evaluation of need, and scrutiny of major environmental impacts that are appropriate for the type of technologies involved. Move the environmental review tasks to earlier stages of the Advance Plan and the CPCN statutes to major decision points.

3. Transfer environmental review to the DNR: PSCW would support shifting the responsibilities of environmental review and its environmental staff to DNR

As noted above, there was no comparable gestation period in New York. Hence the issue of how environmental factors are treated in the gestation period is not relevant. Note, however, the NYPSC has an ongoing docket addressing how issues related to the treatment of environmental externalities - Case 92-E1187 - in which an ALJ's recommended decision is pending before the Commission (NYPSC 1995a).

\subsubsection{Start of Formal Proceeding}

As formal proceedings were started, all three states covered different aspects of environmental protection issues. In California, there was a marked change in coverage on environmental protection from that included in the Yellow Book. In the Blue Book, the CPUC explicitly addressed environmental protection in two ways. First, the CPUC stated that resource additions would still be subject to the requirements of the CEQA and other existing regulations. Second, the CPUC proposed to promote green pricing, allowing utility customers to choose to pay a premium so the utilities could acquire electricity from renewable sources. In New York, the NYPSC explicitly incorporated maintenance of environmental quality as a condition to the objective of moving toward a more competitive electric industry by increasing the efficiency of providing electric service. In Wisconsin, the PSCW noted that environmental protection and land use compatibility is an existing 
electric utility regulatory objective. The PSCW then requested that parties comment on the following three issues: (a) whether the environmental protection and other existing regulatory objectives should be maintained, eliminated, or expanded in the future electric industry and its regulation; (b) which institutional arrangement would be best to achieve the objectives; and (c) what regulatory regime could provide the best future balance of the desired objectives. According to the PSCW, existing regulatory objectives are not internally consistent and the commission's decisions necessarily must reflect an attempt to strike a balance among the competing objectives.

\subsubsection{Interim Decisions}

The initial CPUC proposed approach to environmental and other public policy issues was intensively criticized as inadequate and inappropriate. ${ }^{20}$ Even the state legislature got involved and issued Assembly Concurrent Resolution (ACR) 143. It urged the CPUC not to implement any performance based regulation and any electric industry restructuring until after submitting a report to the legislature by January 31, 1995. The requirements included analysis of the impacts of restructuring on public policy programs such as energy efficiency, renewables, environmental protection, and low-income assistance. ${ }^{21}$ In response, the CPUC issued an interim decision on December 7, 1994. This decision (a) established a working group to address the sustainability of social, economic and environmental obligations under a restructured electric industry; asked the parties to prepare briefs on laws that might be implicated by any electric industry restructuring proposals; and (c) disposed of the motion to prepare an EIR in accordance with the CEQA.

As defined by the CPUC, the purpose of the working group was to "comment on the sustainability of social, economic, and environmental obligations and restraints in each of the restructuring models and to provide implementation options for carrying out these social, economic and environmental policy goals under each of the broad restructuring models" (Working group, 1995). For the working group, the commission identified eleven issues of concern: reasonable and nondiscriminatory rates; nondiscriminatory transmission access; public health and safety; service quality and reliability; demand side management and energy efficiency programs; low-income ratepayer programs; fuel diversity and renewable resource technologies; environmental protection; low emissions vehicles and other technology development; women - minority - and disabled veteran-owned business enterprise; and economic development. The commission directed the working group to develop options for achieving four objectives: unbundling of electric service, maintaining or advancing public policy programs or both, pursuing resource procurement, and cost recovery mechanisms (CPUC 1994b, pp. 9 - 10). ${ }^{22}$

The CPUC's December 1994 Interim Decision touched on environmental issues in several areas. First, environmental protection was one of the eleven issues of concern specifically identified by the CPUC. Related issues included demand-side management and energy efficiency, fuel diversity and renewable resource technologies, public health and safety, and low emission vehicles. Second, the objective to promote resource diversity implies the promotion of environmentally sensitive electric generation and service. Third,

20 For a summary of the comments on the green pricing approach, see Section 4.4.7 below.

21 For additional discussion of ACR 143 and the role of state legislature, see Section 4.2 below.

22 For a description of the results of the working group's efforts, see Section 3.2.4 below. 
the objective to develop a cost recovery mechanism is aimed at developing alternative methods of paying for environmental programs. Fourth, the commission stated that it will be committed to determining the applicability of CEQA when it adopts its final policy decisions.

Subsequently, the CPUC issued another interim decision on May 24, 1995, on the preferred and alternative industry structures (the Majority and Minority proposals). In the Majority proposal, the CPUC indicated that it was leaning toward having environmental agencies take over the commission's environmental responsibilities. The CPUC also initiated the first step in conducting a preliminary analysis of the environmental impact of electric restructuring by asking for comments on two issues:

1. Do any of the policies proposed herein constitute a "project" subject to CEQA, as defined in Public Resources Code 21065 and interpreted by the courts? Comments should specify which policy elements, if any, are believed to trigger definition as a CEQA "project," as well as cite authority for the party's analysis and conclusions.

2. Do any changes proposed by the party to this Proposed Policy either trigger definition as a CEQA project OR remove such definition? Again, comments should specify which changes, if any, are believed to affect definition as CEQA "project," as well as cite authority for this conclusion.

In New York, the NYPSC adopted a set of nine guiding principles in its interim decision on June 7, 1995. Among them, the preamble, Principle \#1, and Principle \#3 have either explicit reference to environmental protection or implications on environmental quality (NYPSC, 1995b, Appendix C):.23

Preamble: In accordance with the commission's mandate that all New Yorkers must have access to reliable and reasonably priced electric service provided safely, cleanly, and efficiently, the following guiding principles apply in the transition to a more competitive electric industry:

Principle 1: Competition in the electric power industry will further the economic and environmental well-being of New York State. The basic objective of moving to a more competitive structure is to satisfy consumers' interests at minimum resource costs. Prices should therefore accurately reflect resource costs, and consumers should have a reasonable opportunity to realize savings and other benefits from competition.

Principle 3: Increased emphasis should be placed on market-based means or competitively neutral approaches to preserve research, environmental protection, cost effective energy efficiency and fuel diversity.

${ }^{23}$ Only those guiding principles that have relevance for environmental factors are listed and discussed in this section. Hence the numbering is not continuous. For example, Guiding Principle No. 2, and No. 4 through No. 9 are not listed. 
In New York, the ALJ's Recommended Decision was issued on December 21, 1995. It concluded that "a nonbypassable system benefits charge, imposed on all customers using the distribution system, appears to be a fair way of ensuring that such (public policy) programs be continued" (NYPSC 1995c, p. 84). The Recommended Decision directed the utilities to address, in their individual filings, the issues concerning the level of funding for public policy programs including demand-side management, research, and development, and direct environmental protection costs. It requested that the parties propose mechanisms to administer the system benefits charge (NYPSC 1995c, pp. 83-84). It also found that the requirements of SEQRA were applicable and that an environmental analysis needed to be performed. Hence, the staff should be directed to prepare a draft generic EIS. In addition, the Recommended Decision also ruled that an EIS needs to be prepared before the commission can make a final selection on the market structures so that the information on the potential environmental impacts of different options can be used in the commission's deliberations (NYPSC 1995c, pp. 101-104). The NYPSC (1996) concurred with these recommendations about the EIS review.

In Wisconsin, the interim order (PSCW 1995a) set forth three objectives of the investigation and seven principles for restructuring. Objective 3 is "to create a system in which providers maximize economic efficiency and environmental stewardship." Principle No. 6 states that "regulatory, social, environmental, and financial commitments have been made in the past and cannot and should not be ignored or discarded in the transition to a new structure. ${ }^{124}$ The commission further established an Advisory Committee to look into every appropriate aspect of the restructuring process. An environmental impact statement process was also started. $^{25}$

\subsubsection{Public Input/Collaborative Process}

The public input process played an integral part of the electric industry restructuring in all three states. As noted in Section 3.1, the collaborative approach was prominently utilized. This section describes those activities with environmental implications.

California. As mentioned above, in its December 1994 interim decision, the CPUC directed that a working group be formed to address options for public policy objectives and programs. The working group completed its work and submitted the report to the CPUC on February 22, 1995 (CPUC 1995b). The working group developed four options for assuring environmental protection in the restructuring process:

- Option 1: Existing Laws and Regulations - Existing laws and regulations would be maintained. The integrated utility would retain responsibility for management of the generation portfolio in its franchise territory. Few changes in laws are needed. New

\footnotetext{
${ }^{24}$ The other principles are: (1) Consumers of all customer classes should benefit, or at least be held harmless from any changes. (2) Nothing done in this proceeding should preclude future movement to the most marketoriented model. (3) Competitive markets are preferred to regulation to meet the objectives, if consumers benefit. (4) Consumers must have ready access to the information necessary to make informed decisions about services and suppliers. (5) Safe and reliable universal service must be maintained. (7) Simple deregulation does not guarantee a competitive market.

25 For a discussion of the EIS/EIR issue, see section 4.5, "Environmental Impact Statement/Report."
} 
entities that may be subject to CPUC or FERC jurisdiction might require authorization to collect environmental cost charges and to implement programs authorized by the CPUC.

- Option 2: Environmental Performance Standards for Local Distribution Company's (LDC). The CPUC would establish environmental performance standards for LDCs under its jurisdiction, covering air, water, and hazardous waste. Such standards would replace current regulations for the integrated utilities. This option would require changes in existing Public Utilities and Public Resources Codes. Federal laws governing utilities would need to be extended to other generators to ensure equal treatment. Air Quality Management District regulations would need to be modified to address broader categories of sources or reclassifying power plant categories. Because new performance standards would be set, they may duplicate existing standards set by non-energy agencies. Additional financial and staff resources would be required for the agencies for setting and implementing the standards.

Option 3: Environmental Agency Regulation - Nonenergy agencies would assume responsibility for environmental protection policies currently implemented by energy agencies. This would require changes in existing laws concerning valuation of environmental benefits and costs in resource planning and acquisition. State and federal laws on utility power plants would need to be extended to cover other power plants. AQMD regulations need to be modified to be consistent with the new environment. Because local agencies may have difficulties with broader systems issues, state agencies may need to assume a larger role in such issues and coordination. Additional allocation of resources to environmental agencies may be required.

- Option 4: Emissions Surcharge/Consortium - This option would impose an emissions surcharge/tax on all or major subsets of environmental externalities from individual facilities, regardless of ownership, to internalize the damages from such externalities. At the same time, a statewide consortium would be set up to engage in environmental research, public information, and other activities not addressed through the emissions charge. Existing laws and codes would need to be changed. New legislation is needed to create the emissions surcharge and the state consortium. There is a need to develop a system for characterizing and quantifying environmental damages. Some of the issues are administration costs, regulatory structure, the difficulty in establishing a new tax, computation of damages, and potential inequity if the tax is imposed on generators only.

Under Option 1, existing investor-owned utilities would not face any changes, but new entrants to the market, such as independent power producers (IPPS), would need to be subject to the regulations that are designed for integrated monopolies. This would raise the costs to the IPPs. Unlike the regulated monopolies, the IPPs would have no ready mechanisms to recover those additional costs. The risk of not recovering the additional costs of compliance would either reduce the level of compliance or create a barrier to entry. There are additional questions as to how power marketers, who usually own no generation assets, would be treated. 
Option 2 has the advantage that the commission may have a more comprehensive view of the relationship between the cost of complying with environmental regulation and cost of electricity. However, there may be risks of duplication with existing regulations by other agencies and of building duplicative staff expertise. The main advantage of Option 3 is the consolidation of all environmental regulations into the environmental regulatory agencies. A potential weakness is that the environmental agencies might not have the same perspective as the utility regulatory commission, possibly promulgating regulations without adequate considerations of compliance costs. Option 4 would employ a market-based mechanism, a surcharge or tax, and, at the same time, provide for the necessary research and public information. However, it may be difficult to establish the surcharge if new legislation is required. There is a need to ensure that the surcharge is imposed on all electricity consumed not just on electricity generated within the state.

In its May 1995 proposed policy decision, the CPUC identified the working group's Option 3, Environmental Agency Regulation, as closest to embodying the Commission's vision. However, the commission viewed it as only an expansion of current environmental protection responsibilities of such agencies not as the initiation of new responsibilities for them (CPUC 1995b, p. 236).

In the coalition building and collaboration process following the CPUC's proposed policy decision, the MOU parties agreed that electric resource diversity is an existing California policy objective. They further agreed that investments in energy efficiency and conservation and in renewable energy resources were consistent with the resource diversity objective. They proposed two funding mechanisms. First, SCE would commit $3.3 \%$ of its total revenue requirement (as of January 1, 1995) for DSM services promoting energy efficiency and conservation, renewable energy resources and technologies, and research and development programs. For all other public policy programs, a nonbypassable surcharge would be used; the amount to be collected via the surcharge to be set at the 1995 level. With respect to environmental review, the MOU stated the following (SCE, et al., 1995):

The CPUC's final Policy Decision and the steps necessary to implement that decision may constitute the "whole of an action" which the CPUC should use in making its CEQA determinations. The parties agree that (in the absence of specific exemptive legislation) neither operation of the Power Exchange nor direct access transactions shall begin until after (1) the CPUC has concluded either its negative declaration (based on its preliminary review and initial study) or its EIR process and has issued any decisions mitigating significant environmental impacts, if any, and (2) any determination of compliance with NEPA is concluded. The parties encourage the CPUC to begin its environmental review as soon as possible after issuance of the final policy decision.

Separately, the Customer Statement parties ${ }^{26}$ (1995) supported a nonbypassable charge during the transition period to fund public policy programs such as energy efficiency, renewables, $R D \& D$, and low-income assistance. The coalition would generally exclude investor-owned utilities from administering such programs after January 1, 1998. A cap on the level of funding should be imposed to allow cost-effective continuation during the transition. A critical assessment of the public policy programs' efficacy and value in the restructured market should be conducted after 5 years.

${ }^{26}$ For the parties that are signatories to the Customer Statement, see Footnote 17. 
In addition, the Framework Parties ${ }^{27}$ (1995), the third coalition, presented the following principles for considering environmental issues:

- $\quad$ All sources of generation must meet the same environmental standards, regardless of plant ownership or the restructuring model adopted.

- Any load aggregation program shall be subject to the same environmental and public policy conditions, transparent pricing requirements, and minimum standards to prevent discrimination based on income levels and ethnic diversity as nonaggregated customers.

- $\quad$ Funding for public policy programs such as investments in energy efficiency shall be provided through a capped, non bypassable system benefits charge. In the short term, such a program can be administered by investor-owned utilities. In the long term, alternative administrative procedures should be developed.

- Investor-owned utilities that supply generation shall maintain a supply portfolio with a minimum level of renewable resources consistent with 1995 levels and diversity. Maintenance of this minimum level of renewables shall become a nonprice criterion in any applicable performance-based regulation (PBR) determination. The above-market cost of maintaining this minimum renewables portfolio, if any, shall be recovered from all customers through the nonbypassable CTC mechanism. Direct access customers or community access aggregators opting to contract for an equivalent level of renewable resource shall receive a commensurate reduction in their CTC.

- A renewable development fund shall be established to increase the level of resource diversity over time. The fund shall be financed through money allocated from a portion of the system benefits charge.

New York. In New York, the results of the collaborative efforts were documented in the Final Phase II Report issued in September 1995 (NYDPS 1995a). The report concluded that in a restructured electric industry, utilities and generators are still expected to comply with applicable federal, state and local environmental laws and regulations. There would be increased use of market-based mechanisms in addressing environmental issues. Generation and transmission siting reviews would be conducted in accordance with the State Environmental Quality Review Act (SEQRA). The report also documented different views and positions. For example, because of its relatively high cost of electricity, New York would likely be a net importer of electricity. Some believed such net import of lower-cost electricity could lead to air quality deterioration in New York State, especially if the sources of supply are from the low-cost, highemitting states. Some suggested that a "universal system benefits charge" be instituted to fund environmental and other public policy programs (NYDPS 1995a, p. 130). In the report, there is no explicit explanation of how New York State's air quality problem would be exacerbated by increased generation in the low-cost, high-emitting states. Presumably, such states are to the west of New York and the prevailing wind conditions are such that emissions from power plants located therein eventually have impacts on air quality in New York and the Northeast.

27 For parties who are signatories to the Framework, see Footnote 18. 
Many believed that expanding the use of renewable resources would help to reduce air emissions and enhance compliance with the CAAA of 1990. The report identified five options for achieving the objectives of increasing fuel and technological diversity through renewable energy:

(1) Implement energy efficiency and renewables through legislative and regulatory actions such as the State Energy Planning (SEP) process and appropriate tax legislation or incentives. This approach could address the concern that the market would focus only on the short run.

(2) Continue integrated resource planning (IRP). This would require utilities to take the long-run view and consider the societal costs of resource utilization.

(3) Reliance on the market forces. Some would argue that the market is efficient, and market-based policies can adequately promote renewables and protect the air and environmental quality.

(4) Green pricing. Let customers decide if they are willing to pay premiums to help promote the use of renewables.

(5) Universal service charge (USC). Many parties suggested adopting the USC to help pay for environmental and other public policy programs. The report discusses the pros and cons of each of these options.

Some believed that electric industry restructuring will have a predominant focus on lowering costs. Since compliance with the Clean Air Act and other environmental regulations would raise costs, generators and utilities would lobby Congress and the state legislature to relax existing regulations in order to lower costs. Some countered that this is highly speculative; that lawmakers will set certain environmental protection limits. Some would like to see older power plants subjected to the same emission limits as the newer plants. Others argued that pollution standards and regulations should be set on regionwide basis to eliminate the competitive bias that might be introduced into the system if individual states and localities have different standards and requirements.

The report also addressed implementation options for addressing environmental externalities in a restructured industry. The report noted that many parties suggested a universal systems benefit charge for pursuing environmental goals. It discussed five implementation options: regulated monopoly, wires or social benefits charge, reliance on market mechanisms, emissions caps with tradeable allowance, and a combination of the above. $^{28}$

Wisconsin. In Wisconsin, a consensus building process by parties resulted in two options for addressing the public policy issues; the market transformation option, and the social benefits fund option. "Under the market transformation option, the goal of energy efficiency efforts would be to transform the market so that it can sustain itself without regulatory or utility intervention. A fund, which would be supported through a distribution access fee, would be established to accomplish the transition to markets and would sunset after a set period such as 3 to 5 years. Initial funding levels would correspond to current industry-wide expenditures on DSM programs" (PSCW 1995c, p. 112). For transmission and distribution, recovery of prudently

${ }^{28}$ See Section 4.3 below for a description of these options. 
incurred costs for participation in specific environmental R\&D would be allowed. For generation, environmental R\&D could be promoted through regulation and internalization of environmental costs (PSCW 1995c, p. 134).

"Under the Social Benefits Fund Option, increased competition would be fostered for energy efficiency services. A social benefits fund would be created for the transition to competitive markets, and the fund would not have a sunset provision. There would be no reductions of low-income programs under this option" (PSCW 1995c, p. 113). Preferably, the fund would be created as an independent, nonprofit organization funded through a statutory fee such as a line charge, revenue fee or pollution tax. Another option would be to create by law a governance body within the PSC funded through a statutorily required assessment on utilities by the commission. The board would administer grants on a competitive basis in the areas of DSM, renewables, $R D \& D$, and advocacy for environmental, small business and residential customers (PSCW 1995c, pp. 138-140).

\subsubsection{Final Decisions}

California and Wisconsin reached "final" decisions on restructuring in December 1995. New York issued its final decision May 16, 1996. Consistent with this study's focus, the following discussion covers only those aspects that have implications for environmental protection, energy, efficiency, renewable energy and related issues.

California. The CPUC's "final" order contains the following items with implications for environmental protection and related issues: (1) set a minimum renewables purchase requirement for promoting the continued development of renewable generation and achieving the goal of resource diversity; (2) adopt, by January 1, 1997, a "public goods charge" (PGC) on all retail sales to support market-transforming energy efficiency activities, public goods $\mathrm{RD} \& \mathrm{D}_{;}^{29}(3)$ continue to collect funds for low-emission vehicle programs through a line item charge on customer utility bills; and (4) issue a Notice of Preparation of an EIR by March, 1996. With respect to the minimum renewable purchase requirement, the CPUC would prefer it be set at the same level for all electric utilities on a statewide basis but would allow a transitional strategy to account for the differences in the current resource portfolios of utilities. Similar to the federal tradeable allowances under the CAAA of 1990 , credits for meeting the minimum purchase requirement would be tradeable. The minimum levels will be for the period from 1998 through 2000 and will be reviewed then. Meaningful penalties would be imposed for noncompliance (CPUC 1995c, pp. 147 - 152).

The CPUC expects that the PGC funding for energy efficiency will be focused on market transformation and education activities. More of the funds for educational purposes would be directed at residential and small commercial customers than at large electricity users. The CPUC indicated that the PGC should be nonbypassable. It will initially be a line item on utility bills and will become a surcharge if it becomes legislatively mandated. Levels of funding will initially be set to correspond to authorized DSM funding and will be reevaluated after implementation workshops are conducted. The CPUC did not adopt a percentage cap on the PGC that was proposed by some parties (CPUC 1995c, pp. 152 - 159). The CPUC would also use the PGC for public goods R\&D after January 1, 1997. The PGC is not to be used for competitive research functions (CPUC 1995c, pp. 159 - 162).

\footnotetext{
${ }^{29}$ The PGC funds are also to be used for assistance to low-income families. This item is not mentioned in the text because it does not have apparent environmental impacts.
} 
In contrast, the commission decided against applying the PGC to low-emission vehicles. Instead, funds for such purposes would continue to be collected by the regulated utilities and identified as a line item on customer bills (CPUC 1995c, pp. 172 -173). The CPUC ordered the preparation of the EIR without making a finding as to whether electric restructuring constitutes a CEQA project and without an initial study. "The EIR will attempt to anticipate likely future scenarios that could develop under our policy, and will, therefore, contain a more general discussion of impacts, alternatives, and mitigation than is typical for discrete, sitespecific projects." (CPUC 1995c, p. 178).

Wisconsin. In "A Reasonable Strategy" the PSCW decided that the generation business will be competitive and that public benefits will be preserved. Under a competitive generation scheme, the review on the need for additional generation resources will be eliminated. Siting review will be limited to checking for consistency with the transmission plan and for "environmental fatal flaws." In Phase I, the PSCW will retain its generation siting authority and streamline its procedures to facilitate competition but maintain environmental protection. Specifically, in the generation Stage I competitive bidding process, the commission staff, not the independent evaluator, would score the bids for environmental compliance consistent with Power Plant Siting Criteria and the AP-7 bid filing requirements.

With respect to the preservation of public benefits, the commission decided that conservation programs will be continued, renewable energy promoted, and green pricing programs implemented. Specifically, in individual rate cases, the PSCW will require investor owned and municipal utilities to establish green pricing programs. In addition, in Phase I, the commission will establish a Public Benefits Policy Advisory Board to address low-income issues and services, conservation and DSM, customer-installed renewables, R\&D issues, and market reforms to encourage renewable resource development. It will further develop the concept of green aggregation. In Phase II, the commission will move and act on the recommendations of the board regarding funding levels and appropriate funding mechanisms. Every 3 years, the commission will conduct a review to determine the need for the board's programs (PSCW 1995e).

New York. In New York, the NYPSC followed the ALJ's recommendation and decided that a system benefits charge be used to fund environmental and public policy programs during the transition and possibly over the long term. The practice would be revisited after retail competition has begun to determine whether there is a continued need and whether the level is sufficient for the purpose. The commission directed that the detail of implementation issues be worked out in individual utilities' filings (NYPSC 1996b, pp. 53-57, 90). In addition, the NYPSC also noted two other mitigation measures that would minimize the potential environmental impacts of the policy to implement wholesale and retail competition: monitoring of environmental impacts, and assisting efforts by other agencies to address interstate pollution transport (NYPSC, 1996b, p. 81).

\subsubsection{Implementation}

In California, implementation issues of concern to this study include the EIR, renewables, energy efficiency, and RD\&D. The CPUC issued a Notice of Preparation of Environmental Impact Report in late March 1996 (CPUC 1996b). It stated that the EIR will present an "analysis of the environmental impacts of the Preferred Policy and comparative environmental effects of the alternatives." The EIR will also identify mitigation measures for any potentially significant impacts. As the matter under consideration is a change in regulatory policy, not a specific site or facility, the EIR will be more conceptual than a site- or facility-specific EIR.

To implement the adopted policy of minimum renewables purchase requirement, the CPUC directed a working group to look into relevant issues and submit a report by July 1,1996 . The issues include definition 
of renewable resources, level of renewables on utility systems from 1990 to present, discusion of which market participants should be responsible for minimum target and the supporting analysis, strategies to achieve statewide standards, implementation proposals, policies and penalty for noncompliance, and proposed legislation. In the area of energy efficiency and RD\&D, a working group was directed to address competitive and public interest DSM, competitive and public interest $R D \& D$, definition of market transformation, proposed public funding level for January 1, 1998, the independent administrator for the funds, proposed implementation legislation, and an analysis of the impact of treatment of electric energy efficiency and RD\&D on natural gas programs.

In Wisconsin, the commission adopted a two-phase 32-step process to implement retail competition by 2000 (PSCW 1995e). Among the 32 steps outlined, 12 will be started in 1996. Six of the 12 are expected to be completed during 1996:

- Request utilities to file plans for functionally segmenting generation, transmission, distribution, and customer services

- Determine PSC intent to retain generation siting authority with necessary process reform

- Request legislature to increase intervenor compensation to $\$ 500,000$ annually

- Adopt affiliated interest standards consistent with those in place for the gas industry

- Make legal and policy determination on whether merchant plants should be allowed to file CPCN applications

- Establish an ISO to operate and coordinate transmission system on a statewide basis.

The other six are expected to be completed during the first half of 1997:

- Establish Public Benefits Policy Advisory Board and implement recommendations; coordinate with gas industry and explore coordination with Telecommunications Fund Administrator

- Examine generation and transmission market power and take necessary action in merger and interface transmission cases

- $\quad$ Establish quality of service standards and mechanisms for measuring and monitoring service quality

- Workshop studies and reports on issues associated with spinning-off or divesting utility assets

- $\quad$ Reopen Docket 05-El-112 to reform Stage I bidding process

- Initiate and complete process to further reform Advance Plan. 
In New York, the commission directed that utilities make separate filings by October 1, 1996, with FERC or the commission or both depending on specific issues involved. The issues include transmission pricing, the ISO, the Market Exchange, proposed resolutions to market power problems, recommendations concerning energy service companies in a retail competitive market, a report on new reporting requirements, public educational forums concerning the new competiton, corporate structure, proposal for retail access including unbundled rates, mechanisms to recover strandable costs, public policy programs, utility-specific load pockets problems, and a plan to provide energy services. For the area of focus of this report, the utilities are directed to identify public policy programs that would be not supported by the competitive market, that would need special rate treatment and competitively neutral mechansims to recover the costs (NYPSC 1996b, pp. 75-76). 


\subsection{Issues}

This chapter will discuss and compare environmental quality and protection issues considered in the electric industry restructuring process. The issues are: What should be the role of different state agencies in the restructured industry? What is the role of the state legislatures in the restructuring process? How would environmental externalities be treated? How should environmental protection and other public policy objectives or programs be funded or implemented? Were there differences in the timing and treatment of the EIS or the EIR in the three states? What was the role of environmental and other interest groups?

\subsection{Role of State Agencies}

As described in Section 2.2, existing practices prior to restructuring were such that environmental quality and stewardship responsibilities were generally shared by the environmental and utility/energy regulatory agencies. As competition in the electric marketplace increases, should the responsibility of environmental oversight be assigned to the utility regulatory agency, the environmental regulatory agency, or continue to be divided between the two sets of agencies? This section discusses the treatment of this issue in the three states.

In Califomia, the working group developed four options for addressing environmental protection under a competitive electric industry structure: existing laws and regulations, environmental performance standards for local distribution companies (LDCs), environmental agency regulation, and emissions surchargeconsortium. In the existing laws and regulations option, the relative roles of the environmental agency and utility regulatory agency, as they existed prior to restructuring, will be retained. In the environmental performance standards for the LDC option, the CPUC would establish the standards for LDCs. This requires new laws granting the CPUC this authority. In the environmental agency regulation option, most of the environmental regulatory responsibility would be transferred to the nonenergy agency. The emission surcharge/consortium option involves taxes or surcharges and a new institution. The CPUC, in its Majority Proposal, indicated that it was leaning toward the option of environmental agency regulation. In the subsequent MOU, and in the coalition forming and comments period, this approach was not directly discussed. However, the CEC recommended that utilities, independent power producers, environmental agencies, and other interested parties "participate in a multiagency forum to: (a) develop proposals for revised laws necessary to ensure environmental protection; (b) identify potential modifications in administrative regulations to maintain existing environmental requirements for all facilities now controlled by utilities; and (c) identify changes in powerplant operating procedures that are compatible with the newly proposed industry structure but also comply with existing environmental protection laws and regulations "(CEC 1995b, p. 40). In the December 1995 final order, there was no explicit statement regarding this issue. However, the order did indicate the need and desirability of legislative actions on many of the public policy programs. In addition, it appears that the issue might be addressed in the EIR process. In the Notice of Preparation (NOP) of the EIR (CPUC, 1996b), the commission stated:

This NOP has been sent to interested state, local, and federal agencies and to the State Clearinghouse. We need to know the views of the affected agencies as to the scope and content of the environmental information which reflects the agency's statutory responsibilities in connection with the Preferred Policy. Agency responses should identify the issue to be considered in the Draft EIR, including significant environmental issues and feasible alternatives and mitigation measures.... 
In Wisconsin, the question of which agency should have environmental protection responsibility received considerable attention. Before the formal restructuring proceeding began, the WPUI report outlined three options: adding to existing procedures, revamping current review procedures, and transferring environmental review to the $\mathrm{DNR}^{30}$ In its order initiating the formal proceeding, the PSCW asked parties to comment on what regulatory regime would best achieve the objectives for the future. In response, environmentalists, energy efficiency and renewable energy proponents, and consumer groups opposed complete transfer of the current environmental responsibilities of the PSCW to the DNR. In contrast, electric utilities, particularly investor-owned utilities, argued that either such responsibilities should be shifted to the DNR or that the market would take care of environmental protection. Some groups took the position that the PSCW should work cooperatively with the DNR and other agencies. ${ }^{31}$

During the collaborative process, the Advisory Committoe also paid attention to this issue. Its recommendations depend on the market structure adopted. After detailed consideration of alternatives for transmission, generation, and distribution individually, the Advisory Committee adopted five consolidated options for the future structure of the electric industry: (a) the Sequential Approach to Change and Competition; (b) the Retail Energy Services Company (RESCO) model; (c) Minimum Standards Requirements for Restructuring; (d) Managed Progress; and (e) Deregulated Generation and Complete Retail Access.

- The Sequential Approach involves forming a strong regional transmission group, implementing competitive bidding for all new generation, requiring ratepayer consent for selling existing generation, monitoring development of regional generation market as a precondition to initiate retail wheeling, and unbundling electric services to provide customer choice. Under this approach, the PSC would play a central role in generation and transmission planning. Both the PSCW and the DNR would share environmental responsibilities.

- The RESCO model would first make retail energy service as competitive as possible, lay the groundwork for retail access, and then initiate action to implement retail access. The environmental responsibilities of the PSCW and the DNR will not change in any significant manner under RESCO.

- The Minimum Requirements for Restructuring option enunciated eight principles, but there are no details given about how the environmental responsibilities might be assigned between the environmental and energy regulatory agencies.

- The Managed Progress option will let the market decide on the type of generators to be built and the level of reliability. It would allow existing generation to be exchanged with "purchased power contracts." There would be bilateral contracting, a short-term spot market, and a futures market. FERC's role in transmission regulation is expected to grow, and regional reliability councils will continue to function. After certain prerequisites are met, direct retail access would be implemented under this option. The existing PSC and DNR authority for environmental review and approval of the construction and operation of the electric distribution system and associated facilities remains unchanged. The PSC's authority over planning and siting of power plants would be eliminated and its planning authority over transmission lines would be diminished. DNR and EPA regulations over

\footnotetext{
${ }^{30}$ See Section 3.2.1 above for details of these options.

${ }^{31}$ See Fang \& Galen (1995a), pp. 33-35 for more discussion on this issue.
} 
generating facilities would continue. Furthermore, under this option, DNR's authority over siting of new power plants would be expanded to include an additional set of pennitting standards, including standards for land use. This option also suggests that additional market-based mechanisms for limiting emissions growth would be implemented. Under this option the PSCW would no longer be evaluating the need for new transmission lines of 69 kilo volt $(\mathrm{Kv})$ or greater.

- Under the Deregulated Generation and Complete Retail Access option, the Advance Plan and the certificate of public convenience and necessity processes are eliminated. Local governments would approve siting of generation facilities. The utility regulatory agency would issue periodic review of energy demand forecasts, the number of suppliers, and the development of market structures. Such reviews would be for information only. They would not have regulatory implications (See PSCW 1995d, pp. 143 - 220).

In "A Reasonable Strategy for Restructuring Wisconsin's Electric Utility Industry," PSCW's final decision on restructuring, the PSC would retain, in Phase I, its generation siting authority and would implement reforms to streamline the generation siting review procedures to facilitate competition and maintain environmental protection. In the end state, such a review would be for the purpose of checking the confonnance with the transmission system and for "environmental fatal flaws." The need (for power) review will be eliminated. For transmission, the PSCW retains its planning and siting authority in Phase I. In Phase II, the PSCW's proceeding for transmission planning and siting will be reformed to coordinate with the regional transmission group and the regional market while maintaining environmental protection. In the end state, there would be continued environmental protection and application of measures to mitigate environmental harm resulting from transmission construction (PSCW 1995e).

In New York, both the DEC and the NYPSC have responsibilities for environmental protection with respect to the planning and siting of generation and transmission facilities. Some parties believe that in a restructured industry the EIR will continue under the State Environmental Quality Review Act. Other parties argue that there will be a much greater reliance on market-based mechanisms, such as emissions trading. In the Wholesale model, existing laws governing the siting of transmission facilities are intended to remain in place and provide for appropriate public participation in reaching a siting decision (NYDPS 1995a, p. 195). In the Retail model, a regional transmission group could plan transmission for new generation and interconnection, or the independent system operator may be able to do the job (NYDPS 1995a, p. 227). The ALJ's Recommended Decision asserts that the commission has a statutory responsibility to consider environmental issues in its decisions. Further the ALJ believes that the commission reiterates its environmental responsibilities in issuing its principles for guiding the transition to a more competitive industry (NYPSC 1995c, p. 83). In the Final Generic EIS, the commission indicated that there is a need to monitor the likely occurrence of increases in emissions of pollutants (that could result in acid rain) and of particulates. "If such deterioration occurs, the Commission will explore with the New York Department of Environmental Conservation (DEC) mitigation strategies which are consistent with federal and state requirements and which are competitively neutral" (NYDPS, 1996b, p. S-18). In addition, the DEC could play a central role in managing a special auction of emission credits designed to alleviate the potential localized impacts on such environmentally sensitive areas as the Adirondacks and Catskills (NYDPS, 1996b, p. S-19).

In summary, among the three states considered in this report, Wisconsin has explicitly considered and outlined the environmental responsibilities of the PSC in a restructured electric industry. In generation, the PSCW will reform its procedures to streamline the siting review to facilitate competition and maintain environmental protection in Phase I, and to check for conformance with the transmission system and for the existence of environmental fatal flaws in the end state. In transmission, the PSCW retains its planning and 
siting authority in Phase I and reforms its proceedings to conform to the regional transmission group or regional market with environmental protection. It will retain its environmental protection and mitigation authority with respect to transmission systems in the end state. In the California proceeding, there was no such explicit consideration of agency responsibility and authority in a restructured market in the "final" policy decision. However, the commission did indicate the need and desirability of legislative actions on many of the public policy programs. In addition, the issue may be covered in the EIR process initiated as part of the implementation process. In New York, it appears that the roles of the economic and environmental regulatory agencies would reamin relatively the same. The NYPSC would work with the DEC to monitor potentially adverse environmental impacts of wholesale and retail competition and to develop mitigation strategies which are competitively neutral. It is also envisioned that the $\mathrm{DEC}$ would play a central role in managing the special auction of emission credits for emissions that would adversely impact the environmentally sensitive regions such as the Adirondacks and Catskills.

\subsection{The Role of State Legislature}

What is the role played by the state legislature in the electric industry restructuring process? As explained below, there are marked differences among the states of Califormia, New York, and Wisconsin. In Califormia, ever since the CPUC issued its initial Blue Book Proposal in April 1994, the Califormia General Assembly took a keen interest in the electric industry restructuring process. On May 23, 1994, approximately one month after the issuance of the initial CPUC proposal, the Assembly Committee on Utilities and Commerce and the Assembly Committee on Natural Resources held a joint oversight hearing on the commission's orders. Subsequently, the General Assembly adopted Assembly Concurrent Resolution (ACR) 143 on August 31, 1994.

ACR 143 essentially did two things. First, it urged the CPUC not to start implementing any performancebased regulations and policies in restructuring the electric industry through direct access until after the CPUC met certain specified reporting requirements to the state legislature. Second, it established the Joint Oversight Committee on Lowering the Cost of Electric Services to monitor the CPUC's restructuring process and to consult with the governor, CPUC, CEC, and other parties on matters related to electric deregulation and reform. Specifically, ACR 143 asked the CPUC to report back to the legislature by January 31,1995 . The reporting requirements of the CPUC were as follows: (1) the CPUC's proposed policies on performancebased ratemaking and on electric industry restructuring; (2) how those policies conflict with existing state and federal laws and how such conflicts can be resolved; (3) the amount of competition transition surcharges for each utility and the allocation of such charges to customer classes; (4) the impacts of the proposed policies on the financial status of the utilities; (5) rate or other funding options to pay for public programs including low-income ratepayer assistance, economic development, fuel diversity and renewable resource development, demand-side management, environmental protection, low-emission vehicle development, women and minority owned business programs; (6) effects of the proposed policies on existing investment in nonutility power generation and the climate for new investment in that generation; and (7) consistency of the proposed policies and programs with the criteria of (a) just and reasonable rate treatment that would lower electricity rates toward national averages, (b) performance standards, (c) fair competition and customer choice through nondiscriminatory transmission access, (d) public health and environmental laws and regulations, (e) reducing utility and other regulatory costs and burdens, (f) system safety and reliability, and (g) resource diversity and energy efficiency.

It is clear from the content of ACR 143 that the legislature is interested in the public policy programs, including environmental protection. In response, the CPUC issued its December 1994 interim decision, 
establishing a working group to assess public policy issues and transmitted to the legislature an interim status report on January 24, 1995. The report described the CPUC's process of considering electric industry restructuring since its initial exploratory analysis in 1992 and provided an overview of the positions of the participants in the process. In addition, the CPUC clearly acknowledged the legislature's role in the electric industry restructuring process in both the December 1994 interim decision and the May 1995 proposed policy decision (CPUC 1994b \& 1995b). In its final order, the CPUC delayed taking any actions to implement its decisions for 100 days to allow the legislature to examine the policies adopted by the commission (CPUC 1995c, p. 182). The commission further stated in a footnote (CPUC 1995c, p. 184):

We expect to work closely with the legislature on public purpose programs to ensure that the programs continue to meet legislative goals. It is possible that some public purpose programs will not be effective and will need to be revamped in a competitive market place. Recognizing the legislature's role as crafter of these policies, we will work closely with the legislature and interested parties to refine the programs that implement these policies.

From 1994 to 1996, the State Legislature conducted public hearings on proposed bills with impacts on the electric industry restructuring. One bill would set guidelines for restructuring and ensure that current safeguards are maintained. Another bill that would require restructuring proposals comply with the design criteria of customer choice, faimess, and safety and reliability of the transmission system. It would establish a nonbypassable, usage-based distribution charge to support DSM services, renewable energy resources, and services for low-income customers. A third bill would require utilities to purchase energy produced by biomass generators. There was also a bill that would authorize the CPUC to implement electric industry restructuring. Other proposed bills would address recovery of stranded costs and reauthorization of all public benefits programs currently funded through rates; eliminate the biennial resource plan update (BRPU) process; reorganize the CPUC; set broad policy goals for restructuring and requireing consideration of such goals and issues.

In New York, the legislature has considered several bills that would have an impact on the electric industry competition, but they are not directly aimed at the restructuring process being conducted by the NYPSC. For example, one bill would authorize electric utilities with excess capacity to establish and offer special industrial economic development rates to eligible industrial customers for the purpose of expanding a facility or business in New York or for other competitive reasons. It would authorize the PSC to approve implementation and cost recovery of certain cost-effective DSM programs. It would also permit targeted competitive sourcing of electricity; i.e., qualified industrial customers would be allowed to purchase electricity from certain independent power producers. Another bill would authorize the New York State Power Authority to provide electricity to hospitals at reduced rates. A separate bill would allow municipal utilities to purchase power and steam from suppliers other than NY State Power Authority. The proposed bill envisions that diversifying the sources of power and steam supply could lead to lower costs and, thus, lower rates to the customers. Yet another bill would authorize utilities to sell "public health protection power" to public benefits corporations at rates that include only the transmission and distribution costs but not the generation costs. Public health protection power is defined as "power not subject to prior contracts and 
commitments." There is a bill that would eliminate or reduce the $3 \%$ gross receipt tax on certain utilities. ${ }^{32}$ It addition, following the adoption of the final decision by the NYPSC, the relevant legislative committees have scheduled hearings to review the commission's order.

On January 2; 1996, a proposal for phased transition to a fully competitive energy market by 2000 was released by Assembly Speaker Sheldon Silver. The proposal would freeze electricity rates immediately and reduce them $25 \%$ through increased competition. It would offer no guarantees on stranded cost recovery and reduce the costs of current independent power contracts. It would continue to encourage environmental protection efforts and direct the PSC to establish an ISO and to monitor utility activities. In Phase I from 1997 to 2000, utilities will be required to purchase power from a competitive wholesale market and PSC regulation of sales to customers would be continued. In Phase II beginning in September 2000, customers would be allowed to choose their own supplier. Utilities would be required to provide transmission and distribution of electricity as a regulated function. Utilities would be required to separate generation from the rest of the business. After 2002, utilities would no longer be allowed to own generation. It was expected that Speaker Silver's proposal will be incorporated into a bill.

In Wisconsin, the legislature adopted a "hands off" approach. Although the final decisions of the PSCW on electric industry restructuring would require changes in state laws goveming the commission's authority and responsibilities, the Wisconsin legislature has not taken an active role in the restructuring process to date. So far, no electric industry restructuring bills have been introduced in the legislature. In marked contrast to what happened in Califomia. In October 1995, a legislative committee reached consensus with the stakeholders that it would not be appropriate to consider any legislative initiatives on electric industry restructuring during 1996. Instead, the first steps will be specifically taken by the PSCW under its existing statutory authority.

In "A Reasonable Strategy for Restructuring Wisconsin's Electric Utility Industry," the PSCW identified 2 of 32 steps that would involve legislative action. In Step 3, the commission would request the legislature to increase intervenor compensation to $\$ 500,000$ per year in order to maintain the continued ability of interested organizations to provide meaningful input into the regulatory process. In Step 23, the commission would recommend possible statutory reform of the Advance Plan process and construction need review. On February 22, 1996, the PSCW submitted a report to the Wisconsin legislature on its electric utility restructuring, including a 32-step work plan (PSCW 1996).

In summary, the legislatures in the three states have played different roles in the electric industry restructuring process. The California General Assembly was the most active among the three states. It got involved early and required the CPUC to report on progress and to look into public policy matters more intensively. It conducted hearings to consider various restructuring related bills. In contrast, the Wisconsin legislature stayed away from the electric restructuring arena during the course of the consideration of the issues by the PSCW. In New York, the state legislature was somewhat active in considering proposed legislation that might impact the restructuring process being conducted by the NYPSC.

The differences in the roles played by state legislatures in the restructuring process in the three states may be due to, in large measure, the differences in electricity prices among them and in the initial phases of the restructuring processes. As explained in Section 2.1, Wisconsin enjoyed relatively low electricity prices, while Califomia and New York were among the high-cost states. High electricity prices were more likely to

32 This is not intended to be a complete enumeration of all the bills proposed in the state legislature. It is intended only to give a sampling of what the state legislature has considered so far. 
lead to high level of consumer dissatisfaction and agitation for change through various mechanisms, including the legislative process. Organized stakeholder groups would lobby their lawmakers to propose legislation and other measures that could result in changes favoring their respective positions. In contrast, there was less consumer dissatisfaction in low-cost states such as Wisconsin and, hence, less agitation for legislative action. In addition, the PSCW took a proactive role in addressing the restructuring issue. Thus, the legislature could afford to take a.more leisurely approach. In terms of the initial proposal, the CPUC presented a formal proposal that caused many stakeholders to perceive themselves as potential winners or losers. Such sentiments were soon picked up by state legislators. As a result, the Califormia legislature took an early and substantial interest in restructuring issues. In contrast, Wisconsin started with the more limited objective of adopting a set of principles for restructuring. This proved to be much less controversial than the Califomia approach.

\subsection{Environmental Externalities}

As explained in Section 2.2, prior to the start of the electric industry restructuring process, Califomia, New York, and Wisconsin required electric utilities to monetize environmental externalities in the resource planning and acquisition process. Under a restructured electric utility industry, what would happen to such a requirement? In this section, the consideration of this issue in the restructuring process is discussed.

In Califomia, both the Majority and Minority proposals in the CPUC's May 1995 proposed policy decision would eliminate the BRPU process of resource planning and acquisition. Thus, there would be no explicit treatment of environmental externalities in resource acquisition decisions. In the coalition building and response stage, a broad agreement emerged that, in the transition period, either utility funds or a nonbypassable system benefits charge could be adopted for funding energy efficiency, renewables, and R\&D objectives. In addition, the Framework Parties $(1995$, p. 8) proposed that "all sources of generation must meet the same environmental standards, regardless of plant ownership or the restructuring model adopted." In the interim decision issued in May 1995, the CPUC also stated that the renewables portfolio standard would be adopted to promote renewable energy and resource diversity. In the December 1995 final order, the CPUC adopted both a nonbypassable system benefits charge and the renewables portfolio standards. ${ }^{33}$

In New York, a case addressing the issue of environmental externalities is pending. In Case 92-E-1187, the ALJ has recommended that "the current policy of mandating the use of monetized externalities in supply-side bidding and in demand-side management programs be discontinued and that the proposals to expand the current policy be rejected" (NYPSC 1995a, p.32). In the industry restructuring process, the Phase II Final Report is a product of the working group collaborative process. The report identified five options for a restructured industry (NYDPS Staff 1995a, pp. 144 -150): (a) Option 1: A regulated monopoly utility will be required to develop a portfolio of energy supply contracts. Price, environmental externalities, and other nonprice factors will be assigned weights. Scores will be computed for use in ranking various bids. (b) Option 2: Use a nonbypassable wires charge or a social benefits charge to subsidize electric generation sources that are more environmentally benign. The charge could be usage-based or fixed. (c) Option 3: Rely solely on the market forces. Energy service companies would market electric capacity and energy derived from environmentally friendly technologies. This option would extend the green pricing approach and require substantial public education efforts to yield major impacts. (d) Option 4: Apply fuel-neutral emissions caps with allowance trading. This approach places a cap on emissions of specific type for the

\footnotetext{
${ }^{33}$ For discussion on the nonbypassable system benefits charge and on renewables portfolio standard, see section 4.4.1 and 4.4.6.
} 
electric industry as a whole. The allowance trading system would facilitate electric suppliers' efforts to optimize their responses either by creating allowances through installation of specific emission control equipment, or buying emissions credits to meet the requirements. (e) Option 5: Combination of the above. For example, it may be possible to combine the portfolio standard option with the wires charge option. Option 5 is intrinsically flexible; a commission can pick and choose among the other four options to fashion a mechanism that would yield the most desirable results. In the Recommended Decision, the ALJ recommended that the nonbypassable system benefits charge be adopted and that the details of implementation be worked out in the individual utility's filings. ${ }^{34}$ The Recommended Decision does not otherwise make explicit references to the environmental externalities issue, perhaps because of the other proceedings on the subject. In the final decision, the NYPSC adopted the ALJ's recommendation. In addition, the commission still has not issued a final decision on the environmental externality case.

In Wisconsin, the PSCW explicitly addressed in the Environmental Impact Statement (EIS) how the consideration of environmental externalities would be affected by the generation models adopted. From the Commission's view, consideration of environmental externalities would likely continue or even increase under the Flexible Regulation Model, which would be part of the Sequential Approach to Change and Competition option. Under the Incremental Change Model, consideration of environmental externalities would continue only if new rules with such requirements are promulgated. Under the Commercial Model and the Plausible Extreme Alternative postulated in the EIS, utility consideration of environmental externalities would be substantially reduced or eliminated. However, additional market-based mechanisms for emissions reductions could be implemented under the Deregulated Generation and Complete Retail Access approach. Since the primary aim of the approach embodied in the Commercial Model and the Plausible Extreme Alternative is to lower the direct cost of electricity (PSCW, 1995b, p. 345), specific state or federal legislation would be needed to preserve the consideration of environmental externalities (PSCW 1995b, p. 388).

In its December 1995 plan for restructuring the electric utility industry, the PSCW stated that it would require investor-owned and municipal utilities to establish green pricing programs. The PSCW would establish the Public Benefits Policy Advisory Board and direct it to address renewables, particularly the green aggregator concept (PSCW 1995e, pp. 6-7). In addition, the PSCW further stated that it would reopen the proceeding in Docket 05-EI-112 to conduct a paper hearing on the proposed reform of the generation Stage I competitive bidding process. According to the proposed reform, the commission staff would score the bids for environmental compliance consistent with Power Plant Siting Criteria and recent bid filing requirements outlined in the AP-7 order (PSCW 1995e, pp. 1 - 2).

In summary, prior to the restructuring, all three states - Califormia, New York and Wisconsin - required monetization of environmental externalities. In California, the CPUC, in its final restructuring order, adopted both the nonbypassable system benefits charge approach and the renewables portfolio standard to encourage energy efficiency, renewable energy, and other public policy programs. Because the BRPU process will no longer be applied, there will be no explicit consideration of environmental externalities. In New York, there is a pending case explicitly addressing the environmental externalities issue, in which the ALJ recommended that the monetization requirement be eliminated. In the electric industry restructuring case, the commission adopted the ALJ's recommendation that the nonbypassable system benefits charge be instituted for energy efficiency and renewables, with the details of implementation be worked out in the individual utility filings. In Wisconsin, the PSCW's Reasonable Strategy would require investor-owned and municipal utilities to

${ }^{34}$ See Section 4.4 .1 below for additional discussion on the system benefits charge. 
investigate and propose green pricing programs. It would also develop the green aggregator concept further. In addition, it would reform the generation Stage I competitive bidding process, which requires scoring the bids according to environmental compliance.

\subsection{Funding and Implementation Mechanisms}

How should environmental protection and other public policy objectives or programs be funded or implemented in a restructured electric industry and during the transition? Various funding or implementation

mechanisms considered by the three states are analyzed in this study. These mechanisms include a nonbypassable system benefits charge, utility fund, state general fund, special funds, pollution tax, renewable portfolio standard, green pricing, and pollution caps with tradeable credits. ${ }^{35}$

\subsubsection{Non-bypassable System Benefits Charge}

A nonbypassable system benefits charge is also called a universal service charge ${ }^{36}$ or end-user charge or fee. The charge is imposed on all system users. It can be imposed as a charge on distribution or transmission access, or as usage tax. In California, the MOU among SCE, California Manufacturers Association, Califomia Large Energy Consumers' Association, Independent Energy Producers, and Californians for Competitive Electricity specifies the system benefits charge as one of two funding mechanisms. ${ }^{37}$ It was proposed that the charge be set at SCE's 1995 DSM program funding level. This nonbypassable system benefits charge proposal was supported by a coalition of 12 customers who signed on to the "Customer Statement of Principles on Electric Restructuring", ${ }^{38}$ another coalition of eleven public interest groups who signed the "Framework of Restructuring in the Public Interests", ${ }^{39}$ PG\&E, and the National Association of Energy Service Companies. In its final order, the CPUC suggests that the legislature adopt a nonbypassable

35 Renewables portfolio standard and emission caps with tradeable credits do not involve direct allocation of funds. Hence, they are not "funding mechanisms" in the strict sense of the term. However, they do contribute to objective of environmental protection and quality. Thus, the term "implementation mechanisms" seem more applicable to them.

36 See NYPSC (1995a), pp. $137-138$.

37 The other mechanism is the use of utility funds that is set to be equal to $3.3 \%$ of SCE's revenue requirement as of January 1995. These utility funds are part of SCE's operating budget, and, hence are passed on to ratepayers.

38 Signatories to Customer Statement of Principles are: Association of California Water Agencies, Agricultural Energy Consumers Association, California City-County Street Light Association, California Department of General Services, California Farm Bureau Federation, California Hotel and Motel Association, California Industrial Users, California League of Food Processors, California Restaurant Association, California Retailers Association, Division of Ratepayer Advocates, and the School Project for Utility Rate Reduction. They are referred to as "Customer Statement parties" in this report.

39 Signatories to the Framework are: Utility Consumer Action Network, Union of Concerned Scientists, Toward Utility Rate Normalization, Sierra Club, Public Citizen, Natural Resource Defense Council, Environmental Defense Fund, Center for Energy Efficiency and Renewable Technologies, California Public Interest Group, California/Nevada Community Action, and American Wind Energy Association. They are referred to as the "Framework parties" in this report. 
surcharge to fund market transforming energy efficiency activities. ${ }^{40}$ The CPUC calls it the "public goods charge." It will be applied to retail electric sales. The CPUC expects such a surcharge to begin by January 1 , 1997. Additional details of implementation are being developed through the working group process (CPUC 1995c, pp. 157-159).

In New York, the system benefits charge is considered to be applicable to both the Wholesale Model and the Retail Model. Under the Evolving Regulation Model, public programs are generally financed through the ratemaking process, and, hence, there is no need for a separate system benefits charge. However, some parties argued that a system benefits charge can be used to preserve the level of investment in renewable energy during the transition period (NYDPS 1995a, pp. 186, 219, and 254). In the Recounmended Decision, the ALJ stated: "Any restructuring model should include a mechanism for recovering costs required to be spent on environmental and other public policy considerations that would not otherwise be recovered in a competitive market. A nonbypassable system benefits charge appears to be a fair way of ensuring that such programs be continued. These matters should be thoroughly considered in the context of individual utility filings" (NY PSC 1995c, Vol. I, p. 110). Toward this end, the active parties to the proceeding were directed to provide comments in their brief on exceptions on "how should the commission administer a system benefits charge, and what mechanisms should be considered that will result in the assurance of quality programs?" (NYPSC 1996a, Vol. I, pp. 83-84, and p. 115)

The Public Interest Intervenors (PII) responded by providing suggestions regarding goals, funding level, funding term, oversight, and programs. According to the PII, the goals for the systems benefits charge should be to: foster competition in energy efficiency service delivery; stimulate economic development; reduce the long-term costs of electric service and leakage of wealth from the state; reduce market barriers to energy efficiency; improve the environmental performance of New York businesses and industries; and enhance the ability of low-income consumers to pay for electric energy services. With respect to funding level, the PII suggested using the 1994 DSM spending level as the starting point and to decide a final level through further analysis and negotiations. The PII argued that the system benefits charge be continued for a minimum of 5 years or until a self-sustaining market for energy efficiency services emerges. The funds generated can be administered by the distribution utility in the near term or by a government or quasi-governmental entity, such as an independent governmental authority, for the longer term. There would be an advisory board made up of the full range of consumer and provider interests. Program types can include financing, technical assistance, market transformation, information, and standard offer purchases (PII 1996a, pp. 8 - 12).

In its final decision, the NYPSC adopted the nonbypassable system benefits charge. According to the commission, during the transition to fully competitive electric markets, and possibly in the longer term, a systems benefits charge would provide a funding source for public policy initiatives that would otherwise not be adequately addressed by the markets. The NYPSC (1996b, pp. 56-57) states:

It would be designed to ensure that the cost of carrying these public policy initiatives was fairly allocated across most, if not all, users of the power distribution system, and recovered in a competitively neutral manner. Initially, the system benefits charge would be set at approximately the level of current utility expenditures, with the expectation that these charges will be closely scrutinized with

\footnotetext{
${ }^{40}$ It should be noted that this is only one track of the CPUC's two-track approach to energy efficiency funding. The other track is that customer-specific energy efficiency activities should be financed through other market based mechanisms (CPUC 1995c, p. 152).
} 
respect to their impacts on rates. Programs funded in this way, along with the innovative programs likely to be developed by energy service companies, provide ample reasons to be confident, as we are, that cost-effective energy conservation

measures, including demand-side management, will flourish in the new environment. We anticipate the levels of energy efficiency programs accomplished in this way will be higher than existing levels.

In Wisconsin, one of the Advisory Committee's options for sustaining energy efficiency and environmental benefits is through market transformation activities supported by a special fund. The group suggested that the special fund be financed through a distribution fee (PSCW 1995d, p. 134), which is a form of system benefits charge. In adopting "A Reasonable Strategy for Restructuring Wisconsin's Electric Utility Industry," the PSCW indicated that it would establish, in Phase I, a Public Benefits Policy Advisory Board to address issues such as low-income customers, conservation and DSM, renewable energy, particularly the aggregator concept, and will determine funding levels in Phase II (PSCW 1995e). In the strategy, there is no explicit mention of a specific funding mechanism.

In summary, there appears to be substantial support for the use of a nonbypassable system benefits charge for environmental, energy efficiency, renewable energy and other public policy purposes. The commissions in California and New York have explicitly adopted it. The Wisconsin commission would set up an advisory board to further consider public policy issues, including funding mechanisms. The implementation details are still being developed. Some implementation issues are as follows: Who should administer the funds generated? What should be the level of funding for environmental and other public policy programs? What are the criteria for making such allocations? Should there be a cap on such spending? Should the charge be applied only during the transition or should it be applied beyond the transition? How long should the transition period be? Should there be periodic review of such funding? How can non-bypassability be ensured?

California has addressed the "who should administer the funds" question to some extent. Traditionally, the investor-owned utilities have administered the funds for such public policy programs because such funds are part of their budgets. In California, the Framework Parties (1995, p. 11) would exclude the investor-owned utilities from administering such funds in the long-run; assure that nonutility energy service companies have equal access to the funds; and subject energy efficiency investment to performance based accountability. Similarly, the Customer Statement Parties (1995, p. 5) would limit the investor-owned utilities' administration of such funds only until January 1,1998 . Thereafter, the funds would be administered by an independent entity. These parties also proposed a critical assessment of the programs after 5 years. In its final order, the CPUC decided that, after a short transition period, the funds for energy efficiency should be allocated by an independent, nonprofit organization. During the transition, the commission would like to capture the expertise and knowledge that utilities have gained in DSM program administration (CPUC 1995c, p. 157). The commission may direct the workshop participants to work out the details of the independent funds administration and ways for capturing utility expertise. The CPUC did not set a percentage cap on the amount of funds earmarked for energy efficiency (CPUC 1995c, pp. 158 - 159). In New York, the commission had directed that initially, the level of funding be set at the current utility expenditure levels and that such charges be examined closely for their impacts on rates (NYPSC, 1996b, p. 56). 


\subsubsection{Utility Funds}

The utility funds option would use the traditional utility ratemaking process by including the costs of environmental and other public policy programs in the cost of utility services. In other words, utility customers (ratepayers) provide the funds through the rates they pay. In a competitive electric market, many traditional utility customers would become direct access customers and they would pay the local utility for the transmission and distribution services, not for the commodity kilowatt hours (kWhs). Thus, it would be necessary to properly allocate costs for public policy objectives among the utility's retail and direct access customers. Such a task, though complex, is within the expertise of the PUC.

In California, SCE stated in the MOU that it would commit 3.3\% of the total revenue requirement for January 1,1995 , for demand-side management services promoting energy efficiency and conservation, renewable energy resources and technologies, and R\&D programs. PG\&E supported the basic idea but suggested that the appropriate level should be determined by all stakeholders when the details of the programs and required

funding can be analyzed in more detail. In New York, it is thought that utility funds would be applicable in the Evolving Regulation Model. In Wisconsin, utility funds would be used in the transition period for the Sequential Approach and the RESCO Model. ${ }^{41}$

\subsubsection{State General Fund}

Many utilities in all three states argued that, as competition in the electric industry increases, utilities lose their monopoly status. As a result, it is no longer appropriate for them to shoulder the responsibility of achieving the public policy objectives. In the utilities' opinion, the state's general fund is a more appropriate source for support of environmental protection, energy efficiency, renewables, and research and development objectives. Under the state general fund approach, the total costs needed for environmental protection and other public policy programs will be determined and included in a State's spending programs and factored into its budgeting decisions. Such increases in public spending would usually be financed through traditional means such as general income tax or sales tax. However, current budget-cutting realities in many states often preclude additional claims on the state general funds.

\subsubsection{Special Funds}

Special-purpose funds have also been proposed for financing programs to achieve environmental and other public policy objectives. For example, in Wisconsin, the Advisory Committee suggested a "social benefits fund" as one of two options for such purposes. The fund would create as an independent, nonprofit organization financed through a statutory fee such as a line charge, a usage fee, or a pollution tax. Alternatively, it could be an entity created by state law, located within the PSC, and financed through an assessment on the utility. The fund would administer grants on a competitive basis in areas such as demandside management, renewables, $R \& D$, and public advocacy for environmental concerns, and small business and residential customers (PSCW 1995d, pp. 138-140). The fund might also be located in another state agency. For example, in Wisconsin, it could be in the Wisconsin Department of Administration (PSCW 1995b, p. 380). The fund may be established for only a short transition period, or it could become a

\footnotetext{
${ }^{41}$ See Section 4.1 for descriptions of the Sequential Approach and the Retail Energy Service Company (RESCO) model.
} 
permanent body. California provides another example of special funds. The working group mentioned a bond authority for the public policy objectives. It would be a state-sponsored bond agency pattemed after the California Pollution Control Financing Authority (Working Group, 1995).

\subsubsection{Pollution Tax}

A tax can be imposed on the pollutants emitted into the environment. The level of the tax could be based on the damages that the pollutants could cause. With such a tax, the costs associated with environmental damages would become part of the cost of electricity and the environmental impacts would become internalized. This is a market-based option. However, it is difficult to assess the damages caused by pollutants because it is resource intensive, site specific, and controversial.

\subsubsection{Renewables Portfolio Standard}

In California, the Renewables Portfolio Standard was proposed as one of the principles in the "Framework for Restructuring in the Public Interests" (Framework Parties, 1995). The Renewables Portfolio Standard states that follow:

All of the state's investor-owned utilities that continue to supply generation shall maintain a supply portfolio with a minimum level of renewable resources consistent with 1993 levels and diversity. Maintenance of this minimum level of renewables shall become a nonprice criterion in any performance-based regulation which is applicable to a utility's supply function. The above-market cost of maintaining this minimum renewables portfolio, if any, shall be recovered from all customers through the non-bypassable competition transition charge (CTC) ${ }^{42}$ mechanism. Direct access customers or community access aggregators opting to contract for an equivalent level of renewable resources shall receive a commensurate reduction in their CTC.

The Renewables Portfolio Standard is basically intended to increase fuel diversity and promote development and penetration of renewable energy technologies. However, since renewable energy technologies are comparatively environmentally benign, imposition of minimum portfolios for such resources in utility resource planning contributes to reducing emissions of air and other pollutants. In this sense, the renewables portfolio standard can be a mechanism for environmental stewardship.

Both the Majority and the Minority Proposals in the CPUC's interim policy decision issued on May 24, 1995, contained a similar renewables portfolio standard. Both proposals would have the state legislature determine the appropriate level of resource diversity expressed as percentage of total generation purchases throughout the state and establish the targets for renewable resources. The portfolio would be imposed as a supplier requirement. The renewables requirement could be traded among customers and suppliers, so long as the requirements are met in the aggregate. This aspect is similar to the sulfur dioxide emission credit trading of the Acid Rain Program and the Regional Clean Air Incentive Market of the South Coast Air Quality Management District. (See CPUC 1995b, p. 258 and p. 396) In other words, the May 1995 proposals of the

42 The CTC is per kWh charge to help pay for the stranded investment such as high-cost nuclear generation, other fossil generation, and purchasing power contracts . 
CPUC suggested two ways to achieve the goals of maintaining California's existing fuel diversity and encouraging development of new renewable resources: "(1) establishing a tradeable renewables target (assigned to either the buyer or seller) or (2) setting minimum diversity targets for the pool." (CPUC 1995c, p. 147) In the final order, the CPUC reaffirned its belief that "a minimum renewables purchase requirement is the best approach" to meet California's resource diversity goals. The requirement can be placed on either retail providers or on generators. Credits for meeting the requirements would be tradeable. The minimum renewables levels would be in place from 1998 through 2000. The need for the requirement will be reviewed then (CPUC 1995c, pp. 150 - 152).

Further developments of the renewables portfolio standard have occurred during the working group process in the implementation stage. The standard is now described as follows (Rader 1996):

As a condition of doing business in the state, every retail power supplier - including investor-owned utilities, municipal and cooperative utilities, direct access suppliers, and potentially, self-generators above a certain size - would be required to purchase "Renewable Energy Credits" (RECs) equivalent to some percentage of its total annual MWh energy sales. Retail suppliers could purchase RECs when they purchase renewable power, or they could purchase RECs separately - either directly from a renewables generator or from a REC broker. Government involvement would be limited to certifying RECs (though it might be possible for the private sector to perform this function within a set of guidelines) and monitoring compliance.

There would be two separate reporting requirements. One is the REC certification process, which would apply to generators who wish to certify their renewables output. The other is the demonstration of ownership of sufficient RECs compared to electricity sales, which would apply to retail seller.

In New York, a similar Renewables Portfolio Standard has been proposed by the PII. ${ }^{43}$ It is argued that the PSC has the authority, under state law, to set the standards (PII 1995a, pp. 34-40). Independent Power Producers of New York also supports the renewables portfolio standard, but the Multiple Intervenors opposes any market intervention to support development of renewable energy. The Recommended Decision by the ALJ did not explicitly address the renewables portfolio standard per se. The PII provided additional comments and made the following recommendations: (1) adopt a renewables "target" for the pool; (2) design pool and ISO rules to accommodate intermittent renewable resources; (3) require all retail suppliers to meet the renewables standard; and (4) create a separate market-clearing price for renewables within the pool to achieve the standard (PII 1996c, pp. $17-23$ ).

In Wisconsin, the renewables portfolio standard has been incorporated into the generation models discussed in the report of the Advisory Committee on Electric Utility Restructuring and in the analysis conducted in the EIS. In the Flexible Regulation Model, all retail suppliers in the state would be required to purchase a certain

\footnotetext{
43 The Public Interest Intervenors include American Lung Association, American Wind Energy Association, Citizen Action, Citizens Advisory Panel, Citizens Utility Board, Environmental Advocates, Hudson Riverkeeper, Hudson River Sloop Clearwater, Natural Resources Defense Council, New York Public Interest Research Group, New York Rivers United, Pace Energy Project, Scenic Hudson, Sierra Club-Atlantic Chapter, The Association for the Protection of the Adirondacks, and the New York Energy Efficiency Council.
} 
percentage of their electric supplies from renewable energy. The percentage would start from the current level and increase gradually. The renewable allowances would be tradeable (PSCW 1995d, p.54; 1995b, p. 355). Similarly, the renewables portfolio standard may also be required under the Incremental Change Model (PSCW 1995d, p. 59; 1995b, p. 357). In adopting the "Reasonable Strategy," the PSCW does not explicitly

state whether it would impose a renewables portfolio standard. In contrast, PSCW stated that it would require the investor-owned and municipal utilities to establish green pricing programs in their individual rate cases and that the green aggregator concept would be one of the topics to be addressed by the Public Benefits Policy Advisory Board (PSCW 1995e).

In summary, the renewables portfolio standard is a potentially useful mechanism for promoting the development of renewable energy resources. Some renewables, energy efficiency, and environmental groups support it while others think it is unworkable. With the tradeable credits or allowances, it is a market-based mechanism similar to the emissions allowance trading programs established under the Acid Rain Program in the CAAA of $1990 .^{44}$ Among the three states studied in the project, only California has clearly adopted this approach as of May 1996, but the implementation details of such an approach remain to be developed.

\subsubsection{Green Pricing/Green Aggregation}

One objective of electric industry restructuring is to increase customer choice. Thus, electricity users may be given the option of choosing between electricity generated from conventional fuels such as coal, oil, nuclear, and natural gas, or from renewable sources, or "green power". If green power is more expensive, then a utility would be allowed to charge higher prices than that of electricity generated from conventional fuel sources. Consumer surveys have indicated that environmentally-conscious consumers may be willing to pay more for clean power. The additional amount collected would be used by the utility to pay for the additional cost of green power, helping to lower the cost of green power to the electric utility to equal to its avoided costs. This approach is called green pricing.

An example of green pricing is the photovoltaic (PV) Pioneer Program being implemented by Sacramento Municipal Utility District. The program allows residential customers to voluntarily pay a higher monthly electricity bill, for which the utility installs a PV generating system on the customer's house. After a specified period of time, ownership of the PV system is transferred to the homeowner. This program is different from other green pricing cases because the customer sees a direct connection between paying more and the expanded investment in solar electricity. Started in 1992, this program averaged about 100 new participants annually, installing between 300 and $400 \mathrm{KW}$ a year.

In California, the CPUC's initial Blue Book proposal relied on existing environmental regulation and a modified form of green pricing for improving the state's environmental quality and resource diversity under a competitive industry structure. With respect to the modified form of green pricing, the commission stated that it would build on SCE's green pricing proposal in a significant manner by allowing electricity consumers to choose among a wide array of service providers, marketers, and brokers, including green providers whose supply of electricity will be generated from renewable sources such as solar, wind, geothermal, and biomass. In addition, unlike the SCE's proposal, the CPUC's enhanced green pricing proposal did not presume that the service provided by renewables resources would be more costly than other services (CPUC 1994a, pp. 5253).

44 See Section 4.4 .8 below for a discussion of this approach. 
Public interest groups criticized the CPUC's proposed green pricing approach on several fronts. First, although the Blue Book stated that SCE had explored green pricing, the utility chose not to pursue it even on a pilot basis (Towards Utility Rate Normalization [TURN] 1994, p. 10). In addition, it is not possible for a utility to direct electrons generated from green projects to specific consumers. Hence, the green pricing approach relies on the vague notion that somewhere a wind turbine or a PV generation facility is operating because certain customers participate in green pricing. Such indirect linkage is unlikely to generate sufficient interest among consumers to achieve the objective of increasing renewable energy's share of total generation resources. For example, because green pricing requires participants to pay a premium on electric services, commercial and industrial customers will generally not participate for competitive reasons. This would eliminate about two thirds of potential customers' loads from participating in green pricing programs. As for residential customers, they are more likely to join the green pricing program if they know that other customer classes are also participating. In a voluntary program, commercial and industrial customers would opt out of the program. Thus, the proportion of residential customers joining the green pricing program is likely to be very low. Moreover, in a sense, a green pricing program might become regarded as a "charity" program because of the "extra" nature of the money used to fund environmentally friendly renewable generation technologies. As a result, renewable technologies may be viewed as a "frill." Once tagged in this manner, it would be difficult to bring them back for funding considerations at the legislative level. Another comment was that use of green pricing for assuring environmental quality risks similar arguments being made for nuclear waste cleanup, decommissioning, and installation of smokestack scrubber. In other words, it may also be argued that voluntary contribution be the means of addressing other essential environmental cleanup tasks. Such an outcome would set back the progress being made in the environmental protection area. Finally, application of green pricing requires donations, necessitating substantial marketing efforts and costs (TURN, 1994, pp. 10 - 13).

In the end; the CPUC placed little emphasis on green pricing. Instead, the commission decided to establish a target level of generation from renewables backed by a meaningful penalty for non-compliance and a nonbypassable "Public Goods Surcharge" on retail sale of electricity to fund public goods R\&D, and energy efficiency programs (CPUC 1995c, p. 146).

In New York, many parties agreed that green pricing could contribute to promoting fuel diversity, economic growth, health, and environmental protection. In a competitive market, green pricing would allow consumers to exercise their environmental preferences in a market setting. However, the PII cautioned that green pricing is only a complement to, but not a substitute for, a renewables portfolio standard for some of the same reasons as discussed above in the Califomia case (PII 1995b, pp. 9 - 10). Both the ALJ's recommended decision and the commission's final decision did not address the green pricing issue.

In Wisconsin, the PSCW decided to require investor-owned and municipal utilities to investigate and propose "green-pricing" programs to gather information about customer preference for renewable energy and conservation technologies and to facilitate more rapid market development and transformations (PSCW 1995e, p. 6).

A related idea is the green aggregator concept. Consumers who choose to purchase electric power generated using renewable technologies can buy from green retail companies which could procure electricity through bilateral contracts from green generators. The green retail companies are green aggregators who bundle individual consumers' load for green power into a larger block of power. In Wisconsin, the Advisory Committee on Electric Restructuring included such concept into the "Commercial Model" for the generation segment of the electric industry (PSCW 1995d, pp. 72-73). The PSCW (1995e) will direct the Public Policy Advisory Board to address the green aggregator concept further. 
In short, the concepts of green pricing and green aggregation are based on the preference of many consumers for renewable energy. These mechanisms conform to the customer choice theme underlying electric industry restructuring, and could play a role in promoting development of renewable energy. However, for competitive reasons, most industrial and commercial customers would probably choose not to participate in such programs when the cost of green power is substantially higher than electricity from conventional power plants. Thus, it may not be realistic to rely on green pricing and green aggregation as a primary policy tool for renewable energy development. Nevertheless, it can be a complement to other mechanisms, such as the renewables portfolio standard and nonbypassable system benefit charge. Among the three states reviewed in this report, only Wisconsin had declared that it will direct the utilities to look into the implementation of green pricing and will further develop the green aggregator concept.

\subsubsection{Emission Caps with Tradeable Credits}

The option of emission caps with tradeable credits is a market-based approach. A current example is the emission credit trading program for sulfur dioxide under the Acid Rain Program of the CAAA of 1990. The total amount of allowable emissions would be set for each pollutant. To emit one unit of pollutant into the air, an entity must hold one unit of the credit. The credits are tradeable. Depending on the relative costs of controlling the emissions and the costs of the credit, some entities may decide to reduce emissions to yield credits in excess of their own need. The extra credits could then be sold, transferred to other plants of their own, or banked for later use. In contrast, other entities may buy the credits to avoid the cost of installing expensive control equipment. The flexibility of credit trading allows individual utilities and other power producers to optimize their strategies with respect to compliance with environmental regulations. This can increase overall economic efficiency.

\subsubsection{Summary}

Eight funding or implementation mechanisms for ensuring environmental protection and achieving other public policy objectives are discussed above. They are: nonbypassable system benefits charge, utility funds, state general fund, special fund, pollution tax, renewables portfolio standard, green pricing/green aggregator, and pollution caps with tradeable credits. Among them, the non-bypassable system benefits charge appears to enjoy rather wide support. It has been adopted in both Califomia and New York. The Califomia PUC termed it the "Public Goods Charge."

The renewables portfolio standard is a potentially useful approach for promoting development of renewable generation. Some renewable, environmental, and energy efficiency interests support it while other groups think it is unworkable. Califomia will impose a minimum renewables purchase requirement on either retail providers or on generators from 1998 through 2000. A review of the requirement will then be conducted.

In Califormia, the CPUC's initial Blue Book proposal relied on existing environmental regulation and an enhanced version of green pricing for improving the state's environmental quality and resource diversity under a competitive electric industry. Following critical comments from many parties, the CPUC did not specifically mention green pricing in the final decision. Instead, it adopted both the Public Goods Charge and the renewables portfolio standard. In Wisconsin, the PSCW will require investor-owned and municipal utilities to investigate and propose green-pricing programs. It will also develop the green aggregation concept further. 
The utility fund approach is useful during the transition period. Beyond the transition, care must be taken to allocate costs between retail customers of the local distribution company and direct access customers. The State General Fund approach would include the total costs of environmental protection and other public policy programs into the State's spending plan and fmance through general tax revenues. A special fund can be established as an independent, non-profit organization or a statutory entity within an existing state agency to administer funds for DSM, renewables; R\&D and public advocacy for environmental, efficiency, and small business and residential matters. Such a fund may be financed through a line charge, usage fee, pollution tax, or a bond authority. Pollution tax and emission caps $w$ th tradeable credits are market-based mechanisms that may play an increasing role in the future.

\subsection{Environmental Impact Statement/Report}

In restructuring the electric industry, should a state PUC prepare an EIS or environmental impact report EIR? When should it be prepared? The answers to these two questions depend on the requirements of the state law and the interpretation of the specific languages of the applicable regulations. There are marked differences in the manner these two issues are treated in Califomia, New York, and Wisconsin. Wisconsin decided early on that an EIS would serve the useful purpose of providing valuable information on the impacts of alternative industry structures to decision-makers and was able to complete the environmental impact review process in a relatively short time from the start of the formal proceeding. In New York, the administrative law judge (ALJ) recommended, and the commission concurred, that the EIS be prepared prior to the commission's final decision so that the information from the EIS process could be incorporated into the commission's decisions. The California PUC decided that the EIR should be prepared after the commission adopted its final policy decision on restructuring.

In Wisconsin, the PSCW, in September 1994 (at the start of the formal proceeding of the electric industry restructuring case), recognized that the docket could have significant environmental consequences. However, the commission stated that it was too early to determine the level of environmental review required because the options were not yet determined (PSCW, 1994). In early February, 1995, the PSCW stated in its Supplemental Notice (1995a):

The preparation of an environmental impact statement is warranted in this docket for two major reasons. First, this docket could result in the implementation of principles and policies that significantly alter the regulatory responsibilities of the commission which could possibly have environmental consequences. Second, the public involvement requirements associated with preparing an environmental impact statement would help meet the need for adequate and appropriate public involvement in this docket. A workplan will be developed with significant milestones and submitted to the commission by March 1, 1995. Staff must complete an environment impact statement in time to allow the commission to prepare a report to the legislature on recommendations for legislative changes by December 1, 1995.

Ten months from the start of the formal proceeding, the PSCW staff issued a draft EIS (DEIS), analyzing the economic, system, environmental and sociooconomic impacts of the Plausible Extreme Altemative, as compared to the status quo case. The Plausible Extreme Alternative was defmed to include disaggregation of the vertically integrated electric utilities. There would be free entry into the generation business and no central planning in defming the need for new generating plants. New plant construction would still require a 
permit from the DNR A poolco would perform the market exchange function in the spot market and economic dispatch. The poolco would be an independent entity with no ownership in any generation, transmission, or distribution facilities. Transmission facilities would be owned and operated by an independent transco, a price-regulated monopoly with a statewide franchise. The distribution system would be composed of two parts: a regulated monopoly of the distribution lines (lineco) and an unregulated retail service entity (Retailco). The lineco would provide customers access to the electricity market. The retailco would aggregate purchases from the spot market, generators, and power merchants and offer different pricing mechanisms to meet customer demands (PSCW Staff 1995, pp. 4 - 10).

The DEIS derived the following general findings concerning environmental impacts (PSCW Staff 1995, pp. xiv-xv):

- $\quad$ Economic issues are likely to take precedence over environmental issues with regard to power plant siting and operational decisions. The Plausible Extreme Alternative is likely to lead to an increase in the trend to site power plants in rural, less developed areas near available transmission facilities.

- Under the Plausible Extreme Alternative, the commission would no longer have planning or siting authority over power plants, so the only environmental protection would be through the DNR air, water and solid and hazardous waste permits. Public input into siting power plants would be limited to local zoning decisions.

- It is not clear how issues relating to nuclear power plants, including nuclear waste storage and liability for decommissioning costs, would be dealt with under the Plausible Extreme Alternative.

- To accommodate an increase in power transfer transactions, the amount of new transmission lines is expected to be higher than currently planned. Many of these additional lines will be of high voltage ( $161 \mathrm{kV}$ and above) and the potential for significant impacts on the environment is greater for this type of facilities. The potential increase in power transfers may partially offset the need for new generation facilities in Wisconsin and some of the associated environmental impacts under the Plausible Extreme Alternative.

- The present commission planning and siting process for transmission lines helps mitigate many environmental, social, and economic costs of transmission. If such authority is lost, as under the Plausible Extreme Alternative, the potential that such factors will not receive adequate consideration is much greater.

Thirteen months after the start of the formal proceeding, the PSCW issued a final EIS (FEIS) in October, 1995. The FEIS considered the impacts of the Advisory Committee recommendations, and the Plausible Extreme Alternative (PSCW 1995b). The FEIS also presented the comments by the interested parties on specific aspects of the DEIS and described how those comments are addressed in the FEIS (PSCW 1995c).

In Califomia the Natural Resource Defense Council (NRDC) filed a motion on June 20, 1994 (two months after the start of the proceeding), requesting that the CPUC prepare an EIR on the potential impacts of the commission's policy proposals in accordance with the CEQA. Other parties such as the Coalition of California Utility Employees and the Center for Energy Efficiency and Renewable Technologies supported 
the motion. Eight months from the start of the formal proceeding, the CPUC responded in its December 7 , 1994, interim decision, stating its commitment to determining the applicability of CEQA when the commission frames its policy decision. Thirteen months after the proceeding formally began, the CPUC, in its May 1995, proposed majority policy decision, asked the parties to comment on the issue. Specifically, two questions were posed (CPUC 1995b, p. 259-260):

1. Do any of the policies proposed herein constitute a "project" subject to CEQA, as defined in Public Resources Code 21065 and interpreted by the courts? Comments should specify which policy elements, if any, are believed to trigger definition as a CEQA "project," as well as cite authority for the party's analysis and conclusions.

2. Do any changes proposed by the party to this Proposed Policy either trigger definition as a CEQA project OR remove such definition? Again, comments should specify which changes, if any, are believed to affect the definition as a CEQA "project," as well as cite authority for this conclusion.

Nine parties provided comments. Two suggested that the CEQA was not applicable. Six concluded that the CEQA was applicable. One did not take a position but urged a quick resolution of the issue. Twenty months from the start of the proceeding, the CPUC stated in its final policy decision that, although it could not decide whether restructuring the electric industry constitutes a CEQA project, it is reasonable to conduct the necessary analysis required by the CEQA. The CPUC concluded that an EIR should be prepared and directed the commission staff to contract with a consultant to prepare an EIR on the environmental impacts of the commission-adopted policy decision, compare environmental effects of the alternatives, and identify mitigation measures for any potentially significant impacts (CPUC, 1995c, pp. 175-179). On March 29, 1996, the CPUC issued a Notice of Preparation of an EIR and released the schedule for public scoping meetings to initiate the public involvement process.

In New York, the Pace Energy Project and the NRDC, on July 5, 1995, (approximately eleven months from the start of formal proceeding), jointly released a proposal to evaluate the issue of compliance with the State Environmental Quality Review Act (SEQRA). Parties to the collaborative process attempted, but failed, to reach agreement on whether the SEQRA was applicable to the commission's actions and decisions in the case. The NYPSC staff then prepared and distributed a draft environmental assessment form (EAF) to parties for comment on September 29, 1995. On November 17, 1995, the staff submitted to the ALJ in Case 94-E-0952 a recommended full EAF and a motion outlining the staff's position on the application of SEQRA to the proceeding (NYDPS, $1995 \mathrm{~b} \& \mathrm{c}$ ). The recommended full EAF identified the potential changes under a full retail access competitive electric industry as compared to the current evolving regulated monopoly structure, and the resulting potential impacts on land, air, and water resources and the human environment. The staff's EAF also concluded that a number of the potential environmental impacts could be considered "significant" as defined under the SEQRA criteria. This would require the preparation of an EIS "to scope, describe, and quantify the identified environmental impacts to determine the likelihood that adverse impacts will result, and to identify mitigation measures for those impacts" (NYDPS, 1995c, p. 35). In its motion, the staff requested that the ALJ: (1) accept the staff's recommended full EAF; (2) recommend that the commission issue a negative declaration of potentially significant adverse environmental impact if the Commission takes no action to restructure the electric industry and selects the Evolving Regulatory Model; (3) recommend that the commission issue an EAF with a positive declaration of potentially significant adverse environmental impact 
if the commission selects and seeks to implement a wholesale or retail model of electric competition; and (4) in the event of a positive declaration, recommend that the commission direct the staff to prepare a draft generic EIS in Phase III of the proceeding.

At sixteen months from the beginning of the proceeding, the ALJ's Recommended Decision accepted most of the staff's recommendations, except its conclusion conceming the timing of the preparation of draft generic EIS. The ALJ reasoned that information concerming the potential impacts of altemative models would be useful to the Commission in its deliberations concerming alternative market structures and hence, should be made available to the Commission prior to making the final decision. Instead of preparing the draft generic EIS in the Phase III of the docket after the Commission has selected the restructuring model, the ALJ's Recommended Decision directed Staff to complete the preparation of the draft generic EIS as soon as possible so that the information on the potential environmental impacts of alternative models could be used as input to the Commission in its deliberations (NYPSC 1995c, Vol. I. pp. 93-106). On February 13, 1996, the NYPSC issued a memorandum and resolution concurring with the Recommended Decision with respect to SEQRA compliance and directed that an EIS be prepared. On March 6, 1996, a draft Generic EIS was issued by the NYDPS (NYDPS 1996a) for comments. The report considered three alternative electric industry structures: retail competition, wholesale competition, evolving regulation model. Following comments by stakeholders, the Final Generic EIS (FGEIS) was issued on May 3, 1996.

In terms of environmental impacts, the FGEIS indicated that different levels of $\mathrm{SO}_{2}$ and $\mathrm{NO}_{\mathrm{x}}$ emissions "could result from different assumed structures for the electric industry," but the federal tradeable allowances for $\mathrm{SO}_{2}$ and the potentially tradeable allowances for $\mathrm{NOx}$ would mean that the overall national emission level would not be affected. Nevertheless, there are three areas of concem. First, while New York power plants would emit $\mathrm{NO}_{x}$ at the cap level, the Midwest plants would not be subject to the strict $\mathrm{NO}_{\mathrm{x}}$ requirements, and a large portion of $\mathrm{NO}_{x}$ emitted there could be transported into New York. Second, the geographic distribution of pollutants is also of concern. If more electricity is acquired from the Midwest, both $\mathrm{NO}_{x}$ and $\mathrm{SO}_{2}$ could become problems for New York because more acid rain would fall upon New York's environmentally sensitive regions. Third, since the regional cap on $\mathrm{NO}_{x}$ as part of the ozone control for the Ozone Transport Region applies only to the summer months, ozone emission is still a problem (NYDPS, 1996b, pp. S-7 to S9). The FGEIS found that although the Commission need not be concemed with the emissions of $\mathrm{CO}_{2}$, fine particulates, and air borme mercury in the near term, the Commission may have to address them in the future (NYDPS, 1996b, pp. S-9 through S-12).

In summary, the elapsed time from the start of formal proceeding to the issuance of a final EIS varies greatly among the three states. Wisconsin took only 5 months for the commission to order the review of potential environmental impacts and 13 months to have a final EIS for use by the Commission in its deliberations. In contrast, it took New York 18 months and California 20 months, respectively, to direct that an EIS or EIR be prepared. The NYPSC adopted a final EIS in early May 1995, about 21 months from the start of the restructuring proceeding. In California, the final EIR is expected to be completed by the spring of 1997 , approximately three years after the formal proceeding began. It follows that, if the electric industry restructuring process requires preparation of an EIS, it is possible to reduce the time lines significantly if care is taken to consider the issue early and make an early decision to undertake the EIS process. In addition, where state laws do not specify otherwise, early preparation of the EIS affords the commission the added opportunity to consider, prior to making final choice, the potential adverse impacts of altemative market structures and useful public inputs and involvement. 


\subsection{The Role of Environmental and Other Interest Groups}

Environmental, energy efficiency, renewable energy, and consurner interest groups have actively participated in the electric industry restructuring proceedings in all three states. In the areas of environmental and related

issues, they have argued for the full consideration of environmental issues and proposed various funding or implementation mechanisms. In this section, we describe the role played by such groups.

In the transition to a competitive electric industry, there may be a tendency to leave the treatment of environmental issues to the market, resulting in a lack of, or inadequate, consideration of them.

Environmental and other interest groups have successfully argued that such issues need to be considered fully to avoid exposing utilities and their customers to unnecessary future risk and cost increases. California provides a good example.

In its initial restructuring proposal (the Blue Book), the CPUC stated that its proposal to promote competition in electric services would help to improve the state's environmental quality and resource diversity for two reasons. First, resource additions would continue to be subject to the requirements of the CEQA. Second, the commission would build on SCE's "green pricing" proposal in a significant manner by allowing electricity consurners to choose among a wide array of service providers, including green providers whose supply of electricity will be generated from renewable sources such as solar, wind, geothermal, and biomass (CPUC 1994a, pp. 52-53). This is the extent of treatment of environmental protection in the Blue Book. Thus, the initial CPUC proposal relied on existing environmental regulation and green pricing to address environmental problems and to achieve the objective of increased fuel diversity.

Some parties such as ELCON and California Manufacturers' Association agreed with the CPUC that it was appropriate to let the market decide, placing complete reliance on market-based mechanisms. ELCON (1994) stated that direct access by end users can yield environmental protection benefits by changing the manner in which power plants and transmission facilities are sited in the future. The California Manufacturers' Association (1994) urged the CPUC to unburden electric service rates from the social and environmental baggage they have been made to carry and work with the legislature to find other ways to meet these important public policy objectives.

On the other hand, environmental, energy efficiency, and other public interest groups criticized the CPUC's relative lack of emphasis on environmental and related issues. The NRDC filed a motion on June 20, 1994, for a determination by the commission of whether the proceeding involved a project subject to or exempt from CEQA. The Center for Energy Efficiency and Renewable Technologies (CEERT) called attention to the Blue Book's lack of attention to the impact of state and federal environmental laws on the electric services industry. In CEERT's view, environmental laws and their impacts must be considered fully in the restructuring process. Otherwise, utilities and their customers may be exposed to "costly near- and long-term environmental risks and liability" (CEERT 1994, p. 4).

As described in Section 4.4.7, public interest groups criticized CPUC's proposed green pricing approach on the following fronts: SCE's refusal to implement green pricing even on a pilot basis; inability to generate sufficient interest in supporting the development of renewable energy, due to the opting out of the program by commercial and industrial customers and low participation by residential customers; the danger that renewables might be regarded as a "frill" and that the environmental protection argurnent might be misapplied to nuclear and other hazardous waste disposal problems; and the high administration and marketing costs that 
will be incurred in implementing green pricing. The CPUC provided responses to the above and other comments on such public policy objectives in its Docember 7, 1994, interim decision. The decision directed utilities and interested parties to form a working group to examine how the issues of social, economic, and environmental objectives could best be achieved in the restructuring of the electric industry, and asked parties to file briefs on state and federal laws that might be implicated by the restructuring proposals. As defined by the CPUC, the purpose of the working group was to "comment on the sustainability of social, economic and environmental obligation and restraints in each of the restructuring models and to provide implementation options for carrying out these social, economic and environmental policy goals under each of the broad restructuring models" (Working group, 1995). For the working group, the Commission identified 11 issues of concern: reasonable and nondiscriminatory rates, nondiscriminatory transmission access, public health and safety, service quality and reliability, demand-side management and energy efficiency programs, low-income ratepayer programs, fuel diversity and renewable resource technologies, environmental protection, low emissions vehicles and other technology development, women-, minority-, and disabled veteran-owned

business enterprise, and economic development. The commission directed the working group to develop options for achieving four objectives: unbundling of electric service, maintaining or advancing public policy programs or both pursuing resource procurement, and cost recovery mechanisms (CPUC 1994b, pp. 9 - 10).

The commission's Interim Decision touches on environmental issues in several areas. First, environmental protection is one of thel 1 issues of concern specifically identified by the CPUC. Related issues are demandside management and energy efficiency, fuel diversity and renewable resource technologies, public health and safety, and low emission vehicles. Second, the objective to promote resource diversity implies the promotion of environmentally sensitive electric generation and service. Third, the objective to develop a cost recovery mechanism is aimed at developing alternative methods of paying for environmental and related programs. Fourth, the commission stated that it is committed to make a determination on the applicability of CEQA when it framed its final policy decisions. The CPUC further stated that only after the completion of the EIR process would the provisions of its policy decisions be implemented. As explained above in Section 4.5, the CPUC eventually decided that an EIR should be prepared.

The example above shows that, in California, environmental, energy efficiency, renewable energy, and consumer interest groups succeeded in calling attention to issues that needed to be addressed in the restructuring process. Note, however, that the collaboration between environmental and low-income groups in California was not smooth. In fact, one observer regarded it as "a relatively painful and difficult process." Nevertheless, the alliance between the two groups became a politically strong force in the restructuring debate (Wiser, 1996).

In New York, 19 such interest groups banded together to form Public Interest Intervenors (PII): American Lung Association, American Wind Energy Association, Citizen Action, Citizen Advisory Panel, Citizens Utility Board, Environmental Advocates, Hudson Riverkeeper, Hudson River Sloop Clearwater, Natural Resources Defense Council, New York Public Interest Research Group, New York Rivers United, Pace Energy Project, Scenic Hudson, Sierra Club-Atlantic Chapter, The Association for the Protection of the Adirondacks, New York Energy Efficiency Council, The Adirondack Council, Association For Energy Affordability, Inc., and Citizens Campaign for the Environment. The PII supported the commission staffs overall approach to SEQRA review but challenged the Staff's timing recommendation. ${ }^{45}$ In PII's view, the

45 See Section 4.5 for a discussion on New York's approach to conduct analysis of environmental impacts of the Commission's actions related to electric industry restructuring. 
purpose of the EIS should be to inform decision makers and the general public about potential adverse environmental impacts before a decision was made. Thus, Staff's recommendation that it be directed to prepare an EIS after the Commission has chosen a competition model was not appropriate. PII's argument in this regard helped to convince the ALJ. In the recommended decision, the ALJ directed staff to complete a SEQRA review so that the review results could be used by the Commission in making decisions (NYPSC. 1995c, Vol. I, pp. 98-99, 103-106). The NYPSC (1996a) concurred with this recommendation.

In Wisconsin, interest groups such as environmental, energy efficiency, renewables, and consumer groups actively participated in the restructuring activities. Representatives from Citizens Utility Board (CUB), Wisconsin Community Action Group Association (WisCAP), RENEW Wisconsin, and Wisconsin's Environmental Decade (WED) were members of the Advisory Committee on Electric Utility Restructuring. They and other representatives from such interest groups participated in various work groups organized by the Advisory Committee to address different topical issues. For example, CUB, RENEW, and WED contributed to the development of the "Statewide Transco Option" for the transmission system, the "Flexible Regulation Model" in generation, and the "Customer Options Without Retail Wheeling" in distribution. These groups were among those who argued for the need to fulfill certain conditions before considering full retail wheeling. ${ }^{46}$ It appears that the strategy adopted by the PSCW in December, 1995, was affected by their arguments. In addition, the environmental and other interest groups also provided detailed comments on the DEIS to point out the deficiencies and suggested additional analysis and information for inclusion in the final EIS (PSCW 1995c).

The environmental and other interest groups also helped develop funding and implementation options for environmental, energy efficiency, renewables and other public policy objectives. In California, similar interest groups supported a nonbypassable system benefits charge for energy efficiency programs. The CPUC adopted the "public goods charge" to collect funds for energy efficiency programs related to market transformation and funding for R\&D related to the broader public good (CPUC 1995c, pp. 157-159 and 226).

In New York, the PII advocated establishment of a system benefits fund through the imposition of a nonbypassable systems benefits charge on electricity distributed by a local distribution utility regardless of the suppliers of the electricity to the end-use customer (i.e., a wires charge). The fund would support energy efficiency programs, low-income and elderly programs, and renewable energy resources (PII, 1995a, pp. 29. 43). PII's arguments helped convince the ALJ. The Recommended Decision included a recommendation that "a nonbypassable system benefits charge appears to be a fair way of ensuring that environmental and other public policy programs be continued" (NYPSC 1995c, p. 110). The commission adopted this recommendation in its final decision.

In Wisconsin, public interest groups joined with some power companies to propose a social benefits fund to finance energy efficiency, renewables, and environmental programs. ${ }^{47}$ This fund would be administered by an independent nonprofit organization and paid for through a statutory fee such as a line charge, revenue fee, or a pollution tax. It was proposed that funds to DSM, renewables, RD\&D, and environmental, small businesses, and residential advocacy would be allocated by a board representing various stakeholders (PSCW

46 For details of the conditions, see PSCW (1995d), pp. $80-85$.

47 The interest groups and power entities are Adams-Columbia Electric Cooperative,CUB, Dairyland Power Company, Municipal Electric Utility of Wisconsin, Madison Gas and Electric, RENEW, WED, WisCAP, and Wisconsin Public Power System, Inc. 
1995d, pp. 138 - 142). The PSCW adopted at least two aspects of this proposal. First, the PSCW recognized the contribution of such interest groups and decided to request that the legislature increase funding for interested organizations to $\$ 500,000$ annually to provide meaningful input into the regulatory process. Second, in Phase I of the restructuring process, the commission will establish a Public Benefits Policy Advisory Board to address low-income issues and services, conservation and DSM, renewables (particularly

the aggregator concept), and R\&D issues. In Phase II, the PSCW will implement the board's recommendations. In the 32-step process envisioned by the commission, these are Step 3 and Step 6, respectively (PSCW 1995e).

Another mechanism initially proposed by such interest groups and eventually adopted by the California PUC is the renewables portfolio standard. This has been discussed above in detail in Section 4.4.6.

In summary, environmental and other interest groups have successfully argued that environmental and other public policy issues need to be fully considered in the electric industry restructuring process. In Califomia, such interest groups have effected a change in the proposed mechanisms: the CPUC shifted from its initial proposed strategy of relying on existing environmental regulations and enhanced green pricing to adopting both the "Public Goods Charge" and the renewable portfolio standard. In addition, in both Califormia and New York, the environmental groups were also the organizations that first raised the issue of the need to evaluate the environmental impacts of the PUC's restructuring policies. In New York, these groups have also succeeded in promoting the system benefits charge for funding energy efficiency programs. They convinced the ALJ and the commission that an EIS needs to be prepared prior to the commission making final decision concerning the restructuring models to be adopted. Finally, in Wisconsin, they have contributed to the PSCW's decision to seek increases in the statutory funding for intervenors' organizations and to establish a Public Benefits Policy Advisory Board to oversee the tasks of allocating the available funds for renewable, energy efficiency, low-income, and other public policy programs. 


\section{Findings And Conclusions}

In the previous two chapters, the consideration of environmental issues in the electric industry restructuring process in California, New York, and Wisconsin were described. Specific issues such as the role of state agencies and state legislatures, treatment of environmental externalities, funding and implementation mechanisms, preparation of EIS/EIR, and the role played by environmental and other interest groups were also discussed. In concluding this report, we first summarize the findings and then offer some conclusions.

\section{1 $\quad$ Findings}

1. Prior to restructuring their respective electric industries, Califomia and New York had relatively high electricity prices, while Wisconsin was a relatively low-cost state. In 1993 and 1994, the average price per $\mathrm{kWh}$ for end use sectors in California and New York ranged from $17 \%$ to $61 \%$ above the national average. In contrast, the average price in Wisconsin was about $15 \%$ to $24 \%$ below the national average.

2. Prior to restructuring, responsibility for environmental quality and stewardship in Califormia, New York, and Wisconsin was shared in some manner by the environmental and utility/energy regulatory agencies. All three states required monetization of environmental externalities in the resource planning and acquisition process. In fact, they were among only seven states in the United States that have adopted monetized values for specific emissions. The other four states were Massachusetts, Minnesota, Nevada, and Oregon. ${ }^{48}$ In acting to develop externality values, the CPUC followed the explicit direction of a state law. The New York and Wisconsin commissions based their authority to require monetization of environmental externalities on their interpretation of the agency's responsibilities under state laws. It should be noted, however, that in New York the ALJ in Case 92E-1187 has recommended eliminating the requirement to include environmental externalities in the evaluation of competitive bidding and DSM programs. As of the publication of this report, the NYPSC has yet to decide on the recommendation.

3. Califormia had a relatively long gestation period, about 2 years from April 1992 through April 1994. The CPUC staff conducted an internal study of the electric utility industry and its regulation in Califomia and released the report (The Yellow Book) for public comments and hearings. In Wisconsin, the gestation period lasted from March to September 1994. The WPUI Roundtable on Electric Power Industry Trends and Regulatory Policy Directions addressed various issues and developed options for consideration by the PSCW. There was no similar gestation period in New York. In a case addressing selected issues of competition in the overall energy market, the NYPSC adopted, in July 1994, an order setting forth general guidelines for the sale of electricity at flexible rates to customers with competitive opportunities. The NYPSC decided that it was appropriate to investigate issues related to the future regulatory regime in light of the competitive opportunities for electric services.

Thus, the initial preparation of the parties involved in the electric industry restructuring process were quite different in the three states. California had a long gestation period, and the commission staff was the principal generator of the initial ideas, which became inputs to the CPUC's vision and initial

${ }^{48}$ See Footnote 14. 
proposals. Wisconsin had a public gestation period with open public discussion of the ideas, and the resulting report served as a starting point for further debate. New York's process was started within a formal proceeding addressing a number of competitive issues in the overall energy market.

4. California was the first state to start a formal proceeding to restructure the electric service industry, preceding New York and Wisconsin by about 4 and 5 months, respectively. The dates on which formal proceeding was started were April 24, 1994, for California, August 9, 1994, for New York, and September 8, 1994, for Wisconsin.

5. All three states issued some interim decisions. In California, interim decisions were issued on December 7, 1994, and May 24, 1995, respectively. The latter decision designated the CPUC's preferred policy (the Majority proposal) and an alternative policy (the Minority proposal). New York has issued five interim decisions. The first, issued on December 27, 1994, presented the NYPSC's proposed principles for comments. The second interim decision, on June 7, 1995, adopted the final guiding principles for restructuring the electric industry. The third was an ALJ's recommended decision, released on December 21, 1995. The fourth was a memorandum and resolution issued on February 13, 1996, concurring with the ALJ's finding on the preparation of an EIS and directing that an EIS be prepared. The fifth was issued on May 3, 1996 when the commission released it's final generic EIS. In Wisconsin, the PSCW adopted only one interim decision on February 2, 1995. It set forth the objectives of the investigation and the principles for restructuring. It also appointed an advisory committee to develop and assess alternative market structures, transmission and distribution systems, and as public policy issues.

6. In California, the CPUC issued a final policy decision on electric industry restructuring on December 20, 1995 (Decision 95-12-063). On January 10, 1996, it made minor corrections and changes to the decision (Decision 96-01-009). In Wisconsin, the PSCW adopted "A Reasonable Strategy for Restructuring Wisconsin's Electric Utility Industry" on December 19, 1995. In New York, the NYPSC issued a final decision on May 20, 1996.

7. In California, the CPUC proposes to set minimum renewables purchase requirements for promoting the continued development of renewable generation and achieving the goal of resource diversity. The CPUC would prefer the minimum level to be the same level for all electric utilities in the state, but would allow a transitional strategy to account for the differences in the current resource portfolios of utilities. Credits for meeting the minimum purchase requirement would be tradeable. The minimum levels will be for the period from 1998 through 2000 and the requirement will be reviewed then. Meaningful penalties would be imposed for noncompliance.

8. The CPUC would adopt, by January 1, 1997, a nonbypassable "public goods charge" on all retail sales to support market-transforming energy efficiency activities, public goods RD\&D, and lowincome assistance. Initially, it would be a line item on utility bills. With a statutory mandate, it would become a surcharge. Levels of funding would initially be set to correspond to authorized DSM funding and be reevaluated after implementation workshops are conducted. The CPUC did not adopt a percentage cap on the charge proposed by some parties.

9. In Wisconsin, the PSCW decided to preserve public benefits by continuing conservation programs, promoting renewable energy, and implementing green-pricing programs. Specifically, in individual rate cases, the PSCW will require investor-owned and municipal utilities to establish green-pricing programs. In addition, the commission will establish, in Phase I, a Public Benefits Policy Advisory 
Board to address low-income issues and services, conservation and DSM, customer-installed renewables, $R \& D$ issues, and market reforms to encourage renewable resource development. It will further develop the concept of green aggregation. In Phase II, the commission will act on the recommendations of the board regarding funding levels and appropriate funding mechanisms. Every 3 years, the commission will conduct a review to determine the need for the board's programs.

10. The PSCW decided that the generation business will be competitive. With competitive generation, the nead for power review is eliminated. Siting review will be limited to checking for consistency with the transmission plan and for the existence of "environmental fatal flaws." In Phase I, the PSCW will retain its generation siting authority and streamline its procedures to facilitate competition but maintain environmental protection. Specifically, in the generation Stage I competitive bidding process, it will be the commission staff's responsibility, not the independent evaluator's, to score the bids for environmental compliance with Power Plant Siting Criteria and the AP-7 bid filing requirements.

11. In New York, the NYPSC also adopted the nonbypassable system benefits charge to fund environmental, energy efficiency, and other public policy programs that are not likely to be adequately pursued by competitive markets. Initially, the charge would be set so as to generate the current expenditures levels of the utilities and allocation of costs will be done in a competitively neutral manner.

\subsection{Conclusions}

1. The differences in existing electricity prices have affected the initial attitudes of stakeholders and their support for retail competition in the electric industry. Where electricity prices were relatively high, as in California and New York, support for retail competition was initially more pervasive. Where electricity prices were relatively low, as in Wisconsin, support for retail competition was limited to large investor-owned utilities, some independent power producers, and some large industrial customers. One reason for this difference is fairly obvious: In California and New York, competition from out-of-state suppliers holds the promise for lowering electric prices for all customer classes. In Wisconsin, competition from out-of-state buyers of electricity could lead to higher electric prices for those who currently enjoy low rates. This concern is reflected by Commissioner Scott Neitzel's view that the prices associated with Wisconsin's current low-cost generating facilities be tied to Wisconsin customers (PSCW, 1996, Attachment A). In addition, there is an interesting comparison. While large industrial users in New York and California support retail competition, some of their counterparts in Wisconsin initially doubted that the process being pursued by the PSCW would eventually lead to true retail competition.

2. There are some differences in the timing and duration of, and participation in, the collaborative processes in the three states. With respect to timing, the collaborative process began at the outset of the investigation in New York, but sometime later in California and Wisconsin. The duration of the collaborative process was shorter in California, where the working group was asked to address issues pertaining only to public policy programs. Alternatively, the collaborative approach can be used continually during the restructuring process, as in New York and Wisconsin, where the groups were directed to address all applicable issues. As to participation, the commission staff can be either included or excluded in the collaborative working group. In addition, the working group can be 
formally appointed by the commission, as in Wisconsin, or participation can be voluntary, except for the investor-owned utilities, as in California and New York. Another aspect is that a coalition building approach seemed to play a more prominent role in California.

3. Wisconsin has explicitly considered and outlined the environmental responsibilities of the PSC in a restructured electric industry in its final decision. In generation, the PSCW will reform its procedures to streamline the siting review to facilitate competition and maintain environmental protection in Phase I, and to check for conformance with the transmission system and for the existence of "environmental fatal flaws." In transmission, the PSCW retains its planning and siting authority in Phase I and reforms its proceedings to conform to the regional transmission group or the regional market and with environmental protection. It will retain its environmental protection and mitigation authority with respect to transmission systems throughout. In New York, it appears that the roles of the economic and environmental regulatory agencies would remain relatively the same. The NYPSC would work with the DEC to monitor potentially adverse environmental impacts of wholesale and retail competition and to develop mitigation strategies, which are competitively neutral. It is also envisioned that the DEC would play a central role in managing the special auction of emission credits for emissions that would adversely impact environmentally sensitive regions such as the Adirondacks and Catskills. In California, the final CPUC decision did not explicitly consider state agency responsibility and authority on environmental protection in a restructured market structure. However, it did indicate the need and desirability of legislative actions on many of public policy programs. In addition, such agency roles could be developed further in the on-going EIR process.

4. The legislatures in the three states have acted differently in the electric industry restructuring process. The California General Assembly was the most active among the three states. It got involved early and required the CPUC to report on progress and to look into public policy matters more intensively. It conducted hearings to consider various restructuring related bills. In contrast, the Wisconsin legislature stayed away from the electric restructuring arena during the course of the consideration of the issues by the PSCW. In New York, the state legislature was somewhat active in considering proposed legislation that might have an impact on the restructuring process being conducted by the NYPSC.

The difference in the role played by state legislatures in the restructuring process in the three states may be due, in large measure, to the differences in electricity prices among them and in the initial phases of the restructuring process. As explained in Section 2.1, Wisconsin enjoyed relatively low electricity prices while Califormia and New York were among the high-cost states. High electricity prices were more likely to lead to high level of consumer dissatisfaction and agitation for change through various mechanisms, including the legislative process. Organized stakeholder groups would lobby their lawmakers to propose legislation and other measures that could result in changes favoring their respective positions. In contrast, there was less consumer dissatisfaction in low-cost states such as Wisconsin and, hence, less agitation for legislative action. In addition, the PSCW took a proactive role in addressing the restructuring issue. Thus, the legislature could afford to take a more leisurely approach. In terms of the initial proposal, the CPUC presented a formal proposal that many stakeholders immediately perceived themselves to be potential winners or losers. Such sentiments were soon picked up by state legislators. As a result, the California legislature took an early and substantial interest in restructuring issues. In contrast, Wisconsin started with the more limited objective of adopting a set of principles for restructuring. This proved to be much less controversial than the Califomia approach. 
5. Prior to the restructuring, all three states - California, New York and Wisconsin - required monetization of environmental externalities. In California, the CPUC, in its final restructuring order, adopted both the nonbypassable system benefits charge approach and the renewables portfolio standard to encourage and fund energy efficiency, renewable energy, and other public policy programs. Since the BRPU process will no longer be applied, there will be no explicit consideration of environmental externalities. In New York, there is a pending case explicitly addressing the environmental externalities issue in which the $\mathrm{ALJ}$ recommended that the monetization requirement be eliminated. The NYPSC has not acted on the recommendation yet. In the electric industry restructuring case, the ALJ recommended, and the commission ordered, that the nonbypassable system benefits charge be adopted to fund environmental and other public policy programs with the details of implementation to be worked out in the individual utility filings. In Wisconsin, the PSCW would reform the generation Stage I competitive bidding process, which requires scoring the bids according to environmental compliance, in addition to the green pricing and green aggregation requirements mentioned above.

6. Eight funding or implementation mechanisms for ensuring environmental protection and achieving other public policy objectives are discussed in this report. They are: nonbypassable system benefits charge, utility funds, state general fund, special fund, pollution tax, renewables portfolio standard, green pricing/green aggregation, and pollution caps with tradeable credits. Among them, the nonbypassable system benefits charge appears to enjoy more support. The California PUC has adopted it and called it the "Public Goods Charge." In New York, the PSC also adopted the nonbypassable system benefits charge to fund environmental and other public policy programs.

The renewables portfolio standard is a potentially useful approach for promoting development of renewable generation. Some renewable, environmental, and energy efficiency interests strongly support it while others regard it as unworkable. Califomia will impose a minimum renewables purchase requirement on either retail providers or on generators from 1998 through 2000. A review of the requirement will then be conducted. The CPUC would prefer the minimum level be set at the same level for all electric utilities on a statewide basis but would allow a transitional strategy to account for the differences in the current resource portfolios of utilities. Credits for the minimum purchase requirements would be tradeable. Meaningful penalty would be imposed for noncompliance.

In California, the CPUC's initial Blue Book proposal relied upon existing environmental regulations and a modified green-pricing approach for improving the state's environmental quality and resource diversity under a competitive industry structure. Under the commission's proposal, electric consumers will be allowed to choose among a wide array of service providers, marketers, and brokers, including green providers whose supply of electricity is generated from renewable resources such as solar, wind, geothermal, and biomass. Unlike the basic green-pricing approach, the commission's proposal did not presume that the services provided by renewable resources would be necessarily more costly than other services. Following critical comments from many parties, the

CPUC no longer relies on green pricing. Instead, it adopted both the Public Goods Charge and the renewables portfolio standard. In Wisconsin, the PSCW will require investor-owned and municipal utilities to investigate and propose green-pricing programs. It will further develop the concept of green aggregation. 
The utility fund approach could be useful during the transition period. After the transition, care needs to be taken to allocate the costs of public policy objectives among the utility's retail and direct access customers. The State General Fund approach would include the total costs of environmental protection and other public policy programs into the state's spending plan and finance through general tax revenues. A special fund can be established as an independent, non-profit organization or a statutory entity within an existing state agency to administer funds for DSM, renewables, and public advocacy for environmental concerns as well as small business and residential matters. Such a fund may be financed through a line charge, a usage fee, a pollution tax, or bond authority. Pollution tax and emission caps with tradeable credits are market-based mechanisms that may play an increasing role in the future as the electric industry becomes more competitive.

7. The elapsed time from the start of formal proceeding to the issuance of a final EIS varies greatly among the 3 states. Wisconsin took only 5 months for the commission to order the review of potential environmental impacts and 13 months to have a final EIS for use by the commission in its deliberations. In contrast, it took New York 18 months and California 20 months, respectively, to direct that an EIS or an EIR be prepared. The NYPSC issued the final generic EIS in May 1996, about 2 lmonths from the beginning of the formal proceeding. In Califormia, the final EIR is expected to be completed in the spring of 1997, about 3 years after the initiation of the formal process to restructure the electric industry. It follows that, if the electric industry restructuring process requires preparation of an EIS, it is possible to reduce the time lines significantly if care is taken to consider the issue early and make an early decision to undertake the EIS process. In addition, where state laws do not specify otherwise, early preparation of the EIS affords the commission the added opportunity to consider, prior to making final choice of the market structure, the potential adverse impacts of alternative structures and useful public inputs and involvement.

8. Environmental and other interest groups have successfully impacted the electric industry restructuring process, arguing that environmental and other public policy issues need to be fully considered. In California, such interest groups have effected a change in the proposed mechanisms: the CPUC shifted from its initial proposed strategy of relying on existing environmental regulations and enhanced green pricing to adopting both the "Public Goods Charge" and the renewables portfolio standard. The PGC would collect funds for energy efficiency programs related to market transformation and funding for $R \& D$ related to the broader public good. The renewables portfolio standard will promote the use of renewable energy and support the objective of resource diversity and contribute to improving environmental quality. In addition, in both Califormia and New York, the environmental groups were first to raise the issue of evaluating the environmental impacts of the PUC's restructuring policies. In New York, these groups also succeeded in promoting the system benefits charge to the ALJ and the commission for funding environmental, energy efficiency, and other public policy programs. They have also convinced the ALJ and the commission that an EIS needs to be prepared prior to the commission making final decision conceming the restructuring models to be adopted. Finally, in Wisconsin, they have contributed to the PSCW's decision to seek increases in the statutory funding for intervenors' organizations and to establish a Public Benefits Policy Advisory Board to oversee the tasks of allocating the available funds for renewable, energy efficiency, low income, and other public policy programs. 


\section{List of Acronyms}

$\begin{array}{ll}\text { ACR } & \text { Assembly Concurrent Resolution (Califomia) } \\ \text { ALJ } & \text { Administrative Law Judge } \\ \text { AP } & \text { Advance Plan (Wisconsin) } \\ \text { AQMD } & \text { Air Quality Management District } \\ \text { BARCT } & \text { Best available retrofit control technology } \\ \text { BRPU } & \text { Biennial Resource Planning Update (Califomia) } \\ \text { CAAA } & \text { Clean Air Act Amendment of 1992 } \\ \text { CEC } & \text { Califomia Energy Commission } \\ \text { CEERT } & \text { Center for Energy Efficiency and Renewable Technologies } \\ \text { CEQA } & \text { Califomia Environmental Quality Act } \\ \text { CPCN } & \text { Certificate of Public Convenience and Necessity } \\ \text { CPUC } & \text { Califomia Public Utility Commission } \\ \text { CTC } & \text { Competition transition charge } \\ \text { CUB } & \text { Citizens Utility Board } \\ \text { DEC } & \text { Department of Environmental Conservation (New York) } \\ \text { DEIS } & \text { Draft Environmental Impact Statement } \\ \text { DNR } & \text { Department of Natural Resources (Wisconsin) } \\ \text { DSM } & \text { Demand-Side Management } \\ \text { EAF } & \text { Environmental Assessment Form } \\ \text { EIR } & \text { Environmental Impact Report } \\ \text { EIS } & \text { Environmental Impact Statement } \\ \text { ELCON } & \text { Electricity Consumers Resource Council } \\ \text { ERAM } & \text { Energy Rate Adjusted Mechanism } \\ \text { EXMOD } & \text { Environmental Externalities Model (New York) } \\ \text { FEIS } & \text { Final Environmental Impact Statement } \\ \text { FERC } & \text { Federal Energy Regulatory Commission } \\ \text { GAO } & \text { General Accounting Office } \\ \text { GEIS } & \text { Generic Environmental Impact Statement } \\ \text { IPP } & \text { Independant Power Producers } \\ \text { IRP } & \text { Integrated Resource Planning } \\ \text { ISO } & \text { Independent system operator } \\ \text { KV } & \text { Kilo volt } \\ \text { W } & \text { kilo watt } \\ \text { kWh } & \text { kilowatt-hour } \\ \text { LDC } & \text { Local distribution company } \\ \text { MDPU } & \text { Massachusetts Department of Public Utilities } \\ \text { MOU } & \text { Memorandum of Understanding } \\ \text { NEPA } & \text { National Environmental Policy Act } \\ \text { NRDC } & \text { Natural Resource Defense Council } \\ \text { NYDPS } & \text { New York Department of Public Service } \\ \text { NYPSC } & \text { New York Public Service Commission } \\ \text { PBR } & \text { Performance-Based Regulation } \\ \text { PGC } & \text { Public goods charge } \\ \text { PG\&E } & \text { Pacific Gas and Electric Company } \\ & \end{array}$




$\begin{array}{ll}\text { PII } & \text { Public Interest Intervenors } \\ \text { PSC } & \text { Public Service Commission } \\ \text { PSCW } & \text { Public Service Commission of Wisconsin } \\ \text { PUC } & \text { Public Utility Commission } \\ \text { PURPA } & \text { Public Utility Regulatory Policy Act } \\ \text { PV } & \text { Photovoltaic } \\ \text { RD\&D } & \text { Research, development and demonstration } \\ \text { RECLAIM } & \text { Regional Clean Air Incentives Market program } \\ \text { RESCO } & \text { Retail Energy Service Company (model) } \\ \text { SCE } & \text { Southern California Edison Company } \\ \text { SEP } & \text { State Energy Plan } \\ \text { SEQRA } & \text { State Environmental Quality Review Act (New York) } \\ \text { TURN } & \text { Towards Utility Rate Normalization } \\ \text { USC } & \text { Universal Service Charge } \\ \text { WED } & \text { Wisconsin's Environmental Decade } \\ \text { WEPA } & \text { Wisconsin Environmental Protection Act } \\ \text { WisCAP } & \text { Wisconsin's Community Action Group Association } \\ \text { WPUI } & \text { Wisconsin Public Utility Institute }\end{array}$




\section{References}

American Wind Energy Association. (1994). Generic Investigation and Assessment of Costs, Comments of the American Wind Energy Association. PSCW Docket No. 05-EI-114 [November 1].

Califormia Energy Commission (1995a). Electricity Report, 1994. Committee Report, Draft Final [June].

California Energy Commission. (1995b). California Energy Commission Comments on the Memorandum of Understanding. CPUC R 94-04-031 \& I.94-04-032, [October 2].

Califomia Public Utilities Commission Staff. (1993). California's Electric Services Industry: Perspectives on the Past, Strategies for the Future. Report to the CPUC by the Division of Strategic Planning., [February 3].

Califomia Public Utilities Commission. (1994a). Order Instituting Rulemaking and Order Instituting Investigation on the Commission's Proposed Policies Governing Restructuring California's Electric Services Industry and Reforming Regulation. R. 94-04-031 \& I.94-04-032, [April 20].

Califomia Public Utilities Commission. (1994b). Interim Opinion: Procedural Schedule, Call for Briefs, and Applicability of CEQA. Decision 94-12-027, R 94-04-031 \& I.94-04-032, [December 7].

Califormia Public Utilities Commission. (1995a). Status Report on Restructuring California's Electric Services Industry and Reforming Regulation. (Prepared in Response to Assembly Concurrent Resolution No. 143). Vol. I, [January 24].

Califomia Public Utilities Commission. (1995b). Order Designating Commission's Proposed Policy Decisions and Requesting Comments. Decision 95-05-045, R. 94-04-031 \& I.94-04-032, [May 24]. As reprinted in Public Utilities Reports, 1995, Fourth Series, pp. 217-415.

California Public Utilities Commission. (1995c). Order. Decision 95-12-063 (December 20, 1995) as modified by D. 96-01-009 (January 10, 1996), R. 94-04-031 \& I.94-04-032.

California Public Utilities Commission. (1996a). Interim Opinion. Decision 96-03-022 (March 13, 1996). R. 94-04-031 \& I.94-04-032.

Califomia Public Utilities Commission. (1996b). Notice of Preparation of an Environmental Impact Report, R. 94-04-031 \& I.94-04-032. [March 29, 1996].

California Large Energy Consumers Association. (1994). Second Round Comments - Balancing Public Policy Objectives. CPUC R. 94-04-31 and I. 94-04-032, [June 24].

Califomia Manufacturers Association. (1994). Second Round Comments - Order Instituting Rulemaking and Order Instituting Investigation. CPUC R 94-04-031 and I. 94-04-032, [June 23].

Center for Energy Efficiency and Renewable Technologies. (1994). Comments on Balancing Public Policy Objectives in the Competitive Environment. CPUC R. 94-04-031 and I. 94-04-032, [June 24]. 
Citizens' Utility Board. (1994). Initial Comments of the Citizen's Utility Board. PSCW Docket No. 05-EI114, [November 1].

Coalition of California Utility Employees. (1994). Second Round Comments on Balancing Public Policy Objectives and Reply to NRDC Motion for Determination of Applicability of CEQA, CPUC R 94-04-031 and I. 94-04-032. [June 24]

Cullen, L., Mathis, G., Ray, D., and Stevenson, R (1994). Policy Options for Competition in Wisconsin's Electric Power Industry. Report to the Roundtable on Electric Power Industry Trends and Regulatory Policy Directions. Madison, WI: Wisconsin Public Utility Institute, [September].

Customer Statement Parties. (1995). Customer Statement of Principles on Electric Restructuring in Response to the Commission Order for Comments. CPUC R. 94-04-031 and I. 94-04-032, [October 2].

Electricity Consumers Resource Council. (1994). Comments of the Electricity Consumers Resource Council. CPUC R. 94-04-031 and I.94-04-032, [June 23].

Electric Utility Week. (1994). "Wisconsin Coalition Formed to Oppose Proposal on Electric Restructuring," Electric Utility Week. (December 19, 1994), pp. 1, 10 and 11.

Energy Information Administration. (1995). Electric Power Annual 1994, Volume I. DOE/EIA0348(94)/1. Washington, DC: Energy Information Administration, [July].

Fang, J. M. and P. S. Galen. (1994). Issues and Methods in Incorporating Environmental Externalities into the Integrated Resource Planning Process. NREL/TP-461-6684. Golden, CO: National Renewable Energy Laboratory, [November].

Fang, J. M., \&. P. S. Galen. (1995a). Considering Environmental Issues in Electric Industry Restructuring: Descriptions of the Processes in Three States. A Letter Report. National Renewable Energy Laboratory, [October 13, 1995].

Fang, J. M., \&. P. S. Galen. (1995b). Considering Environmental Issues in Electric Industry Restructuring: A Comparative Analysis of Three States. Letter Report No. 2. National Renewable Energy Laboratory, [December 28, 1995].

Framework Parties. (1995). Joint Motion for Consideration of Framework for Restructuring in the Public Interest and for Further Public Process; Joint Response to Memorandum of Understanding. CPUC R. 9404-031 and I. 94-04-032, [October 2].

Independent Energy Producers Association (1994). Comments on the Viability of Environmental/ Fuel Diversity Policies in Consideration of This OIR/OI. CPUC R.94-04-031 and I. 94-04-032, [June 24].

Industrial Users. (1994). Opening Comments (Bluebook Policy Issues -- Round II). CPUC R. 94-04-031 \& I. 94-04-032, [June 23].

Municipal Electric Utilities of Wisconsin. (1994). Initial Comments, Proposing "The Wisconsin Plan", PSCW Docket No. 05-EI-114, [November 1]. 
Natural Resources Defense Council. (1994). Reply Comments and Additional Comments on Balancing Public Policy Objectives in a Competitive Environment and Motion for Determination of Applicability of the California Environmental Quality Act. CPUC R. 94-04-31 and I.94-04-32, [June 24].

New York Department of Public Service. (1995a). Restructuring New York's Electric Industry: Alternative Models and Approaches. Phase II Final Report, Case No. 94-E-0952, [November].

New York Department of Public Service. (1995b). Staff's Motion Regarding SEQRA Compliance. Case No. 94-E-0952, [November, 17]

New York Department of Public Service. (1995c). Recommended Full Environmental Assessment Form. Case No. 94-E-0952, [November, 17].

New York Department of Public Service. (1996a). Draft Generic Environmental Impact Statement. Case No. 94-E-0952 - In the Matter of Competitive Opportunities Regarding Electric Services, [March 6].

New York Department of Public Service. (1996). Final Generic Environmental Impact Statement. Case 94-E-0952 - In the Matter of Competitive Opportunities Regarding Electric Service, [May 3]

New York Public Service Commission. (1994a). Order Instituting Phase II of Proceeding. Case 93-M0229 - Proceeding on Motion of the commission to Address Competitive Opportunities Available to Customers of Electric and Gas Service and to Develop Criteria for Utility Responses, [August 9].

New York Public Service Commission. (1994b). Opinion and Order Regarding Proposed Principles to Guide The Transition to Competition. (Opinion No. 94-27). Case 94-E-0952 - In the Matter of Competitive Opportunities Regarding Electric Service, [December 22].

New York Public Service Commission. (1995a). Recommended Decision by Administrative Law Judge Jeffrey E. Stockholm, Case 92-E-1187, Proceeding to Determine Whether to Incorporate Environmental Costs into the Long-Run Avoided Costs for the State's Electric Utilities and Whether and in What Context Estimates of the Value of Externalities Should be Addressed, [April 12].

New York Public Service Commission. (1995b). Opinion and Order Adopting Principles to Guide The Transition to Competition. (Opinion No. 95-7). Case 94-E-0952 - In the Matter of Competitive Opportunities Regarding Electric Service, [June 7].

New York Public Service Commission. (1995c). Recommended Decision by Administrative Law Judge Judith A. Lee, Ronald Liberty, Deputy Director, Energy and Water Division. Volume I \& II. Case 94-E0952 - In the Matter of Competitive Opportunities Regarding Electric Service, [December 21].

New York Public Service Commission. (1996a). Memorandum and Resolution. Case 94-E-0952 - In the Matter of Competitive Opportunities Regarding Electric Service, [January 13]

New York Public Service Commission. (1996b). Opinion and Order Regarding Competitive Opportunities for Electric Service. Opinion No. 96-12. Case 94-E-0952 - In the Matter of Competitive Opportunities Regarding Electric Service, [May 20]. 
New York State Energy Office, New York Department of Environmental Conservation, \& New York Department of Public Service. (1994). New York State Energy Plan, Vol. I: Summary Report, [October].

Opinion Dynamics. (1995). Qualitative Assessment of Public Opinion on Restructuring of the Electric Utility Industry in Wisconsin. Madison, WI: Energy Center of Wisconsin, [October].

Pacific Gas and Electric Company. (1994). Comments on Environmental and Social Benefit Programs, CPUC R. 94-04-31 and I. 94-04-032, [June 24].

Pacific Power \& Light Company. (1994). Phase II Comments on the Commission's Equity/Social and Environmental Policies. CPUC R. 94-04-031 and I. 94-04-032, [June 23]

Public Interest Intervenors. (1995a). Initial Position Paper of Public Interest Intervenors. NYPSC Case 94-E-0952, [October 25].

Public Interest Intervenors. (1995b). Reply Paper of Public Interest Intervenors. NYPSC Case 94-E-0952, [November 15].

Public Interest Intervenors. (1996a). Briefon Exceptions of Public Interest Intervenors. NYPSC Case 94E-0952, [January 19].

Public Interest Intervenors. (1996b). Reply Briefon Exceptions of Public Interest Intervenors. NYPSC Case 94-E-0952, [February 2].

Public Service Commission Advisory Committee. (1995a). A Framework for Identifying and Evaluating Alternatives for the Future Structure of the Electric Industry in Wisconsin. Docket No. 05-EI-114, [February].

Public Service Commission Advisory Committee. (1995b). The Advisory Committee's Interim Report on Generation System Alternatives, Submitted to the Public Service Commission of Wisconsin. Docket No. 05-EI-114, [August 3].

Public Service Commission of Wisconsin. (1994). Notice of Generic Investigation and Assessment of Costs. 05-EI-1 14. Investigation into the Probable Costs and Benefits of Changing Electric Utility Company Structure and Regulation, [September 8].

Public Service Commission of Wisconsin. (1995a). Supplemental Notice of Generic Investigation. 05-EI114. Investigation into the Probable Costs and Benefits of Changing Electric Utility Company Structure and Regulation, [February 2].

Public Service Commission of Wisconsin. (1995b). The Future of Wisconsin's Electric Power Industry, Environmental Impact statement; Volume I. PSC Docket 05-EI-114. Investigation into the Probable Costs and Benefits of Changing Electric Utility Company Structure and Regulation, [October].

Public Service Commission of Wisconsin. (1995c). The Future of Wisconsin's Electric Power Industry, Comments and Staff Responses on the Draft Environmental Impact statement; Volume II. PSC Docket 05EI-114, Investigation into the Probable Costs and Benefits of Changing Electric Utility Company Structure and Regulation, [October]. 
Public Service Commission of Wisconsin. (1995d). Report of the Advisory Committee on Electric Utility Restructuring to the Public Service Commission of Wisconsin. PSCW Docket No. 05-EI-114, [October].

Public Service Commission of Wisconsin. (1995e). Revised Proposal for Electric Restructuring. Memorandum from Scott Neitzel to Cheryl Parrino and Dan Eastman. PSCW Docket No. 05-EI-114, [December 18, 1995].

Public Service Commission of Wisconsin. (1996). Electric Utility Restructuring in Wisconsin, Report to the Wisconsin Legislature. [February 22].

Public Service Commission of Wisconsin Staff. (1995). Draft Environmental Impact Statement. 05-EI114, Investigation on the Commission's Own Motion into the Probable Costs and Benefits of Changing Electric Utility Company Structure and Regulation. Madison, WI: PSCW, [July].

Rader, N. (1996). The Renewables Portfolio Strandard in California as Envisioned by the American Wind Energy Association, Revised, [March 8].

Rose, K., P. A. Centolella, \& B. F. Hobbs. (1994). Public Utility Commission Treatment of Environmental Externalities. NRRI 94-10. National Regulatory Research Institute, [June].

Southern California Edison Company, California Manufacturers Association, California Large Energy Consumers Association, and Independent Energy Producers. (1995). Memorandum of Understanding, Re: Electric Services Industry Restructuring. CPUC Dockets R. 94-04-031/I.94-04-032, [September 11 ].

Superior Water, Light and Power Company. (1994). Comments of the SWL\&P in Response to the Commission's Notice of Generic Investigation. PSCW Docket No. 05-EI-114, [October 31, 1994].

The Energy Report. (1995). "Industrials Weigh in to Oppose Wisconsin Retail Wheeling Proposal." The Energy Report, January 16, 1995, pp. 28-29.

Toward Utility Rate Normalization. (1994). Comments on Equity/Social and Environmental Policies. CPUC R 94-04-3i and I. 94-04-032, [June 24]

Union of Concerned Scientists and Renew Wisconsin. (1994). Comments on Public Service Commission of Wisconsin's Own Motion into the Probable Costs and Benefits of Changing Electric Utility Company Structure and Regulation. PSCW Docket No. 05-EI-114, [November 1].

United States General Accounting Office. (1995). Electricity Supply: Consideration of Environmental Costs in Selecting Fuel Sources. GAO/RCED-95-187. Washington DC: General Accounting Office, [May].

Wisconsin Department of Natural Resources. (1994). Statement of Interest. PSCW Docket No. 05-EI-114, [October 28].

Wisconsin Electric Power Company. (1994). Wisconsin Electric's View of a More Competitive Electric Industry. PSCW Docket No. 05-EI-114, [November 1]. 
Wisconsin's Environmental Decade. (1994). Response of Wisconsin's Environmental Decade. PSCW Docket No. 05-EI-114, [November 1].

Wisconsin Industrial Energy Group. (1994). Comments of the Wisconsin Industrial Energy Group. PSCW Docket No. 05-EI-114, [November 1].

Wisconsin Public Power Inc, System. (1994). Comments of the Wisconsin Public Power Inc. System PSCW Docket No. 05-EI-114, [November 1].

Wisconsin Public Service Corporation. (1994). Comments of Wisconsin Public Service Corporation. PSCW Docket No. 05-EI-1 14, [November 1].

Wiser, R (1996). Personal Communication. [April 28, 1996].

Working Group. (1995). Options for Commission Consideration. Report in response to Decision 92-12027 of the California PUC R. 94-04-031 and I. 94-04-032, [February 22]. 


\section{Appendix A \\ Informal Advisory Panel}

Ralph C. Cavanagh

Kari Smith

Jim Gallagher

John Hughes

Kenneth P. Linder

David Morse

Stuart Chaitkin

Paul Newman
Natural Resource Defense Council

New York Public Service Commission

ELCON

Edison Electric Institute

Califormia Public Utility Commission

Division of Ratepayer Advocates

Public Service Commission of Wisconsin

A.1 


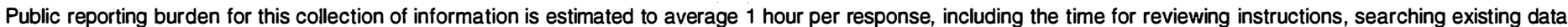

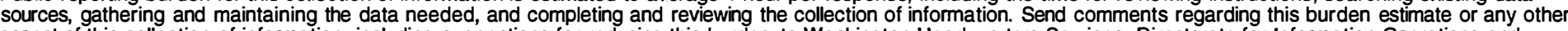

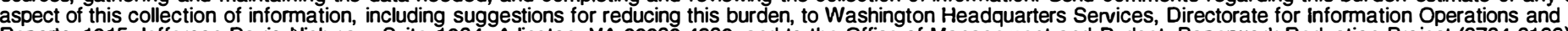

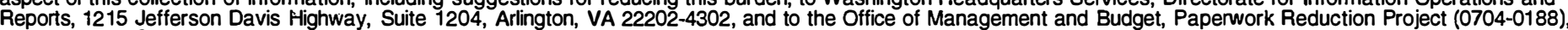
Washington, DC 20503.

\begin{tabular}{|l|l|l|l|}
\hline $\begin{array}{l}\text { 1. AGENCY USE ONLY (Leave } \\
\text { blank) }\end{array}$ & $\begin{array}{c}\text { 2. REPORT DATE } \\
\text { August } 1996\end{array}$ & $\begin{array}{l}\text { 3. REPORT TYPE AND DATES COVERED } \\
\text { Technical Report }\end{array}$ \\
\hline
\end{tabular}
4. TITLE AND SUBTITLE Electric Industry Restructuring and Environmental Issues: A Comparative Analysis of the Experience in California, New York, and Wisconsin

\section{6. $\operatorname{AUTHOR}(S)$}

Jeffrey M. Fang, Paul S. Galen

7. PERFORMING ORGANIZATION NAME(S) AND ADDRESS(ES)

National Renewable Energy Laboratory

1617 Cole Boulevard

Golden, Colorado 80401-3393

9. SPONSORING/MONITORING AGENCY NAME(S) AND ADDRESS(ES)

U.S. Department of Energy

1000 Independence Ave., SW

Washington, D.C. 20585

5. FUNDING NUMBERS

(C)

(TA)AS11502

\section{PERFORMING ORGANIZATION REPORT NUMBER TP-461-20478}

10.

SPONSORING/MONITORING AGENCY REPORT NUMBER

DE96007957

\section{SUPPLEMENTARY NOTES}

12a. DISTRIBUTION/AVAILABILITY STATEMENT

National Technical Information Service

U.S. Department of Commerce

5285 Port Royal Road

Springfield, VA 22161 12b. DISTRIBUTION CODE

UC. Category: 1320

13. ABSTRACT (Maximum 200 words) The electric utility industry in the United States is undergoing fundamental changes in its structure and regulation. This report describes and compares the experience of three states - California, New York, and Wisconsin - in addressing environmental and related issues in their electric industry restructuring processes. Its purpose is to provide stake holders in other states with impartial information from these early adopter states.

\section{SUBJECT TERMS}

electric utility industry restructuring, electric utility industry regulation
15. NUMBER OF PAGES

84

16. PRICE CODE

20. LIMITATION OF

ABSTRACT

\section{SECURITY \\ CLASSIFICATION}

OF REPORT

\author{
18. SECURITY \\ CLASSIFICATION \\ OF THIS PAGE
}

\section{SECURITY \\ CLASSIFICATION OF ABSTRACT}

